\title{
Análise do custo dos pacientes em lista de espera para o transplante hepático
}

\author{
Dissertação apresentada à Faculdade de \\ Medicina da Universidade de São Paulo para \\ obtenção do título de Mestre em Ciências
}

Programa Ciências em Gastroenterologia Orientadora: Dra. Luciana Bertocco de Paiva Haddad

\section{São Paulo}




\title{
Análise do custo dos pacientes em lista de espera para o transplante hepático
}

\author{
Dissertação apresentada à Faculdade de \\ Medicina da Universidade de São Paulo para \\ obtenção do título de Mestre em Ciências
}

Programa em Ciências em Gastroenterologia Orientadora: Dra. Luciana Bertocco de Paiva Haddad 
Dados Internacionais de Catalogação na Publicação (CIP)

Preparada pela Biblioteca da

Faculdade de Medicina da Universidade de São Paulo

Oreprodução autorizada pelo autor

Turri, José Antonio Orellana

Análise do custo dos pacientes em lista de espera para o transplante hepático / José Antonio Orellana Turri. -- São Paulo, 2017.

Dissertação (Mestrado)--Faculdade de Medicina da Universidade de São Paulo.

Programa de Ciências em Gastroenterologia.

Orientadora: Luciana Bertocco de Paiva Haddad.

Descritores: 1.Avaliação em saúde 2.Custos e análise de custo 3.Custos hospitalares 4.Listas de espera 5.Transplante de fígado 6.Cirrose hepática

USP/FM/DBD-037/17 


\section{DedicatóRIA}

A MiNHA AMADA ESPOSA MÁRCIA, QUE INCONDICIONALMENTE ME APOIOU, MESMO EM PERÍOdOS EM QUE PALAVRAS SÃO INSUFICIENTES PARA TRADUZIR.

AOS MEUS FILHOS MATHEUS E LUCAS QUE ME DÃo MUITO TRABALHO, MAS MUITO MAIS ALEGRIAS.

AOS MEUS PAIS, QUE DESDE CEDO JUNTARAM ESFORÇOS PARA MEU ESTUDO, Minha mãe Clara e Meu paI MaURo, QUe tiRaram de SI

PARA COLOCAR UM POUCO MAIS PARA MIM.

\section{AgRAdecimentos}

Agradeço primeiramente aos pacientes que estão ou estiveram em lista de espera para o transplante, hepático ou de outro órgão. Eles, e apenas eles sabem a angústia da espera.

À minha orientadora Luciana, pela dedicação e orientação neste grande e exaustivo período de convivência e de trabalho.

Aos professores e chefes de departamento Ivan Cecconello, Flair José Carrillo e Luiz Augusto Carneiro D'Albuquerque por me concederam a oportunidade de realizar esta pósgraduação.

Aos meus queridos colegas do Departamento de Gastroenterologia que em todos os momentos me auxiliaram de muitas formas para que este estudo fosse adiante. Myrtes, Michele, Márcia Kubrusli, Roberto, Marisa, Vilma, Essy, Débora, Priscila, Fabiana, Marta (pela preciosa revisão geral da escrita, uma verdadeira aula!), Joelice, Silvana Campos, Rosângela, Cynthia, Evelyse, Nataly, Viviane Franceschetti, Luana, Jairo, Anna Victoria, Silvana Figueiredo, Mariliza, Fátima e Marcos (in memoriam).

Aos colegas enfermeiros que me acolheram e permitiram uma convivência enriquecedora e demais colegas do ambulatório de transplante hepático que me auxiliaram com dados preciosos. Karina Segatto, Juliana Marquezi e Dorotéia. 
Um agradecimento especial a Enfermeira Maria que me auxiliou imensamente e em muitos momentos.

Aos colegas de outros departamentos. Juliana Yukari, Tássia Decimoni, Tânia e Chistine.

Aos amigos Márcio Augusto Diniz e Leandro Augusto Ferreira por toda a análise estatística, conversas, conselhos, desabafos e ideias edificantes.

Aos professores do Departamento de Gastroenterologia que me auxiliaram de diversas maneiras, com dados preciosos, com correções importantes, com conselhos e orientações ou simplesmente com uma boa conversa, Wellington Andrauss, José Jukemura, Paulo Hermann, Ulysses, Marco Aurélio, André Montagnini, Joel Faintuchi, Eduardo Cançado, Rodrigo Bronze e Osmar Yagi.

Aos professores do Departamento de Medicina Preventiva que me ensinaram e enriqueceram meus conhecimentos. Patrícia Coelho, Andréa Tenório e Eluf.

Ao professor do ICESP Alessandro Campolina que me ajudou imensamente, me deu importantes orientações e me motivou.

A professor Alberto Mendrone Jr. e aos colegas Vitor e Sílvia do departamento de Hemoterapia do HCFMUSP por abrirem as portas dos bancos de dados de Hemocomponentes em um trabalho exaustivo, mas muito gratificante.

Aos colegas da FMUSP, do DRH, GARH e CBSS nos preciosos auxílios concedidos para apresentação de grande parte dos dados contidos neste estudo em congressos nacionais e internacionais.

“EMBORA NINGUÉM POSSA VOLTAR ATRÁS E FAZER UM NOVO COMEÇO, QUALQUER UM PODE COMEÇAR AGORA E FAZER UM NOVO FIM" 


\section{NORMATIZAÇÃO UTILIZADA}

Esta tese está de acordo com as seguintes normas, em vigor no momento desta publicação:

Referências: adaptado de International Committee of Medical Journals Editors (Vancouver).

Universidade de São Paulo. Faculdade de Medicina. Divisão de Biblioteca e Documentação. Guia de apresentação de dissertações, teses e monografias. Elaborado por Anneliese Carneiro da Cunha, Maria Julia de A. L. Freddi, Maria F. Crestana, Marinalva de Souza Aragão, Suely Campos Cardoso, Valéria Vilhena. 3a ed. São Paulo: Divisão de Biblioteca e Documentação; 2011.

Abreviaturas dos títulos dos periódicos de acordo com List of Journals Indexed in Index Medicus 
ANÁLISE DO CUSTO DO PACIENTE EM LISTA DE ESPERA PARA O TRANSPLANTE HEPÁTICO.

Turri JAO. Análise do custo dos pacientes em lista de espera para o transplante hepático [Dissertação]. São Paulo: Faculdade de Medicina, Universidade de São Paulo; 2017.

Introdução: Há um número crescente de pacientes em lista de espera para o transplante hepático, que atualmente é a única opção de tratamento de pacientes com doença hepática terminal. As complicações da doença hepática avançada acarretam inúmeras intervenções, procedimentos e internações, elevando os gastos com estes pacientes e causando um alto custo para o sistema público de saúde.

Objetivo: O objetivo deste estudo foi avaliar o custo total do paciente cirrótico em lista de espera para o transplante hepático e também, avaliar os principais fatores correlacionados com os custos como o tempo de espera em lista, os desfechos observados e o MELD.

Métodos: Foi realizada uma coorte prospectiva com 492 pacientes cirróticos em lista de espera para o transplante hepático entre os anos de 2012 e 2013. Destes, 134 foram transplantados, 178 permaneceram em lista de espera, 103 foram removidos por melhora ou piora do quadro clínico e 67 faleceram durante o período de espera em lista. Foi utilizada a metodologia de microcusteio, analisando todos os recursos utilizados pelo paciente, incluindo o número total e o custo de cada material, medicamento, procedimento, exame laboratorial, exame de imagem, recursos humanos, quimioterapia, hemoterapia e internações sob a perspectiva do hospital e valores atuais do HCFMUSP. O custo de cada paciente foi obtido e os resultados foram agrupados segundo grupos de desfecho e de gravidade avaliada pelo MELD.

Resultados: O custo médio do paciente em lista de espera para o transplante hepático é de R\$ $29.114,77 \pm 31.541,40$. O custo do paciente transplantado é de $R \$ 17.462,60 \pm 20.087,99$, do paciente removido de lista é de $R \$ 19.354,10 \pm 35.001,14$; do paciente que faleceu em lista é de $R \$ 49.162,30 \pm$ $37.511,10$ e do que permaneceu em lista é de $R \$ 24.717,13 \pm R \$ 28.571,05(p<0,001)$. Com relação ao custo do paciente relativo a gravidade segundo critério MELD, o custo do paciente com MELD menor que 15 é de $R \$ 16.321,45 \pm 25.682,39$, entre 15 e 30 é de $R \$ 30.582,54 \pm 33.453,50$ e com MELD acima de 30 é de $R \$ 34.163,03 \pm 28.368,06$ ( $p<0,001)$. Os principais fatores relacionados ao custo são, internações, ablação por radiofrequência e a hemoterapia.

Conclusão: O custo do paciente em lista para transplante hepático está relacionado significativamente à sua gravidade segundo MELD. Internações, ablação por rádio frequência e a utilização de hemocomponentes foram, isoladamente, os recursos que mais elevaram os custos totais destes pacientes.

Descritores: Avaliação em saúde; custo e análise de custos; custos hospitalares; listas de espera; transplante de fígado; cirrose hepática. 
COST ANALYSIS OF CIRRHOTIC PATIENT ON WAITING LIST FOR LIVER TRANSPLANTATION.

Turrri JAO. Cost analysis of cirrhotic patient on wainting list for liver transplatation [Dissertation]. São Paulo: "Faculdade de Medicina, Universidade de São Paulo"; 2017.

Background: There is a growing number of patients on the waiting list for liver transplantation, which is actually the only treatment option for patients with terminal hepatic disease. Various pathologies, correlate diseases and comorbidities entail to numerous interventions, procedures and hospital stays, which increases the costs of these patients and leading to a high cost to the public health system.

Objective: The aim of this study was to evaluate the total cost of the cirrhotic patient on the waiting list for liver transplantation and evaluate the main factors correlate with the cost as if the time spent on list, the observed outcome and MELD.

Methods: It was evaluated 493 patients on the waiting list for liver transplantation between the years 2012 and 2013. Of these 134 were called to transplantation, 178 remained on the waiting list, 103 were removed by health status and 67 died in the list. We used a detailed analysis of micro-costs on the waiting list, including clinical data and the unitary number and cost of each materials, drugs, procedure, laboratorial tests, imaging, human resources, chemotherapy, haemotherapy and hospitalizations. The data and number of resource were added and the total cost of each cost component was multiplied by the amount of use of each resource. It was thus obtained the total cost of each patient and grouped according to outcome criteria and severity assessed by MELD.

Results: The total cost of the patient on waiting list for liver transplantation is $\mathrm{R} \$ 29.114,77 \pm 31.541,40$. The cost of transplanted patient is $R \$ 17.462,60 \pm 20.087,99$. The cost of removed patient is $R \$$ $19.354,10 \pm 35.001,14$. The cost patient who died is $R \$ 49.162,30 \pm 37.511,10$ and the cost of patient that remains on list is $R \$ 24.717,13 \pm R \$ 28.571,05(p<0,001)$. Regarding the patient cost of concerning to severity by MELD criteria, the cost of patient with MELD < 15 is $R \$ 16.321,45 \pm 25.682,39$. The cost of patient with MELD 15 - 30 is $R \$ 30.582,54 \pm 33.453,50$ and the cost of patient with MELD > 30 is $R \$$ $34.163,03 \pm 28.368,06$ ( $p<0,001)$. The main factors related to cost is hospitalization, radio-frequency ablation and haemotherapy.

Conclusion: In a univariate analysis, more severe patients have a high-cost care in waiting list for liver transplantation. Hospitalizations, radiofrequency ablation and blood bags replacement were, singly, the resources that increased the cost of patients on waiting list and cause a high cost on the public health system.

Descriptors: Health evaluation; cost and cost analysis; hospital costs; waiting lists, liver transplantation; liver cirrhosis. 


\section{Lista de abreviaturas, símbolos e siglas}

$A F$ - Aférese de plaquetas

AMB - Ambulatório

CAPPESQ - Comitê de ética em pesquisa

CBP - Cirrose biliar primária

CBS - Cirrose biliar secundária

CEP - Colangite esclerosante primária

$\mathrm{CH}$ - Concentrado de hemácias

$\mathrm{CHC}$ - Carcinoma hepatocelular

Chi - Concentrado de hemácias irradiado

$\mathrm{CP}$ - Concentrado de plaquetas

$\mathrm{CPi}$ - Concentrado de plaquetas irradiado

Crio - Criopreceptado (hemocomponente derivado de sangue total)

CTP - Child-Turcotte-Pugh

ESOT - European society for organ transplantation

HCFMUSP - Hospital das Clínicas da Faculdade de Medicina da Universidade de São Paulo

HCMed - Prontuário eletrônico de pacientes HCFMUSP

HDA - Hemorragia digestiva alta

HIV - Human immunodeficiency virus

ICESP - Instituto do câncer do Estado de São Paulo 
IMC - índice de massa corporal

INT - Internação

LEVE - Ligadura elástica de varizes esofágicas

MELD - Model of end-stage liver disease

NASH - Non Alcoholic Steato Hepatitis.

OMS - Organização mundial da saúde

OPTN - Organ procurement and transplantation network

PAF - Polineuropatia amiloidótica familiar

PBE - Peritonite bacteriana espontânea

PEP - Prontuário eletrônico de paciente

PFC - Plasma fresco concentrado

RFA - Radio frequency ablation

RNM - Ressonância nuclear magnética

RX - Raios- $X$

HAI - Hepatite autoimune

SAM - Sistema de administração de materiais e medicamentos HCFMUSP

SHR - Síndrome hepatorrenal

Shunt - passagem ou ligação entre duas artérias ou veias

SI3 - Sistema de Informações sobre internações HCFMUSP

SIGH - Sistema de gestão hospitalar

SRH - Síndrome hepatorrenal 
TACE - Trans arterial chemo embolization

TASY - Sistema de gerenciamento de informações dos pacientes do ICESP

TC - Tomografia computadorizada

TIPS - Transjugular intrahepatic portossistemic shunt - Shunt transjugular intrahepático portossistêmico.

UNOS - United network for organ sharing

UTI - Unidade de Terapia Intensiva

VHB - Vírus da hepatite B

VHC - Vírus da hepatite C. 


\section{Lista de Tabelas}

TABela 1: Metodologia de OBTENÇÃo de QUANTIDAdeS E VALORES DOS PRINCIPAIS COMPONENTES DE CUSTO EM AMBULATÓRIO INCLUÍDOS NO ESTUDO

TABELA 2: METODOLOGIA DE OBTENÇÃO DE QUANTIDADES E VALORES DOS PRINCIPAIS COMPONENTES DE CUSTO EM INTERNAÇÕES INCLUÍDOS NO ESTUDO

TABELA 3: DADOS CLÍNICOS DE TODOS OS PACIENTES EM LISTA DE ESPERA PARA TRANSPLANTE HEPÁTICO DE JANEIRO DE 2012 ATÉ DEZEMBRO DE 2013 ( $\mathrm{N}=492$ )

TABELA 4: DADOS CLÍNICOS, DIAGNÓSTICOS E PROCEDIMENTOS REALIZADOS POR TODOS OS PACIENTES DIVIDIDOS POR GRUPO DE DESFECHO. (N=492). DADOS EM NúMEROS TOTAIS E PORCENTAGEM. NúMEROS ENTRE [ ] SÃO DADOS EM MÉDIAS E DESVIO-PADRÃO. TESTE DE FISHER

TABELA 5: NÚMERO TOTAL E PORCENTAGEM DE UTILIZAÇÃO DE CONSULTAS AMBULATORIAIS DE TODOS OS PACIENTES SUBDIVIDIDOS PELO DESFECHO ( $\mathrm{N}=492)$

TABELA 6: NÚMERO TOTAL E PORCENTAGEM DE UTILIZAÇÃO DE TODOS OS EXAMES REALIZADOS DURANTE O PERÍODO DE LISTA DE ESPERA CONFORME OS GRUPOS DE DESFECHO. $(\mathrm{N}=492)$

TABELA 7: DIAGNÓSTICOS, TEMPO, PRINCIPAIS MOTIVOS E PROCEDIMENTOS E NÚMERO TOTAL DE INTERNAÇÕES ENTRE TODOS OS PACIENTES DIVIDIDOS POR GRUPO DE DESFECHO. VALORES EM NÚMERO TOTAL E PORCENTAGEM $(N=277)$ 37

TABELA 8: HEMOCOMPONENTES UTILIZADOS DURANTE O PERÍODO DE INTERNAÇÃO POR TODOS OS PACIENTES DIVIDIDOS POR GRUPO DE DESFECHO. VALORES EM NÚMERO TOTAL E PORCENTAGEM ( $N=350)$ 38

TABELA 9: NÚMERO TOTAL DE INTERNAÇÕES E PRINCIPAIS PROCEDIMENTOS REALIZADOS NOS PACIENTES DIAGNOSTICADOS COM CHC ATENDIDOS NO ICESP ( $\mathrm{N}=83$ ) E TOTAL DE 350 INTERNAÇÕES. VALORES EM NÚMERO TOTAL E PORCENTAGEM

TABELA 10: DADOS CLÍNICOS, DIAGNÓSTICOS E PROCEDIMENTOS REALIZADOS POR TODOS OS PACIENTES DIVIDIDOS POR GRUPO DE MELD. ( $\mathrm{N}=492)$

TABELA 11 - NÚMERO TOTAL E PORCENTAGEM DE TODOS OS DIAGNÓSTICOS DOS PACIENTES EM LISTA DE ESPERA PARA O TRANSPLANTE HEPÁTICO DIVIDIDOS PELO GRUPO DE MELD.

TABELA 12: NÚMERO TOTAL E PORCENTAGEM DE UTILIZAÇÃO DE CONSULTAS AMBULATORIAIS DE TODOS OS PACIENTES SUBDIVIDIDOS PELO GRUPO DE MELD ( $\mathrm{N}=492)$ 
TABELA 13: NÚMERO TOTAL E PORCENTAGEM DE UTILIZAÇÃO DE TODOS OS EXAMES REALIZADOS DURANTE O PERÍODO DE LISTA DE ESPERA CONFORME OS GRUPOS DIVIDIDOS PELO VALOR DE MELD. ( $N=492)$

TABELA 14: DIAGNÓSTICOS, TEMPO, MOTIVOS, PROCEDIMENTOS E NÚMERO DE INTERNAÇÕES ENTRE TODOS OS PACIENTES DIVIDIDOS PELO GRUPO DE MELD ( $\mathrm{N}=277)$

TABELA 15: HEMOCOMPONENTES UTILIZADOS EM INTERNAÇÃO. QUANTIDADES TOTAIS, PORCENTAGENS E MÉDIA DE UTILIZAÇÃO POR PACIENTE DIVIDIDOS POR GRUPO DE MELD (N=277; COM 434 INTERNAÇÕES NO TOTAL). 50

TABELA 16: NÚMERO TOTAL E FREQUÊNCIA DE INTERNAÇÕES DOS PACIENTES COM CHC ATENDIDOS NO ICESP (N=80).....51

TABELA 177: CUSTO TOTAL E PORCENTAGEM DOS PRINCIPAIS RECURSOS UTILIZADOS PELOS PACIENTES EM LISTA DE ESPERA PARA O TRANSPLANTE HEPÁtICO ( $\mathrm{N}=492$ ). VALORES EM REAIS.

TABELA 188: ANÁLISE DOS PRINCIPAIS RECURSOS E COMPONENTES DE CUSTOS UTILIZADOS DIVIDIDOS PELO GRUPO DE DESFECHO. ( $\mathrm{N}=492)$ VALORES EM REAIS.

TABELA 199: ANÁLISE DOS PRINCIPAIS RECURSOS E COMPONENTES DE CUSTOS UTILIZADOS, DIVIDIDOS PELO GRUPO DE MELD (N=492). VALORES EM REAIS (R\$). 60

TABELA 20: ANÁLISE UNIVARIADA DOS PRINCIPAIS FATORES DETERMINANTES DO ALTO CUSTO EM LISTA DE ESPERA PARA O TRANSPLANTE HEPÁTICO 


\section{Lista de Figuras}

FIGURA 1: FREQUÊNCIA DOS PRINCIPAIS DIAGNÓSTICOS ENTRE OS GRUPOS DE PACIENTES CIRRÓTICOS DIVIDIDOS POR DESFECHO

FIGURA 2: HISTOGRAMA DA FREQUÊNCIA DE DISTRIBUIÇÃO DOS VALORES DE CUSTO POR FAIXA DE MELD (N=492) 41

FIGURA 3: A - PORCENTAGEM DE GASTOS AMBULATORIAIS POR RECURSO UTILIZADO EM RELAÇÃO AO CUSTO TOTAL. B - PORCENTAGEM DE GASTOS EM INTERNAÇÕES POR RECURSO UTILIZADO EM RELAÇÃO AO CUSTO TOTAL. 


\section{Lista de Gráficos}

GRÁFICO 1: PRINCIPAIS FREQUÊNCIAS DE DIAGNÓSTICOS ENTRE TODOS OS PACIENTES EM LISTA DE ESPERA SEGUNDO A HEPATOPATIA (N=492).

GRÁFICO 2: NÚMERO E PORCENTAGEM DOS PACIENTES EM LISTA DE ESPERA SUBDIVIDIDOS PELO DESFECHO (N=492) 29

GRÁFICO 3: NÚMERO E PORCENTAGEM DE PACIENTES REMOVIDOS DA LISTA DE ESPERA SUBDIVIDIDOS PELO MOTIVO DA REMOÇÃO (N=103) . 30

GRÁFICO 4: A - MEDIANA E QUARTIS DAS IDADES DOS PACIENTES ENTRE OS GRUPOS DIVIDIDOS PELO DESFECHO (P=0,502). B

- Mediana e quARTIL do PESO dos PACIENTES ENTRE OS GRUPOS DIVIDIDOS PELO DESFECHO (P=0,558). C MEDIANA E QUARTIL DO IMC ENTRE OS GRUPOS DIVIDIDOS PELO DESFECHO $(P=0,841)$

GRÁFICO 5: A - Diagnóstico de CARCINOMA HePATOCELULAR ENTRE OS PACIENTES CIRRÓtICOS DIVIDIDOS PELO GRUPO DE DESFECHO (P<0,001). B - DIAGNÓSTICO DE CIRROSE ALCOÓLICA ENTRE OS PACIENTES DIVIDIDOS PELO GRUPO DE DESFECHO (P=0,024). C - DIAGNÓSTICO DE NASH ENTRE OS PACIENTES CIRRÓTICOS DIVIDIDOS PELO GRUPO DE DESFECHO ( $\mathrm{P}=0,027)$. DADOS EM PORCENTAGEM

GRÁFICO 6: A - FREQUÊNCIA DE UTILIZAÇÃO DE CONSULTAS NO ICESP ENTRE OS PACIENTES COM CHC DIVIDIDOS PELO GRUPO DE DESFECHO $(P<0,001)$. B - FREQUÊNCIA DE REALIZAÇÃO DE TACE ENTRE OS PACIENTES COM CHC DIVIDIDOS PELO GRUPO DE DESFECHO $(P<0,001)$

GRÁFICO 7: NÚMERO E PORCENTAGEM DE PACIENTES EM CADA GRUPO DE MELD DIVIDIDOS PELO DESFECHO.

GRÁFICO 8: A - MÉdIA E QUARTIS DO TEMPO DE ESPERA EM LISTA ENTRE OS GRUPOS DIVIDIDOS POR FAIXA DE MELD (P<0,001 ENTRE OS GRUPOS MELD <=17 E MELD>30). B - MÉDIA E QUARTIL DO MELD ENTRE OS GRUPOS ( $P<0,001$ ENTRE TODOS OS GRUPOS). C - MÉDIA E QUARTIL DA IDADE ENTRE OS GRUPOS DIVIDIDOS POR FAIXA DE MELD ( $P=0,007$ ENTRE OS GRUPOS MELD 25-30 E MELD >30). D - MÉDIA E QUARTIL DO IMC ENTRE OS GRUPOS DIVIDIDOS POR FAIXA DE MELD $(\mathrm{p}=0,865)$.

GRÁFICO 9: FREQUÊNCIA DE DISTRIBUIÇÃO DOS PACIENTES COM RELAÇÃO AOS VALORES DE CUSTO. VALORES EM REAIS......53

GRÁFICO 10: CUSTO TOTAL DO PACIENTE CIRRÓTICO EM LISTA DE ESPERA PARA O TRANSPLANTE HEPÁTICO DIVIDIDO PELO GRUPO DE DESFECHO. VALORES MÉDIOS POR PACIENTE EM REAIS.

GRÁfico 11: A - MEdIANA E QUARTIS do CUSTO TOTAL dOS PACIENTES DIVIDIDOS PELO GRUPO DE DESFECHO (P<0,001). B MEDIANA E QUARTIS DO CUSTO AMBULATORIAL DOS PACIENTES DIVIDIDOS PELO GRUPO DE DESFECHO $(P<0,001)$. C MEDIANA E QUARTIS DO CUSTO EM INTERNAÇÃO DOS PACIENTES DIVIDIDOS PELO GRUPO DE DESFECHO $(P<0,001)$. .56 
GRÁFICO 12: A - MEDIANA E QUARTIS DO CUSTO DOS EXAMES DE IMAGEM DOS PACIENTES DIVIDIDOS PELO GRUPO DE DESFECHO ( $P=0,003)$. B - MEDIANA E QUARTIS DO CUSTO COM EXAMES LABORATORIAIS DOS PACIENTES DIVIDIDOS PELO GRUPO DE DESFECHO ( $P=0,001)$. $C$ - MEDIANA E QUARTIS DO CUSTO COM MATERIAIS UTILIZADOS DOS PACIENTES DIVIDIDOS PELO GRUPO DE DESFECHO (P=0,001). D - MEDIANA E QUARTIS DO CUSTO COM MEDICAMENTOS DOS PACIENTES DIVIDIDOS PELO GRUPO DE DESFECHO (P=0,001). E - MEDIANA E QUARTIS DO CUSTO COM DIÁRIAS EM ENFERMARIA DOS PACIENTES DIVIDIDOS PELO GRUPO DE DESFECHO ( $\mathrm{P}=0,001)$. F - MEDIANA E QUARTIS DO CUSTO COM DIÁRIAS EM UTI DOS PACIENTES DIVIDIDOS PELO GRUPO DE DESFECHO $(\mathrm{P}=0,001)$.

GRÁfICO 13: A - MEDIANA E QUARTIS do CUSTO TOTAL UtILIZAdOS PELOS PACIENTES DIAGNOSTICAdOS COM CHC QUE REALIZARAM INTERNAÇÕES E PROCEDIMENTOS NO ICESP DIVIDIDOS PELO GRUPO DE DESFECHO $(P=0,718)$. B MEDIANA E QUARTIS DO CUSTO TOTAL UTILIZADO COM HEMOCOMPONENTES ENTRE OS PACIENTES DIVIDIDOS PELO GRUPO DE DESFECHO $(P<0,001)$

GRÁFICO 14 - GRÁFICO dE DISPERSÃo DE TODOS OS PACIENTES SEGUNDO CUSTO TOTAL E ESCORE DE MELD (N=492).

VALORES EM REAIS

GRÁfico 15: A -- MEDIANA E QUARTIS do CUSTO do CUSTO TOTAL DIVIDIDO PELO GRUPO DE MELD $(P=0,614)$. B MEDIANA E QUARTIS DO CUSTO EM INTERNAÇÃO DIVIDIDO POR GRUPO DE MELD $(P=0,748)$. C - MEDIANA E QUARTIS DO CUSTO AMBULATORIAL DIVIDIDO POR GRUPO DE MELD ( $P=0,02)$. D - MEDIANA E QUARTIS DO CUSTO DOS HEMOCOMPONENTES UTILIZADOS DIVIDIDO POR GRUPO DE MELD ( $P=0,532)$. E - MEDIANA E QUARTIS DO CUSTO EM INTERNAÇÕES NO ICESP DIVIDIDO POR GRUPO DE MELD ( $P<0,001)$. F - MEDIANA E QUARTIS DO CUSTO EM EXAMES LABORATORIAIS DIVIDIDO POR GRUPO DE MELD $(P=0,05)$ VALORES EM REAIS. 


\section{Sumário}

1. Introdução

1.1 A cirrose hepática 1

$\begin{array}{lll}1.2 & \text { O transplante no tratamento da doença hepática avançada } & 7\end{array}$

1.3 A lista de espera para o transplante hepático 9

$\begin{array}{ll}1.4 & \mathrm{O} \text { custo da doença hepática avançada } \\ \end{array}$

$\begin{array}{lll}1.5 & \text { Avaliação econômica em saúde } & 15\end{array}$

$\begin{array}{ll}\text { 2. Objetivos } & 17\end{array}$

$\begin{array}{ll}\text { 3. Casuística e Método } & 18\end{array}$

3.1 Método de cálculo dos custos ambulatoriais 21

3.2 Método de cálculo dos custos das internações 23

$\begin{array}{ll}3.3 \text { Análise estatística } & 25\end{array}$

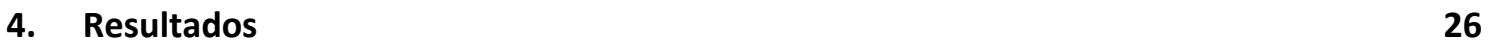

4.1 Resultados clínicos e demográficos 26

4.2 Resultados por grupo de Desfecho 29

4.2.1 Número de pacientes por grupo 29

4.2.3 Diagnóstico por grupo de desfecho 33

$\begin{array}{ll}\text { 4.2.4 Consultas ambulatoriais } & 35\end{array}$

4.2.5 Exames de imagem e suporte ao diagnóstico 36

$\begin{array}{ll}\text { 4.2.6 Internações e procedimentos } & 37\end{array}$

$\begin{array}{ll}\text { 4.2.7 Utilização de hemocomponentes } & 38\end{array}$ 
4.3.8 Pacientes com carcinoma hepatocelular atendidos pelo ICESP por grupo de MELD 51

5. Resultado da Análise de Custo

7. Discussão

7.1 Discussão da Análise de Custo

8. Conclusão 


\section{INTRODUÇÃO}

\subsection{A CIRROSE HEPÁTICA}

A cirrose hepática é caracterizada por um processo inflamatório crônico que leva a degeneração gradual dos hepatócitos, seguido por regeneração tecidual com substituição das células hepáticas por tecido fibroso. A fibrose do fígado causa mudanças estruturais que resultam em hipertensão portal e acarretam com o tempo diminuição da função hepática. ${ }^{1-3}$

Esta doença é causada por várias etiologias diferentes como hepatites virais, hepatite autoimune, doenças metabólicas como Doença de Wilson e Hemocromatose, esteato-hepatite não alcoólica (NASH), distúrbios vasculares como a doença de Budd-Chiari, doenças biliares como cirrose biliar primária e colangite esclerosante primária, atresia biliar, cirrose criptogênica, por drogas hepatotóxicas e pelo consumo excessivo de álcool. ${ }^{4-13}$

Estudos recentes estimam que a cirrose hepática acomete entre 2,2 e $3 \%$ da população mundial, entre 11,3 e 14,7 milhões de adultos na Europa e entre 3,2 a 4,1 milhões nos Estados Unidos, sendo a décima segunda causa de morte neste pais, além de causar alta taxa de morbidade. ${ }^{5,14-19}$. Dados de 2015 mostram que, em nosso país, o número de portadores de hepatopatia é de cerca de $1,38 \%$ da população, o que representa cerca de 3 milhões de pessoas, sendo aproximadamente 300.000 indivíduos portadores do vírus da hepatite $\mathrm{C}(\mathrm{VHC}){ }^{20}$

A progressão da doença hepática é lenta e não ocorre a uma taxa constante, podendo levar mais de 30 anos para o desenvolvimento de uma fibrose, falência hepática e a morte. Muitos pacientes permanecem assintomáticos por muitos anos, porém após instalada a fibrose hepática, a progressão desta patologia se torna mais rápida e, aproximadamente entre $10 \%$ a $15 \%$ destes pacientes progridem para a fibrose hepática e $5 \%$ destes morrem ou necessitam transplante hepático, sendo esta cirurgia a última alternativa de tratamento para a fibrose hepática. ${ }^{3,6,21-23}$

Os primeiros sinais desta doença são a hipertensão portal, elevação de enzimas hepáticas, e esteatose, podendo evoluir para um estadio de fibrose hepática descompensada 
que acomete $28 \%$ dos pacientes após 5 anos de evolução. Os principais sintomas da fibrose descompensada são o aparecimento de complicações como ascites, icterícia, varizes esofágicas com sangramento e encefalopatia, com índice de sobrevivência destes indivíduos de $47 \%$ em 5 anos. $^{24-28}$

A hipertensão portal é uma das primeiras alterações fisiopatológicas decorrentes da fibrose hepática. Envolve a elevação anormal da pressão sanguínea na veia porta, que drena sangue do sistema digestório para o fígado. A elevação da pressão da veia porta por si não causa sintomas ao paciente portador, porém é um pré-requisito para uma série de alterações metabólicas como ascite e a encefalopatia hepática e pode levar também a formação de circulação venosa colateral com o surgimento de varizes esofágicas, hemorragias digestivas e síndrome hepatorrenal. ${ }^{3,29-31}$

A ascite é a complicação mais comum da doença hepática avançada e acomete entre $50 \%$ a $90 \%$ dos pacientes. É definida como acúmulo de mais de $25 \mathrm{ml}$ de líquido na cavidade peritoneal e é causada por uma cadeia de eventos fisio-patológicos e bioquímicos envolvendo a hipertensão portal e progressivas alterações vasculares, mas pode ser causada também por certos tipos de cânceres, pela síndrome de Budd-Chiari ou outra doença veno-oclusiva. Sua presença leva a um prognóstico ruim, com probabilidade de morte de $50 \%$ em 3 anos. ${ }^{32-34}$

A fisiopatologia da ascite envolve a liberação de líquidos ativamente secretados pelo tecido hepático pelas células neoplásicas devido a inflamação, juntamente com elevado conteúdo proteico. A hipertensão portal tem importante papel na ascite ao elevar a pressão capilar hidrostática no leito esplâncnico. Seu tratamento tende a ser prolongado, com a utilização de diuréticos, com paracenteses frequentes para retirada do líquido acumulado no abdome e com a reposição de proteína, sendo a mais utilizada a albumina. Este procedimento leva a um elevado risco de complicações e infecções. Em casos mais graves é realizado um procedimento invasivo endovascular com a colocação de uma prótese entre a veia porta do fígado para a veia hepática chamada TIPS (shunt portossistêmico intra-hepático transjugular), diminuindo a hipertensão portal. Em nosso país, um importante estudo do HCFMUSP encontrou dados que indicam a probabilidade de $58 \%$ dos pacientes cirróticos desenvolverem ascite em 10 anos. ${ }^{35-37}$

Uma complicação relativamente frequente em pacientes com ascite é a peritonite bacteriana espontânea. ${ }^{38-40}$ A peritonite bacteriana espontânea é uma infecção grave e 
algumas vezes fatal do líquido ascítico ocasionada por bactérias translocadas do intestino para a cavidade peritoneal. É uma complicação amplamente estudada em todo o mundo devido a sua importância e gravidade. Muitos estudos mostram que a peritonite bacteriana espontânea ocorre entre $10 \%$ a $30 \%$ das internações relacionadas ao paciente cirrótico, com cerca de $40 \%$ a $70 \%$ de probabilidade destes pacientes serem acometidos por novos episódios de PBE em um ano e frequência de óbitos de cerca de 50\%, necessitando a utilização de antibióticos de última geração, além da mortalidade em pacientes não tratados ou tratados tardiamente ser maior que 80\%.(39-42,44) Dados nacionais mostram resultados semelhantes. Nobre et al ${ }^{43}$, em estudo com pacientes cirróticos com ascite, analisaram 245 internações relacionadas com PBE e encontrou taxa de mortalidade de $37 \%$. Haddad et $a{ }^{38}$, em um estudo recente encontraram $3,3 \%$ de peritonite bacteriana entre os pacientes em lista de espera para 0 transplante hepático que realizavam paracentese por ascite refratária e pior prognóstico destes pacientes devido ao choque séptico, falência renal e de múltiplos órgãos e sangramentos.

Outra complicação comum que acomete os pacientes cirróticos são as varizes esofágicas, que ocorrem em cerca de $90 \%$ dos pacientes, com risco de sangramento de $30 \%$ a $60 \%$, e frequência de morte associadas à hemorragia digestiva alta (HDA) de aproximadamente $12 \%$ a $20 \%{ }^{34,35}$ o tratamento envolve condutas medicamentosas ou endoscópicas como a ligadura elástica de varizes esofágicas (LEVE) ou utilização de balão esofágico na urgência. ${ }^{44}$

Além disso, muito frequentemente está presente a encefalopatia hepática, considerada como uma das maiores complicações da fibrose hepática, atingindo mais de um terço destes pacientes. ${ }^{45}$ Neff et al ${ }^{31}$, em um amplo artigo de revisão encontraram o diagnóstico de encefalopatia hepática entre $20 \%$ a $60 \%$ de todos os pacientes cirróticos, além de hipertensão portal, sangramento de varizes de esôfago e peritonite bacteriana espontânea. Stepanova et al ${ }^{46}$, em outra grande revisão sobre este assunto, verificaram que aproximadamente $0,33 \%$ de todas as internações ocorridas nos Estados Unidos entre 2005 e 2012 ocorreram por encefalopatia hepática, com mortalidades destes pacientes entre 14,13 e $15,61 \%$

Há três tipos básicos de encefalopatia hepática. $\mathrm{O}$ tipo $\mathrm{A}$, onde o motivo é uma falência aguda do fígado, o tipo B, que ocorre pela ligação venosa porto-sistêmica e o tipo C, que ocorre pelo desenvolvimento da própria fibrose hepática. O mecanismo fisiopatológico exato deste acometimento ainda não está claro, mas envolve um aumento de resíduos químicos não 
totalmente metabolizados pelo fígado, uma hiperamonemia devido a um desbalanço no metabolismo de nitrogênio e stress oxidativo sistêmico modulado por alteração no gene da glutaminase. Esta sequência de eventos aumenta os níveis de citocinas pró-inflamatórias que levam, por fim a um edema em astrócitos e em outras células da micro e macróglia cerebral, resultando em alterações na interação neurônio-células da glia e, posteriormente, alterações neuronais. Seu acometimento agudo requer internação de urgência na maioria dos casos e está associado com altos índices de mortalidade. Sintomas de algum tipo de alteração neuropsiquiátrica estão presentes entre $79 \%$ a $90 \%$ dos pacientes cirróticos e envolvem desde distúrbios da função cognitiva até o coma. $O$ tratamento envolve internação em unidade de tratamento intensivo para monitorização dos níveis de amônia, suplementação de oxigênio com ventilação mecânica, a utilização de medicamentos que reduzem a absorção de amônia e diálises ${ }^{45,47}$

Outra complicação bastante grave, porém, menos comum, é a síndrome hepatorrenal (SHR). A SHR é um complexo de disfunções hepáticas e renais que acomete principalmente portadores de doença hepática avançada com ascite. A probabilidade de pacientes com ascite desenvolverem a SHR é de cerca de $18 \%$ no primeiro ano e de cerca de $40 \%$ em 5 anos. A diminuição da função renal é resultado da intensa vasoconstrição secundária às complexas alterações circulatórias produzidas pela doença hepática avançada, como dilatações de artérias esplâncnicas e hipovolemia. $\mathrm{O}$ tratamento geralmente requer internação de urgência e envolve a utilização de drogas vasoativas, de albumina, diálises e drogas que aumentam a função renal. $O$ transplante de fígado pode não ser suficiente para o retorno da função renal em razão do comprometimento orgânico do paciente, sendo necessário o transplante duplo de fígado e rins nos casos mais graves. ${ }^{48,49}$

Vonlanthen et $a l^{50}$, em um estudo com mais de 1200 pacientes cirróticos, investigaram complicações, tempo de internação, utilização de recursos, exames e procedimentos relacionados com a gravidade destes pacientes e com as co-morbidades apresentadas e observaram o carcinoma hepatocelular como uma das doenças mais graves e mais frequentes associadas ao paciente cirrótico. Diversos autores também têm demonstrado aumento considerável do número casos de carcinoma hepatocelular, sendo a hepatite por vírus $\mathrm{C}$ o principal causador deste tipo de câncer.(18,27,30,31)

Dados internacionais mostram que a incidência de $\mathrm{CHC}$ é de 2 a $8 \%$ nos pacientes com hepatite provocada por vírus da hepatite C (VHC). O carcinoma hepatocelular é atualmente o 
quinto tumor mais comum e a terceira causa mais frequente de morte por câncer em todo o mundo.

Em 2008 cerca de 700 mil casos de CHC foram diagnosticados em todo o mundo, com uma incidência de 16 casos por 100 mil habitantes. No Japão, a mortalidade devido ao CHC tem mais que triplicado desde meados da década de 70. A infecção pelo VHC é responsável por $75 \%$ a $80 \%$ dos casos de $\mathrm{CHC}$ e o vírus da hepatite B (VHB) é responsável por $10 \%$ a $15 \%$ dos casos restantes. No Brasil utiliza-se o Critério de Milão para a classificação dos pacientes portadores do carcinoma hepatocelular para elegibilidade ao transplante hepático. Em nosso pais, foi observado que o $\mathrm{CHC}$ está presente entre $17 \%$ a $38 \%$ dos pacientes com doença hepática avançada e entre os principais motivos que levam ao transplante hepático., ${ }^{73-56}$

O tratamento do carcinoma hepatocelular envolve uma série de medidas. O melhor tratamento é sem dúvida o transplante hepático, porém dada a escassez de órgãos, outras opções são utilizadas.

Segundo as últimas recomendações da American Association for the Study of Liver Diseases (AASLD), a ressecção cirúrgica é indicada em estadios iniciais da doença, em tumores únicos menores de dois centímetros e sem doença associada. Em tumores múltiplos, menores que 3 centímetros cada, no total e sem doença associada o transplante hepático é o tratamento de escolha e, em casos com alguma doença associada a ablação por rádio frequência (RFA) passa a ser o tratamento mais eficaz. ${ }^{57}$

A revista The Lancet também publicou longa revisão sobre o tratamento do portador do carcinoma hepatocelular. A detecção precoce, o transplante hepático, a abração por rádio frequência e a quimioembolização podem proporcionar ao paciente uma sobrevida superior a 5 anos. Pacientes em estadios intermediários, com função hepática preservada, porém com tumores multifocais podem ser beneficiados com a quimioembolização transarterial (TACE), com média de sobrevida além de dois anos. Em casos mais avançados, com invasão portal o tratamento medicamentoso com agentes moleculares multi-inibidores de quinases e medicamentos com atividades anti-angiogênicas como sorafenibe, a cisplatina, ou a doxorrubicina passa a ser recomendado, atingindo uma sobrevida ao redor de 7 meses. ${ }^{58}$

Segundo o Critério de Milão utilizado no Brasil para inclusão em lista de transplante hepático, pacientes são considerados candidatos ao transplante hepático quando possuem um 
único tumor igual ou menor de 5 centímetros de diâmetro ou até 3 tumores menores que 3 centímetros, porém sem acometimento vascular macroscópico..$^{54,59}$

Devido ao maior risco de progressão da doença hepática nos pacientes portadores do carcinoma hepatocelular e significativo risco de morte, foi desenvolvido um método de exceção na pontuação de MELD (Model of End-stage Liver Disease) nos portadores deste tipo de tumor, dentro dos critérios de Milão. Dentro destes critérios, os pacientes cirróticos com carcinoma hepatocelular são considerados pacientes em situação especial pela legislação vigente que abrange o transplante hepático em nosso país. Esta situação especial confere pontuação inicial de 20 pontos na escala de MELD para estes pacientes no momento do diagnóstico, com elevação para 24 pontos após 3 meses e, após mais três meses, o paciente atinge 29 pontos na escala de MELD, sendo conferido uma prioridade para o transplante e diminuição no tempo de espera. ${ }^{60-63}$

Com todos estes fatores atuando conjuntamente, a cirrose hepática é a oitava causa de morte no mundo, segundo dados da Organização Mundial da Saúde (OMS). Em 2013 houveram 1.221.300 mortes ocasionadas pela cirrose hepática, um aumento de 45,6\% com relação aos dados de 1990. Dados semelhantes foram publicados em 2010, onde aproximadamente $3,8 \%$ do total de mortes em mulheres e $3,6 \%$ do total de mortes em homens em todo o mundo foram ocasionados pela doença hepática descompensada. ${ }^{5,10}$ Kanwal et al ${ }^{64}$ mostraram que entre 1996 e 2006 a proporção de pacientes que desenvolveram fibrose hepática aumentou de $9 \%$ para $19 \%$ e Seef et al ${ }^{65}$ em um estudo prospectivo observaram um crescimento de $7 \%$ para $17 \%$ no número destes pacientes com um aumento na mortalidade de 1,3\% para 3,7\% na doença hepática descompensada.

Além disso, entre os anos de 1999 e 2007, o número de mortes associadas à cirrose relacionada ao VHC foi maior que o número de mortes relacionadas ao vírus da imunodeficiência adquirida (HIV) nos EUA atingindo cerca de 10 a 15 mil mortes ao ano, sendo a principal causa de indicação para o transplante hepático neste país. ${ }^{66-70}$. McAdam et $a l^{4} \mathrm{e}$ Davies et al ${ }^{71} \mathrm{em}$ um amplo estudo retrospectivo observaram um aumento na taxa de mortalidade de 123\% relacionada a hepatite C entre os anos de 1995 e 2004.

Hipertensão portal e a doença hepática avançada também podem causar complexas alterações do leito vascular pulmonar, dentre elas a Síndrome Hepatopulmonar (SHP) e a Hipertensão Porto-pulmonar (HPP). A associação de hipertensão pulmonar com fibrose 
hepática e hipertensão portal é pouco diagnosticada, sendo sua prevalência estimada por volta de $1 \%$ a $2 \%$ dos pacientes com hipertensão portal ou fibrose hepática, sem preferência por sexo, e com predomínio na faixa dos 40 anos. $^{72}$

A presença de hipoxemia arterial na fibrose hepática é fato bem documentado na literatura e seus mecanismos fisiopatogênicos têm sido muito estudados. Admite-se que haja, acompanhando a doença do fígado, alteração vascular pulmonar que determinem pequenos e inúmeros shunts arteriovenosos. Cerca de um terço dos pacientes com doença hepática descompensada têm saturação arterial de oxigênio reduzida e, algumas vezes, cianose. A Síndrome Hepatopulmonar é caracterizada como uma tríade: doença hepática, dilatação vascular intrapulmonar e hipoxemia arterial. Apesar da SHP ser uma causa infrequente de hipoxemia em adultos e crianças com hepatopatia (5-29\%), pode resultar em hipoxemia ( $\mathrm{PaO} 2$ $<50 \mathrm{mmHg}$ ) severa e debilitante, com necessidade de oxigenioterapia contínua. ${ }^{73}$

A fisiopatologia da hipóxia na SHP consiste da dilatação (e possível proliferação) do leito vascular pulmonar ao nível dos capilares e pré-capilares, onde ocorrem as trocas gasosas. Essa desorganização vascular resulta no desenvolvimento de unidades alveolares nos quais a ventilação é preservada, mas a perfusão é profundamente aumentada, comprometendo a oxigenação arterial. Esse é o mecanismo mais comum na SHP leve, mas nas mais severas o shunt arteriovenoso em vários graus está associado a limitação à difusão de oxigênio. ${ }^{74}$

A presença de hipertensão pulmonar moderada ou severa em pacientes com doença hepática aumenta o risco de disfunção do enxerto e mortalidade relacionada a problemas cardio-pulmonares após o transplante hepático. Durante o transplante hepático há um elevado aumento do volume venoso cardíaco resultante da resolução da obstrução portal pela remoção do fígado comprometido. Este aumento do retorno venoso afeta diretamente o ventrículo direito do coração do paciente, influenciando toda a circulação pulmonar. 0 paciente com hipertensão pulmonar apresenta elevada resistência vascular pulmonar, causando aumento agudo da pressão arterial pulmonar, podendo levar a uma disfunção ventricular direita, congestão vascular e perda do enxerto. ${ }^{73,75}$

\subsection{O TRANSPLANTE NO TRATAMENTO DA DOENÇA HEPÁTICA AVANÇADA}


O transplante hepático representa o avanço terapêutico mais espetacular ocorrido no campo da hepatologia, sendo hoje a única alternativa de tratamento para o doente com doença hepática terminal. ${ }^{76,77}$ Antes do seu advento, o tratamento da hepatopatia crônica incluía apenas medidas paliativas e, atingida uma determinada fase da doença, o indivíduo evoluía invariavelmente para o óbito. O primeiro transplante hepático foi realizado por Thomas Starzl ${ }^{78,79}$ em 1963, mas apenas em 1967 a mesma equipe obteve sucesso e o paciente transplantado obteve sobrevida de 13 meses.

Os dados mais recentes da OMS, de 2014 mostram que em todo o mundo foram realizados 20.200 transplantes de fígado, sendo $14,6 \%$ realizados por doadores vivos e a grande maioria por doadores falecidos. ${ }^{5,80} \mathrm{O}$ Brasil é o segundo país em número absoluto de transplantes hepáticos, porém ficamos apenas na 24a posição em número de doadores por milhão de habitantes. Segundo dados da Associação Brasileira de Transplante de Órgãos (ABTO), foram realizados em 2011 em nosso país 1494 transplantes hepáticos, 1599 em 2012, 1723 em 2013 e 1756 em 2014, onde cerca de 50\% destes pacientes foram diagnosticados com o vírus da hepatite $C$. Este número vem crescendo ano a ano, porém o número de doadores permanece baixo, com média de 8,2 por milhão de pessoas, fazendo com que o número de pacientes em lista seja crescente. ${ }^{81,82}$

Dados atuais mostram sobrevida do paciente de $72,3 \%$ após 5 anos do transplante hepático e de $56,6 \%$ após 10 anos para indivíduos acometidos por cirrose não alcoólica, porém em todo o mundo, o número de pacientes em lista de espera está aumentando e muitos pacientes com condições clínicas não passíveis de terapias médicas não terão acesso ao transplante de fígado..$^{53,83,84}$

Segundo a portaria número 1160, publicada no Diário Oficial da União, edição 103 de 31 de maio de 2006, que estabelece critérios para o transplante hepático segundo a gravidade e estado clínico do paciente. São consideradas indicações para o transplante hepático os pacientes portadores das seguintes hepatopatias: atresia das vias biliares, câncer primário do fígado, cirrose alcoólica, cirrose biliar primária, cirrose biliar secundária, cirrose criptogênica, cirrose pelo vírus da hepatite $\mathrm{B}$ ou $\mathrm{C}$, cirrose por doença gordurosa hepática não alcoólica (NASH), colangite esclerosante primária, doença de Carolli, Doença de Wilson, doenças metabólicas com indicação de transplante, carcinoma hepatocelular fora dos critérios de Milão, hemocromatose, hepatite autoimune, hepatite fulminante, metástases hepáticas de 
tumor neuroendócrino, polineuropatia amiloidótica familiar (PAF), síndrome de Budd-Chiari e síndrome hepatopulmonar. ${ }^{62}$

\subsection{A LISTA DE ESPERA PARA O TRANSPLANTE HEPÁTICO}

A Organização Mundial da Saúde acompanha, desde os anos 80, o número de pacientes em listas de espera para transplantes de órgãos sólidos e tecidos e o número de transplantes realizados nos diferentes países do mundo. Segundo dados da Agência NorteAmericana de transplante (UNOS) e da Organ Procurement and Transplantation Network (OPTN) de dezembro de 2015, existem 122.501 pacientes em lista de espera por órgãos nos Estados Unidos, sendo destes 15.265 à espera do transplante hepático $(12,51 \%)$, com tempo de espera médio maior que um ano. ${ }^{85-88}$

Na Europa, as agências mais importantes no transplante de órgãos, o European Society for Organ Transplantation (ESOT) e o Eurotransplant mostram dados atuais sobre número de pacientes em listas de espera. O Eurotransplant, agência europeia responsável pela organização da lista de transplante em mais de 30 países europeus aponta que, em 2014 havia aproximadamente 13.000 pacientes em lista de espera para diversos órgãos e tecidos e destes, cerca de 3.000 estavam aguardando o transplante hepático. ${ }^{80,89}$

O número de pacientes em lista de espera é crescente. Existem diversos fatores que contribuem para este elevado número de pacientes e para o insuficiente número de órgãos para o transplante hepático. Segundo dados internacionais há uma tendência ao tempo de espera em lista aumentar devido a crescente escassez de órgãos para o transplante, seguido pelo aumento do número de pacientes que necessitam de novo órgão. ${ }^{76,90-96}$

Dados dos números de doadores de órgãos mostram que o Brasil ainda tem um longo caminho a percorrer. 0 número de doadores tem se mantido em aproximadamente 8,2 por milhão de habitantes, sendo que aproximadamente $40,1 \%$ das famílias dos pacientes internados diagnosticados com morte cerebral recusam a doação. ${ }^{81,82,97}$

O escore MELD é hoje o critério mundialmente utilizado para alocação dos pacientes em lista de espera para o transplante hepático, sendo a gravidade do paciente atualmente 
aferida por esta escala. Esta variável é formada pela análise de 3 exames laboratoriais facilmente acessíveis que são a creatinina, a bilirrubina total e o tempo de protrombina ou INR (International Normalized Ratio). Este escore prediz eficientemente a probabilidade de morte em curto prazo e, com base no objetivo de diminuir a quantidade de mortes em lista de espera para o transplante hepático esta escala foi adotada internacionalmente em 2002 pela OPTN para a alocação de órgãos para o transplante. ${ }^{85,87,98-102}$

No modelo atual de escalonamento de pacientes para o transplante hepático, indivíduos com maior gravidade nos exames laboratoriais para o cálculo do MELD (creatinina, bilirrubina total e tempo de protrombina) recebem uma pontuação mais alta, passando à frente na lista para o transplante. ${ }^{38,85}$ Nesta escala, pacientes com resultados de exames mais desfavoráveis, ou piores, além da presença de hepatocarcinoma conferem uma probabilidade maior de o paciente receber um transplante mais rapidamente..$^{52,103,104}$

Diversos autores questionaram esta metodologia desde as suas primeiras utilizações. Farnswortth et al ${ }^{100}$, afirmaram que esta metodologia ocasiona a utilização de órgãos transplantados em pacientes com pior estado de saúde, com maior risco de morte e pior taxa de sobrevida. Nascimento et $a l{ }^{92}$, comparando o escore de Child-Turcotte-Pugh (CTP) com o de MELD apontaram benefícios e malefícios desta nova abordagem, principalmente com relação à disponibilidade de transplantar órgãos em pacientes mais graves.

Existem pouquíssimos estudos até o momento que abordam o custo do tratamento do paciente relacionado com o escore de MELD. Nada ainda foi dito com relação à lista de espera para o transplante hepático, mas alguns estudos mostram maior tempo em internações, maior gasto com medicamentos e maior risco de morte em pacientes submetidos a procedimentos cirúrgicos com valores de MELD mais elevados..$^{98,105}$

Outros estudos mostram a crescente quantidade de internações e infecções oportunistas que acometem os pacientes cirróticos, com grande número de casos de óbitos nestes pacientes ou necessidade de intervenções de urgência. ${ }^{106}$ Peritonites espontâneas, infecções bacterianas como pneumonia ou septicemia também estão presentes. ${ }^{38,107,108} 0$ maior risco de sangramento e uma maior utilização de hemocomponentes foi relacionado com pacientes mais graves, além do maior número de óbitos em pacientes submetidos à transplante hepático. ${ }^{109}$ 


\subsection{O CUSTO DA DOENÇA HEPÁTICA AVANÇADA}

O impacto econômico da doença hepática avançada é crescente, com custos diretos próximos a 360 milhões de dólares e indiretos em cerca de 9 bilhões de dólares em 2012 nos Estados Unidos. ${ }^{17,70,110-112}$

Menzin et $a{ }^{83}$, chegaram a um custo do paciente cirrótico por VHC entre 9.576 e 22.424 dólares ao ano. Armstrong et al ${ }^{18}$, e Rosenberg et al ${ }^{113}$ em outros estudos demonstraram que os custos diretos com pacientes cirróticos e com a doença hepática crônica foram estimados em 2,5 bilhões de dólares e os indiretos em 10,6 bilhões de dólares nos EUA em 2004. Além disso há a expectativa deste custo dobrar nos próximos 20 anos, com o aumento do número de pacientes cirróticos aumentando de 25\% para 37\% em 2020 entre os acometidos pelo $\mathrm{VHC}^{71,114,115}$

Myers et al ${ }^{116}$, afirmaram que o pico do número de pacientes com doença hepática avançada descompensada deverá ocorrer entre 2031 e 2035, com aumento de $60 \%$ dos custos destes pacientes até 2032.

Rotily et $a l^{14}$, e El Khoury et $a{ }^{117}$, em estudo multicêntrico em toda a União Europeia encontraram um valor de $€ 139.000,00$ para o custo do transplante hepático, em que aproximadamente $44,9 \%$ deste valor corresponde ao valor das internações e do leito hospitalar. Um estudo canadense de macrocusteio com empresas de saúde, recentemente mostrou que os gastos destes pacientes crescem à medida que existam mais doenças correlacionadas como insuficiência renal, necessidade de diálises e internações recorrentes. ${ }^{118}$

Aspectos financeiros do paciente cirrótico incluem custos diretos (medicamentos, materiais, recursos humanos e custos de hospitalização) e custos indiretos, como a perda da capacidade produtiva e redução da qualidade de vida. ${ }^{114} \mathrm{O}$ custo do tratamento com pacientes hospitalizados com complicações resultantes da doença hepática avançada que precisam de cuidados em saúde e medicamentos caros (eritropoietinas, hemostasia e terapias medicamentosas para o câncer) são ainda desconhecido. ${ }^{14}$

Leigh, et al ${ }^{119}$, afirmaram que $33 \%$ dos custos do paciente cirrótico são diretos, e $67 \%$ são custos indiretos e as estimativas atuais dos gastos destes pacientes são subestimadas, 
podendo ser o valor total real desembolsado para o tratamento mais de dez vezes superior àqueles que os estudos avaliam.

O transplante é hoje amplamente realizado em todo o mundo. Seu custo foi diminuído, porém permanece alto. ${ }^{120-122}$ Já foi demonstrado que o custo do transplante hepático está relacionado com a gravidade do paciente aferida pela escala de MELD, causado principalmente pelo maior tempo de internação hospitalar, utilização de procedimentos de alto custo e maiores taxas de complicações pós-operatórias. ${ }^{121,123}$

Estudos de avaliação econômica em transplante de órgãos costumam não abordar o custo do período de espera até o desfecho observado e, também não relatam as complicações ou o desfecho desfavorável neste período. ${ }^{124-126}$ A maioria dos estudos se restringe ao custo do período de internação para transplante hepático, em algum tipo de procedimento ou no custo de uma doença ou co-morbidades associadas. . $^{38,123,127}$

A ocorrência de complicações e a presença de co-morbidades faz com que o paciente cirrótico demande uma grande quantidade de recursos do sistema de saúde, necessitando de exames mais frequentes, tratamento medicamentoso específico, além de procedimentos custosos. ${ }^{128-130}$ Diálises em UTI, exames de imagens e procedimentos que exigem mão de obra especializada como biópsias, endoscopias ou colângiografias se encontram no grupo de procedimentos que geram um alto impacto no custo total do tratamento do paciente. ${ }^{14}$ Medicações de alto custo, antibióticos de última geração e medicamentos quimioterápicos também contribuem para aumentar os gastos do paciente em lista de espera. ${ }^{31,131}$

Alguns estudos recentes mostram custo significativamente maior em pacientes que necessitaram de paracenteses em lista de espera para o transplante hepático. ${ }^{126,131,132} \mathrm{O}$ alto valor empregado no tratamento de pacientes que necessitam de paracenteses frequentes também foi analisado em um estudo de Hassanen et al ${ }^{133}$, mostrando que quanto maior a gravidade destes pacientes maior o custo do tratamento e pior o prognóstico.

Pacientes em lista de espera para o transplante hepático apresentam frequentemente insuficiência renal, muitos deles necessitando de diálises. Alguns estudos demonstraram o impacto financeiro ocasionado pela necessidade destes procedimentos em pacientes internados em unidade de terapia intensiva. Thuluvath et al ${ }^{134}$, realizaram um estudo mostrando o alto custo do tratamento de pacientes com insuficiência renal aguda em leito hospitalar. 
Estudos envolvendo pacientes com hepatocarcinoma em vários estadios mostram alto custo do tratamento destes pacientes quando o tumor está mais avançado, principalmente pela medicação de alto custo empregada. ${ }^{14,135} \mathrm{O}$ custo do tratamento do câncer em pacientes cirróticos também foi abordado em outros estudos em que foi demonstrado alto custo, e pior prognóstico em pacientes mais graves. ${ }^{4,46}$

O tempo de espera em lista também é um fator significativo de gastos no sistema de saúde. Alguns estudos mostram que durante o período de espera a gravidade do paciente vai gradativamente aumentando, ocasionando maiores gastos. ${ }^{13,136,137}$

Periodicamente, o paciente em lista é solicitado a comparecer ao hospital, realizando exames, consultas e procedimentos. Alguns estudos mostram que o tempo de espera gera um custo baixo em comparação ao custo total do procedimento final, seja ele o transplante ou a cirurgia para retirada de um tumor. ${ }^{126}$ Porém, outros estudos demonstram que, quanto maior ao tempo de espera, maior o custo deste paciente..$^{130}$

Alguns estudos abordaram o elevado risco de morte associado ao paciente cirrótico, e seu potencial ônus econômico. ${ }^{46,138}$ Alguns autores concluem que o impacto econômico do tratamento do paciente cirrótico menos grave é significativamente menor do que em pacientes com maior gravidade. A utilização dos recursos aplicados nestes pacientes menos graves, avaliando tempo de sobrevida, ou anos de vida ganhos é pequeno, se comparado com o custo aplicado em pacientes mais graves, com menor sobrevida. ${ }^{101}$

O custo das internações também foi objeto de amplos estudos. Um estudo com pacientes em lista mostrou que as internações geram um gasto mais que o dobro com relação a pacientes que não necessitaram de internações. Observamos também que o custo do tratamento de suporte para o paciente em lista gera um valor gasto considerável para os serviços de saúde. ${ }^{127}$

Em países subdesenvolvidos encontramos uma realidade diferente. Dados recentes mostram valores gastos muito maiores em medicamentos e materiais utilizados do que no custo com recursos humanos e pagamentos médicos observados em países desenvolvidos. Em estudo realizado em um grupo de pacientes transplantados de fígado em um hospital na China em 2010, Wang, et al ${ }^{139}$, observou que o custo da mão de obra correspondeu a um percentual bem pequeno em relação ao total de gastos destes pacientes. Coelho et $a{ }^{140,141}$, em dois estudos realizados em nosso país confirma este dado, mostrando que os itens mais custosos 
em internações para o transplante foram materiais, medicamentos e a hemoterapia. Porém este dado ainda não está totalmente esclarecido. Silveira et al ${ }^{101}$, mostraram que o custo do atendimento médico e do leito hospitalar correspondia a mais de $60 \%$ de todo o valor do tratamento durante o período de internação para o transplante hepático.

Existem poucos estudos que abordam o custo desfavorável de um determinado procedimento. Quando o desfecho esperado é atingido, os recursos financeiros e não financeiros utilizados são justificados pelo sucesso do procedimento. $\mathrm{O}$ manejo do paciente envolve um substancial impacto econômico, porém os benefícios do transplante superam este elevado custo. ${ }^{27,67,138}$

Mas, quando o desfecho é desfavorável, como a morte do paciente, todo custo envolvido no tratamento do paciente não é revertido em nenhuma das instâncias participantes do estudo, seja ela o grupo de pesquisa, os profissionais envolvidos no tratamento e a sociedade. ${ }^{101}$ 


\subsection{AVALIAÇÃO ECONÔMICA EM SAÚDE}

O crescimento exponencial dos gastos com saúde resultante do desenvolvimento e incorporação de novas tecnologias coloca enorme pressão sobre orçamentos dos governos e leva ao aumento do interesse nos estudos de avaliação econômica em nosso país. ${ }^{142,143}$

Além disso, nos últimos anos, é reconhecido o conceito de que os recursos em saúde são escassos, e que novas tecnologias, medicamentos ou procedimentos não podem ser incorporados à prática clínica sem a adequada avaliação do seu custo e de sua efetividade. ${ }^{144}$

Segundo Drummond et al ${ }^{145}$, devido a uma pressão crescente nos orçamentos em saúde, há um aumento no interesse por métodos que avaliam o valor monetário das intervenções em saúde.

A análise econômica em saúde propõe identificar, quantificar, avaliar, comparar e estudar os custos e as consequências de técnicas e procedimentos realizados. Esta ferramenta possibilita melhor compreensão, distribuição e eficiência na utilização dos recursos na saúde..$^{31,131,144,146-148}$ Além disso, gestores em saúde dependem frequentemente de indicadores reais entre os resultados obtidos pelos recursos alocados para uma melhor tomada de decisão sobre o orçamento. ${ }^{149}$ Os custos das intervenções tornam-se cada vez mais relevantes nas decisões em políticas de saúde. ${ }^{150}$ Apesar de grandes avanços terem sido obtidos no sentido de melhorar as técnicas cirúrgicas dos transplantes hepáticos e do aumento da sobrevida do paciente com doença hepática crônica os custos desta doença ainda não foram totalmente determinados. ${ }^{84,150,151}$

O número de estudos envolvendo análises econômicas em saúde vem crescendo rapidamente, no Brasil e em todo o mundo. ${ }^{141,146,147,152-154}$ São considerados, normalmente nestes estudos os custos diretos da intervenção no paciente, incluindo medicamentos administrados, materiais utilizados e o custo das internações. Alguns métodos de estudo também abrangem os custos indiretos como os gastos com o deslocamento, ausência do trabalho, gastos com medicamentos adquiridos fora do hospital ou salários pagos pelo sistema de previdência no país. ${ }^{145}$ 
Em recente revisão sistemática publicada por Haddad et al ${ }^{155}$ em 2016 pela FMUSP, foram encontrados 535 estudos em análises econômicas no Brasil, desde os anos 80, com grande crescimento no número de publicações nos anos recentes.

A avaliação econômica das diferentes formas de tratamento disponível permite aperfeiçoar a tomada de decisão sobre onde investir mais recursos, levando em conta fatores orçamentais, sem que estes interfiram diretamente na saúde dos pacientes. É possível avaliar se os gastos com uma determinada intervenção ou não intervenção são custo-efetivos, ajudando a conciliar as crescentes demandas de custos na saúde com os recursos econômicos disponíveis. ${ }^{14,156}$

Porém, para avaliar estes gastos de maneira objetiva é importante buscar quais os principais fatores determinantes de custo para a doença ou intervenção. $O$ termo "determinantes de custo" tem origem na expressão em inglês cost driver, que faz parte da terminologia concebida no contexto das práticas de contabilidade gerencial que eclodiram no final do século vinte.

O determinante de custo (cost driver) é definido como um fator que determina uma mudança importante nos custos totais de algo e também um fator que traz um impacto direto sobre os custos dentro de um sistema. Apresentados como fatores, os cost drivers podem ser um evento, uma atividade, um processo, um indicador, entre outros, que causam alterações nos custos. Assim, o entendimento dos cost drivers é essencial para o entendimento da estrutura de custos de um determinado produto ou serviço. ${ }^{157}$

O termo cost driver é adotado com diferentes propósitos nas práticas de gestão como atribuir valores aos objetos e recursos causadores de custos, para estimar o comportamento dos custos e para designar os fatores que causam os custos em relação ao montante total gasto. ${ }^{158-160}$

Nesta linha de raciocínio, é cada vez maior a importância do estudo dos fatores que causam impacto econômico e elevam os custos do paciente em lista de espera. Poucos estudos foram realizados até o momento abordando o tempo que o paciente permanece, desde a sua admissão em lista até o momento do desfecho, seja ele o transplante hepático, sua remoção de lista ou o óbito. ${ }^{161,162}$ 


\section{OBjetivos}

O objetivo do estudo é avaliar o custo do paciente com doença hepática avançada em lista de espera para o transplante hepático.

Além disso, avaliar os fatores associados ao maior custo e sua relação com tipo de evolução do paciente (desfecho observado) e o MELD. 


\section{Casuística e Método}

Foi realizado um estudo de análise econômica parcial do tipo descrição de custos com metodologia preponderante de microcusteio em uma coorte prospectiva que incluiu todos os 492 pacientes regularmente inscritos em lista de espera para o transplante hepático desde primeiro de janeiro de 2012 até 31 de dezembro de 2013 no Ambulatório do Serviço de Transplante de Órgãos do Aparelho Digestivo do Hospital das Clínicas da Faculdade de Medicina da Universidade de São Paulo. A perspectiva do Hospital foi utilizada na estimativa dos custos. Não houveram pacientes excluídos do estudo.

Foram utilizados dados primários e levantados todos os custos diretos utilizados durante o período deste estudo. Foram analisados individualmente dados clínicos, prontuários eletrônicos de internações, diagnósticos, co-morbidades e procedimentos realizados como diálises e paracenteses.

As variáveis clinicas analisadas foram: idade, sexo, IMC, MELD, diagnóstico da hepatopatia, co-morbidades, dias de internação, diagnóstico da internação, procedimentos da internação, tempo de espera em lista e internação ou procedimentos realizados no ICESP.

As variáveis de custo analisadas foram: consultas ambulatoriais, exames radiológicos, exames laboratoriais, materiais e medicamentos utilizados, recursos humanos, internações por complicações, realização de paracenteses, realização de diálises, utilização de hemocomponentes e procedimentos realizados tanto em nível ambulatorial como em internações durante o período de espera em lista. Os componentes do custo total e os recursos avaliados e analisados foram:

- Dados Clínicos $\longrightarrow\left\{\begin{array}{l}\text { Idade, sexo, IMC, diagnóstico da hepatopatia, co- } \\ \text { morbidades, complicação da hepatopatia, MELD, } \\ \text { internações, procedimentos realizados e tempo em lista }\end{array}\right.$
- Custo Ambulatorial $\longrightarrow\left\{\begin{array}{l}\text { Consultas, materiais, medicamentos, paracenteses, diálises, } \\ \text { exames laboratoriais, exames de imagem e radiológicos }\end{array}\right.$

- Custo em Internações $\rightarrow\left\{\begin{array}{l}\text { Procedimentos, materiais, medicamentos, diálises, exames } \\ \text { laboratoriais, exames de imagem, exames radiológicos, utilização do } \\ \text { leito, nutrição, internações e procedimentos realizados no ICESP e } \\ \text { hemocomponentes }\end{array}\right.$ 
Foi desenvolvido um software para a análise de dados relativos a custos denominado PEP - Transplante Hepático, através do Sistema Gerenciador de Banco de Dados Microsoft SQL Server 2008. Essa base foi implantada no ambiente de tecnologia de informação (TI) do complexo HCFMUSP.

As bases de dados utilizadas foram: SIGH (sistema de gestão hospitalar), Si3 (sistema integrado de informações institucionais), HCMed (prontuário médico eletrônico) e SAM (sistema de administração de materiais e medicamentos), sistema de gerenciamento de hemocomponentes e TASY, sistema de gerenciamento de informações dos pacientes do ICESP.

O fluxograma de acompanhamento dos pacientes durante o estudo foi:

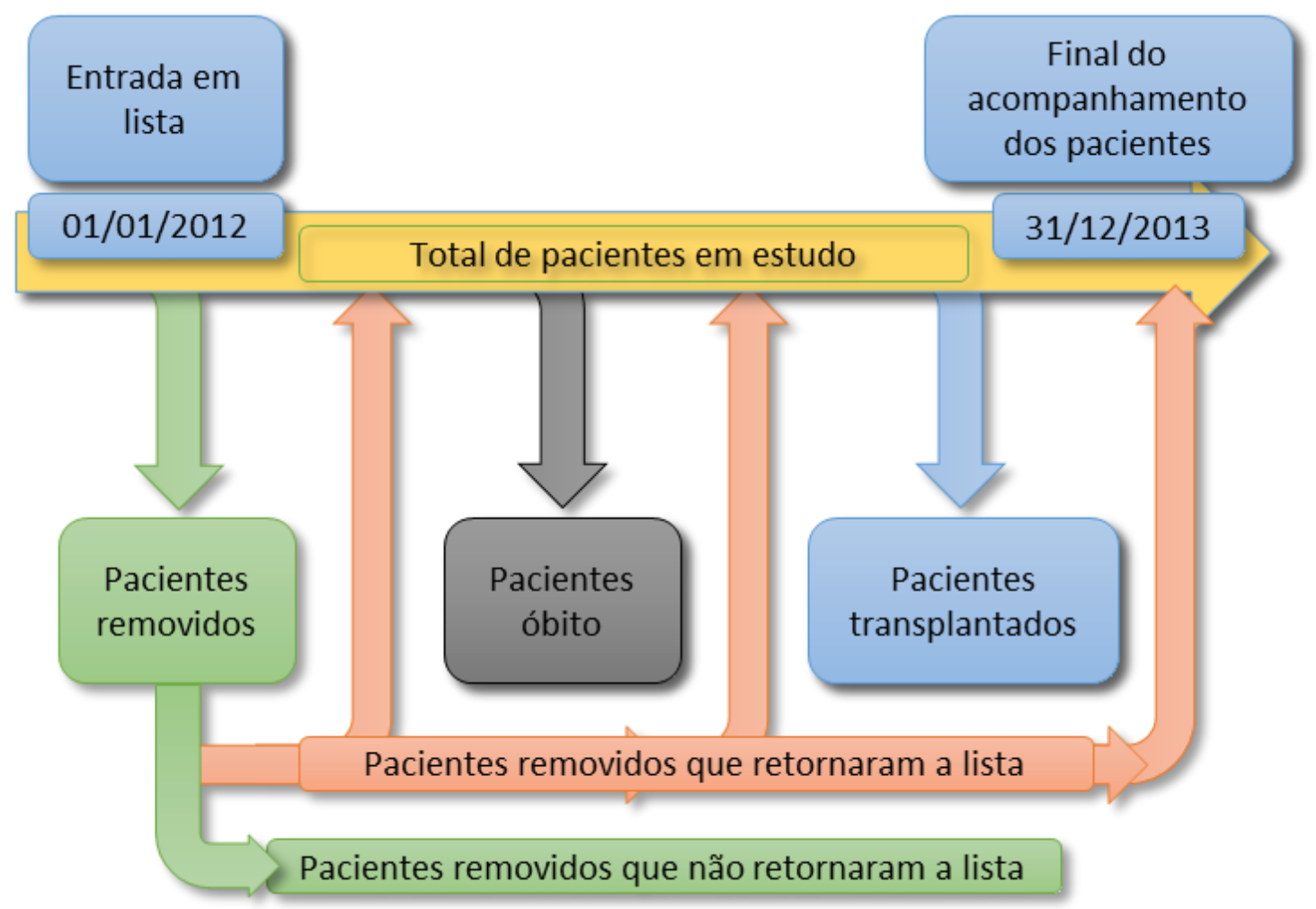


O fluxograma do modelo de análise seguido foi:

\begin{tabular}{|c|c|c|c|c|}
\hline Dados clínicos & Consultas e RH & Custo do RH & \multirow{11}{*}{ Custo por Paciente } & \multirow{11}{*}{ Custo Total } \\
\hline Custo Ambulatorial & Diárias em enfermaria, & Custo da Internação & & \\
\hline \multirow[t]{9}{*}{ Custo em internações } & Diárias em UTI, & Custo dos Exames & & \\
\hline & Exames de Imagem, & Custo dos Medicamentos & & \\
\hline & Radiológicos e Laboratoriais, & Custo dos Materiais & & \\
\hline & Materiais Utilizados & Custo da Nutrição & & \\
\hline & Medicamentos Utilizados & Custos dos Procedimentos & & \\
\hline & Procedimentos & Custo da Diálise & & \\
\hline & Quimioterapia & RFA e TACE & & \\
\hline & Internações ICESP & Custo atendimento ICESP & & \\
\hline & Hemoterapia & Custo da Hemoterapia & & \\
\hline
\end{tabular}

A estimativa dos custos foi feita da perspectiva do hospital e incluiu somente os custos diretos médicos. A identificação e quantificação dos recursos utilizados foram obtidos diretamente do setor responsável. As quantidades de recursos foram multiplicadas pelo valor unitário de custo de cada componente específico, corrigidas pela inflação corrente (IPCA médico). O custo total por paciente foi calculado pela soma de todos os componentes de custo consumidos pelo paciente no período de seguimento em fila de espera. O trabalho foi aprovado Comitê de Ética em Pesquisa da instituição (CAPPESQ) sob número 10983.

A gravidade do estado de saúde dos pacientes foi calculada pelos valores de MELD, atualmente considerado o método mais eficiente em predizer o risco de morte em 3 meses. Os valores de MELD (Model of End-stage Liver Disease) foram calculados para cada paciente no dia da inscrição em lista e no primeiro dia de internação através da fórmula logarítmica dos resultados dos exames de creatinina, bilirrubina total e INR. $(36,37)$

$[M E L D=3,78[$ Ln bilirrubina sérica $(\mathrm{mg} / \mathrm{dL})]+11,2[\mathrm{Ln}$ INR $]+9,57[\mathrm{Ln}$ creatinina sérica $(\mathrm{mg} / \mathrm{dL})]+6,43]$

O seguimento do paciente foi realizado acompanhando a evolução clínica e registrando todos os recursos utilizados. Os pacientes de lista são acompanhados ambulatorialmente com consultas médicas, e de equipe multidisciplinar. Nesse período, alguns pacientes necessitam internação hospitalar devido a complicações do estado de saúde ou para a realização de procedimentos invasivos. Para melhor compreensão dos custos dos pacientes, os recursos foram divididos em custos ambulatoriais e custos em internações. Todos os custos foram somados perfazendo o custo total por paciente. 


\subsection{MÉTOdO DE CÁLCULO dOS CUSTOS AMBULATORIAIS}

A quase totalidade dos dados foram coletados e analisados utilizando a metodologia de microcusteio que consiste na obtenção das quantidades totais de cada componente de custo ou recurso utilizado durante todo o tempo de estudo para cada paciente individualmente. $O$ tempo foi calculado individualmente pela data de inclusão do paciente em lista até um dos seguintes desfechos: remoção de lista por melhora ou piora do quadro clínico, óbito, internação para o transplante ou a conclusão do estudo.

As variáveis de custos ambulatoriais analisadas foram: número de consultas médicas, psicológicas, de enfermagem, de nutricionista, de assistente social e em odontologia, exames laboratoriais, exames de imagem e exames radiológicos, endoscopia, ultrassom, colonoscopia, eletrocardiograma, tomografia computadorizada, ressonância magnética e paracenteses.

Os valores das consultas de cada especialidade foram obtidos junto ao setor de recursos humanos deste hospital, dividindo-se o valor salarial de cada especialidade pelo tempo de atendimento realizado e o número de consultas que o profissional atende no seu período de trabalho. Foram inclusos os custos de profissionais afastados, em férias, e demais encargos.

Valores de exames laboratoriais, exames de imagem e diálise foram fornecidos pelos respectivos setores. O número de paracenteses realizadas por paciente, a quantidade de frascos de coleta e de albumina utilizada foi obtido junto a enfermeira responsável pelo procedimento.

\section{- Componentes do custo ambulatorial}

- Recursos Utilizados

$\left.\begin{array}{l}\text { Número de consultas, } \\ \text { Exames laboratoriais, } \\ \text { Exames de imagem, } \\ \text { Exames radiológicos, } \\ \text { Paracenteses }\end{array}\right\}$

Médicos, Psicólogos, Enfermeiros, Dentistas, Nutricionistas, Assistente social Hemograma, Dosagem de Creatinina, Tempo de Protrombina, Bilirrubina total, etc Ultrassom, Ecocardiograma, Ressonância Magnética, etc Raio-X, Tomografia, Colângiografia, etc

A fonte dos dados ambulatoriais analisados está na tabela 1. 


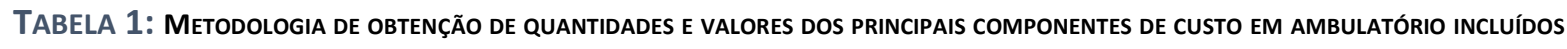
NO ESTUDO

\begin{tabular}{|c|c|c|c|}
\hline Componente & $\begin{array}{l}\text { Método de obtenção } \\
\text { quantidades }\end{array}$ & Local de obtenção dos valores & Método de valoração \\
\hline \multicolumn{4}{|l|}{ Tratamento Ambulatorial } \\
\hline Consultas & Prontuário eletrônico - HCMED & Departamento de recursos humanos & Macrocusteio \\
\hline Exames laboratoriais & Prontuário eletrônico - HCMED & Laboratório Central & Microcusteio \\
\hline Exames de imagem & Prontuário eletrônico - HCMED & Laboratório Central & Microcusteio \\
\hline Procedimentos & Serviço de Enfermagem & Sistema de Administração Hospitalar & Microcusteio \\
\hline Materiais & Folhas de débito & Sistema de Administração de Materiais & Microcusteio \\
\hline Medicamentos & Farmácia central & Farmácia central - pregão de compras & Microcusteio \\
\hline
\end{tabular}

Foi utilizada também a técnica de macrocusteio, que envolve a identificação dos custos gerais dos recursos ou serviços utilizados em um determinado setor e posteriormente faz-se a divisão por área utilizada pela quantidade de leitos, pela quantidade de metros quadrados ou pelo número de pacientes atendidos.

O custo da diária em leito hospitalar foi considerado como um custo composto, isto é a combinação de vários recursos como serviços de limpeza especializada, esterilização de roupas hospitalares e energia elétrica. Assim o cálculo deste recurso requereu a identificação de cada uma das partes constituintes que totalizam o custo deste recurso. Para este tipo de cálculo foi utilizada a técnica de custeio por absorção.

A técnica de microcusteio é mais detalhada e precisa, pois envolve a quantidade exata de cada recurso individual utilizado em cada componente de custo (como a quantidade exata de cada medicamento utilizado, número exato de bolsa de sangue, quantidade exata de seringas, luvas ou dosagem de algum tipo de exame). Isto permite também a obtenção de custos mínimos e máximos, além de médias precisas para cada recuso estimado. 


\subsection{MÉTODO DE CÁLCULO DOS CUSTOS DAS INTERNAÇÕES}

As variáveis analisadas durante as internações foram: tempo total da internação, número de dias em UTI, número de dias em enfermaria, custo de materiais, medicamentos, exames laboratoriais, exames de imagem, gastos com nutrição, hemocomponentes, diálises, gastos relativos a internações e procedimentos realizados no ICESP, além do custo de utilização do leito em terapia intensiva e em enfermaria. O custo diário do leito em internação, sendo ele em unidade de terapia intensiva e em enfermaria incluiu os gastos estimados com luz, água, limpeza e manutenção e foi calculado pela metodologia de custeio por absorção.

Valores correntes de materiais e medicamentos utilizados foram obtidos pelos últimos pregões de compra realizados pelo departamento financeiro do Hospital das Clínicas da Faculdade de Medicina da Universidade de São Paulo, atualizados periodicamente e ao final do período de coleta

Com relação à quantidade e número de internações, foram realizados levantamentos individuais e diários nos sistemas HCMed e Si3 para verificação de todas as internações realizadas pelos pacientes em lista de espera para o transplante hepático.

No sistema HCMed, foram obtidos os dados relativos a todos os exames laboratoriais coletados, exames de imagem e especialidades médicas, além de datas e períodos de internação.

No sistema Si3 foram coletados dados relativos a todos os períodos de internação, medicamentos utilizados, número de dias em enfermaria e UTIs, diagnósticos da internação, motivos que levaram o paciente a ser internado e principais procedimentos realizados neste período.

Os dados relativos ao consumo e utilização de hemocomponentes foram obtidos pelo banco de dados do Departamento de Hematologia do Hospital das Clínicas e cruzados com os períodos de internação. Para cada paciente e período de internação obtivemos as quantidades e os custos de cada hemocomponente e o custo total. Os hemocomponentes computados foram: concentrado de hemácias $(\mathrm{CH})$, concentrado de hemácias irradiado (Chi), plasma fresco 
concentrado (PFC), criopreceptado (Crio), concentrado de plaquetas (CP), concentrado de plaquetas irradiado (CPi) e aférese de plaquetas (AF).

Também foram analisadas todas as internações realizadas por pacientes portadores de Carcinoma Hepatocelular (CHC) por meio do prontuário eletrônico do paciente no ICESP (Tasy). Foram analisados o número de internações, tempo, custo de cada atendimento, procedimentos e hemoterapia. A fonte dos dados das internações está resumida na tabela 2.

TABela 2: Metodologia de obtenção de Quantidades E VAloRes dos PRINCIPAIS COMPONENTES de CUSTO EM INTERNAções INCLUÍDOS NO ESTUDO

\begin{tabular}{|c|c|c|c|}
\hline Componente & Método de obtenção quantidades & Local de obtenção dos valores & $\begin{array}{l}\text { Método de } \\
\text { valoração }\end{array}$ \\
\hline Procedimentos & $\begin{array}{c}\text { Prontuário eletrônico - HCMED; Sistema } \\
\text { Integrado de Internações - Si3 }\end{array}$ & Sistema de Administração Hospitalar & Microcusteio \\
\hline Medicamentos & Sistema Integrado de Internações - Si3 & Farmácia central - pregão de compras & Microcusteio \\
\hline $\begin{array}{l}\text { Diárias em UTI e } \\
\text { Enfermaria }\end{array}$ & $\begin{array}{c}\text { Sistema Integrado de Internações - Si3; } \\
\text { HCMED }\end{array}$ & Departamento de Recursos Humanos & Macrocusteio \\
\hline Materiais & Prontuário eletrônico - Folhas de débito & Sistema de Administração Hospitalar & Microcusteio \\
\hline $\begin{array}{l}\text { Exames } \\
\text { laboratoriais }\end{array}$ & Prontuário eletrônico - HCMED & Laboratório Central & Microcusteio \\
\hline Exames de imagem & Prontuário eletrônico - HCMED & Laboratório Central & Microcusteio \\
\hline Procedimentos & Sistema Integrado de Internações - Si3 & Sistema de Administração Hospitalar & Microcusteio \\
\hline Dieta e Nutrição & Sistema Integrado de Internações - Si3 & $\begin{array}{l}\text { Divisão de Nutrição e Divisão de } \\
\text { Farmácia }\end{array}$ & Microcusteio \\
\hline Hemoterapia & Serviço de Hemoterapia & Hemocentro Central & Microcusteio \\
\hline Internações ICESP & Prontuário eletrônico - Tasy & Sistema de Administração Hospitalar & Macrocusteio \\
\hline
\end{tabular}




\subsection{ANÁLISE ESTATÍSTICA}

Foi realizada uma análise descritiva para apresentar as frequências de ocorrências dos principais recursos utilizados, dados epidemiológicos, custos totais e parciais de cada fonte de gastos. Para essa análise utilizamos o MELD, sexo, idade, causa da doença hepática, procedimentos realizados, desfechos observados, quantidade de internações e os custos de materiais, medicamentos, exames, hemocomponentes e recursos humanos. Os resultados foram apresentados na forma de tabelas, gráficos de barras e gráficos de box-plot, com valores em médias e desvios padrões para as variáveis contínuas e como números totais e porcentagens para as variáveis categóricas.

Para a compreensão das variáveis categóricas, foi realizado uma análise utilizando o teste de Chi-quadrado e o teste exato de Fisher para verificação da associação entre as variáveis estudadas.

Para a compreensão das variáveis contínuas, foi realizada primeiramente um teste de normalidade (Teste de Anderson-Darling), seguido de teste não paramétrico de Levene ou Kruskal-Walis (para variáveis que não seguem normalidade) ou ANOVA (para variáveis que seguem normalidade). Para a comparação de grupos dois a dois foram realizados testes não paramétricos de Tukey.

Foi realizada análise de regressão logística simples para a determinação das variáveis que isoladamente apresentaram significância estatística para o alto custo em lista de espera. Foi optado pela divisão pelo terceiro quartil para delimitação do ponto de corte de determinação dos valores relativos ao alto custo. Esta opção mostrou-se mais válida pois obteve maior homogeneidade das amostras, com menor divergência em observações e menor desvio-padrão dos valores de custo. Em seguida foram utilizados todos os fatores significantes para a análise de regressão logística múltipla, seguindo o método Stepward-Forward.

Foi utilizado o software R (versão 3.3.1 - R Core Team, 2014) ${ }^{163}$ e considerados estatisticamente significantes valores de p menores que 0,05 com nível de significância de $5 \%$. 


\section{RESULTADOS}

\subsection{RESULTADOS CLÍNICOS E DEMOGRÁFICOS}

Entre janeiro de 2012 e dezembro de 2013, foram inclusos 492 pacientes, sendo 307 pacientes do sexo masculino e 185 do sexo feminino, com média etária de 51,27 anos.

Os grupos de pacientes avaliados neste trabalho foram formados de acordo com a evolução clínica individual. A inclusão de novos pacientes foi realizada diariamente, do mesmo modo foi acompanhada a evolução clínica e o desfecho de cada paciente, formando, com o tempo os grupos avaliados neste trabalho (pacientes transplantados, removidos, óbito e em lista).

Ao final dos 24 meses do estudo, aqueles pacientes que não tiveram como desfecho o transplante, remoção ou óbito formaram o grupo dos pacientes que permaneceram em lista de espera para o transplante.

Dados clínicos, demográficos, tempo de espera, internações, diagnósticos e procedimentos são apresentados na tabela 3. 
Tabela 3: Dados clínicos de todos os pacientes em lista de ESPera para transplante hepático de janeiro de 2012 até DEZEMBRO DE 2013 ( $N=492$ )

\section{Sexo}

Masculino

Feminino

Cor/raça

\begin{tabular}{cc}
$(\boldsymbol{n}-\mathbf{4 9 2})$ & $\%$ \\
\hline 307 & 62,4 \\
185 & 37,6
\end{tabular}

Branco

399

81,1

Negro

26

5,28

Oriental

Mulato/Pardo

5

1,02

62

12,6

\section{Estado civil}

Casado

Solteiro/divorciado

146

29,67

Viúvo

31

6,30

Não declarado

3

0,61

Nível de escolaridade

Primeiro grau incompleto 57,92

Primeiro grau completo

Ensino superior incompleto

Ensino superior completo

Não declarado

Etiologia

$\checkmark H C$

$V H C+$ Outros

$V H B$

$V H B+$ Outros

Alcoólica

107

21,75

Alcoólica + Outros

2,44

Outros

$\mathrm{CHC}$
CHC
82
16,67
$\mathrm{Não}-\mathrm{CHC}$
410
83,33

Necessidade de internações

\begin{tabular}{lcc} 
Sim & 277 & 56,3 \\
Não & 215 & 43,7 \\
ro total de internações & & 0,78 \\
\hline de internações por paciente & Média & Dp \\
\hline & 51,27 & $\pm 12,93$ \\
(anos)* & 26,02 & $\pm 5,32$ \\
(kg/m2)* & 23,46 & $\pm 9,76$ \\
* $^{*}$ & 380,4 & $\pm 562,7$ \\
de internação* (UTI e ENF) & 19,72 & $\pm 22,04$
\end{tabular}

*DAdos APRESENTAdos EM VAlores MÉdIOS E DESVIO-PADRÃo 
A frequência de diagnóstico das principais etiologias entre todos os pacientes está apresentada no gráfico 1.

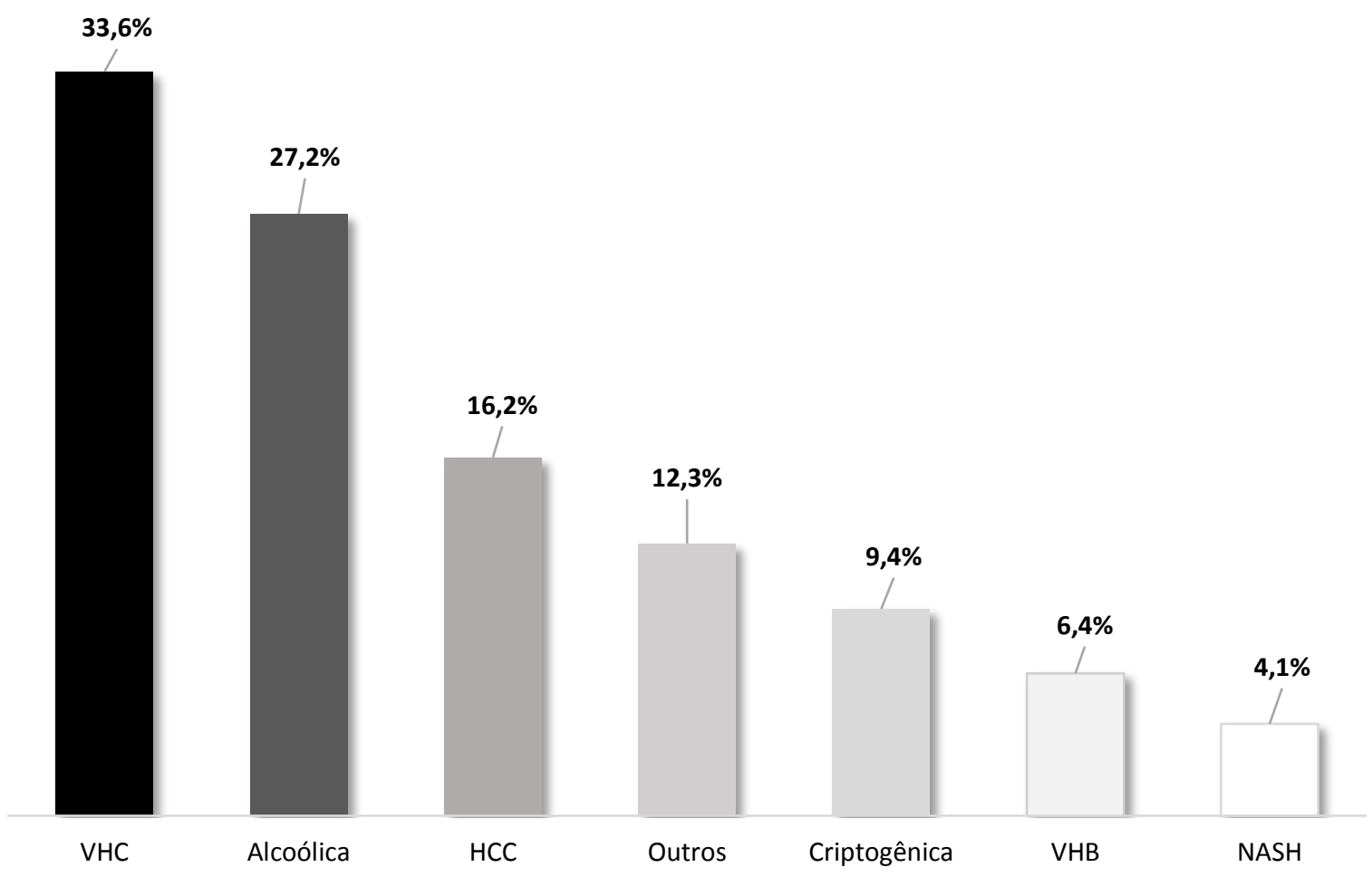

Gráfico 1: Principais frequênCIAS de diagnósticos entre todos os PACIENTES EM LISTA de ESPERA SEgundo a hePATOPATIA $(\mathrm{N}=492)$ 


\subsection{RESULTADOS POR GRUPO DE DESFECHO}

Foram formados quatro grupos entre todos os pacientes em lista de espera para o transplante hepático, divididos de acordo com os desfechos obtidos na evolução clínica individual, formando, com o tempo os grupos avaliados neste trabalho (pacientes transplantados, removidos, óbito e em lista).

A inclusão de novos pacientes foi realizada durante todo o período do estudo e, do mesmo modo foi acompanhada a evolução clínica e o desfecho de cada paciente,

Ao final dos 24 meses do estudo, aqueles pacientes que não tiveram como desfecho o transplante, remoção ou óbito formaram o grupo dos pacientes que permaneceram em lista de espera para o transplante.

\subsubsection{NÚMERO DE PACIENTES POR GRUPO}

Do total de 492 pacientes inseridos neste estudo, 134 (27,8 \%) foram transplantados, $103(21,37 \%)$ foram removidos de lista, 67 (13,9 \%) faleceram e 188 (36,93\%) permaneceram em lista durante todo o período do estudo. Gráfico 2.

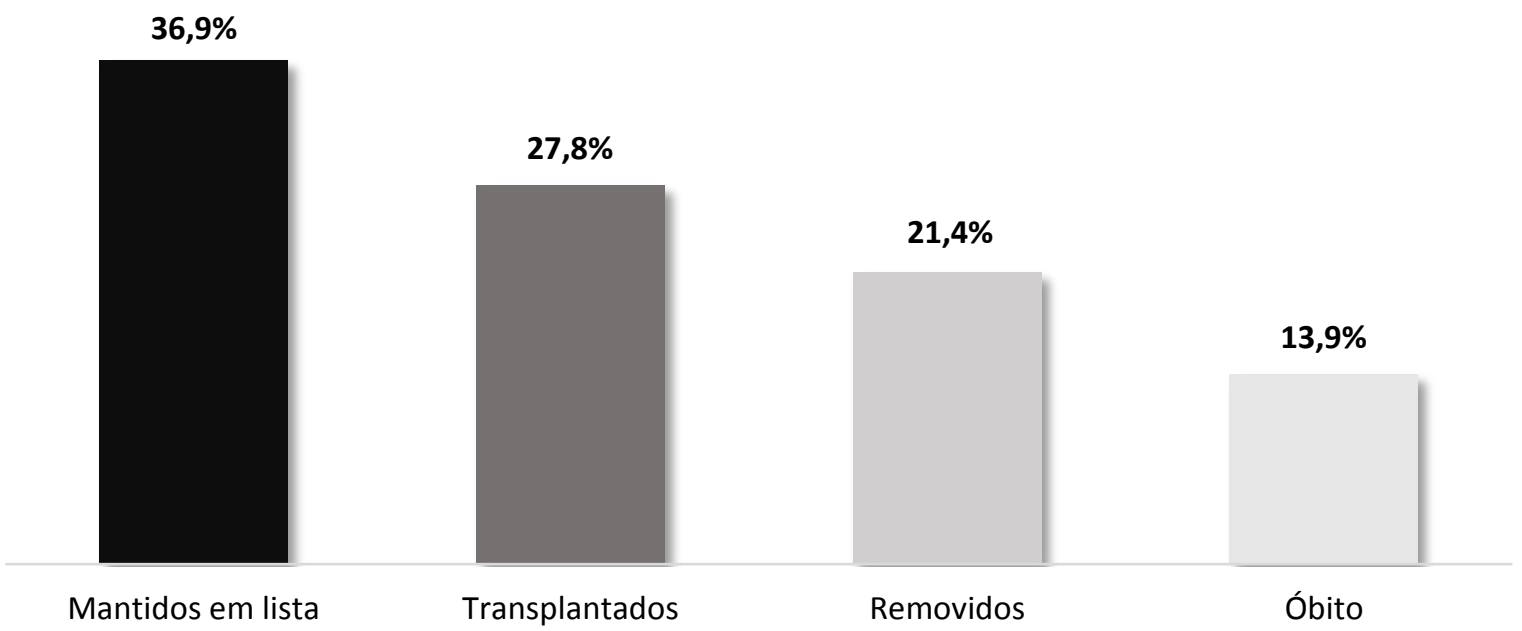

GRÁFICO 2: NúMERO E PORCENTAGEM DOS PACIENTES EM LISTA DE ESPERA SUBDIVIDIDOS PELO DESFECHO (N=492) 
Dos 103 pacientes removidos, 22 foram removidos por falta de condições clínicas para permanecer na lista de espera (21,36\%). Os principais motivos de remoção dos demais 81 pacientes que foram removidos por melhora das condições clínicas $(78,64 \%)$ estão apresentados no gráfico 3.

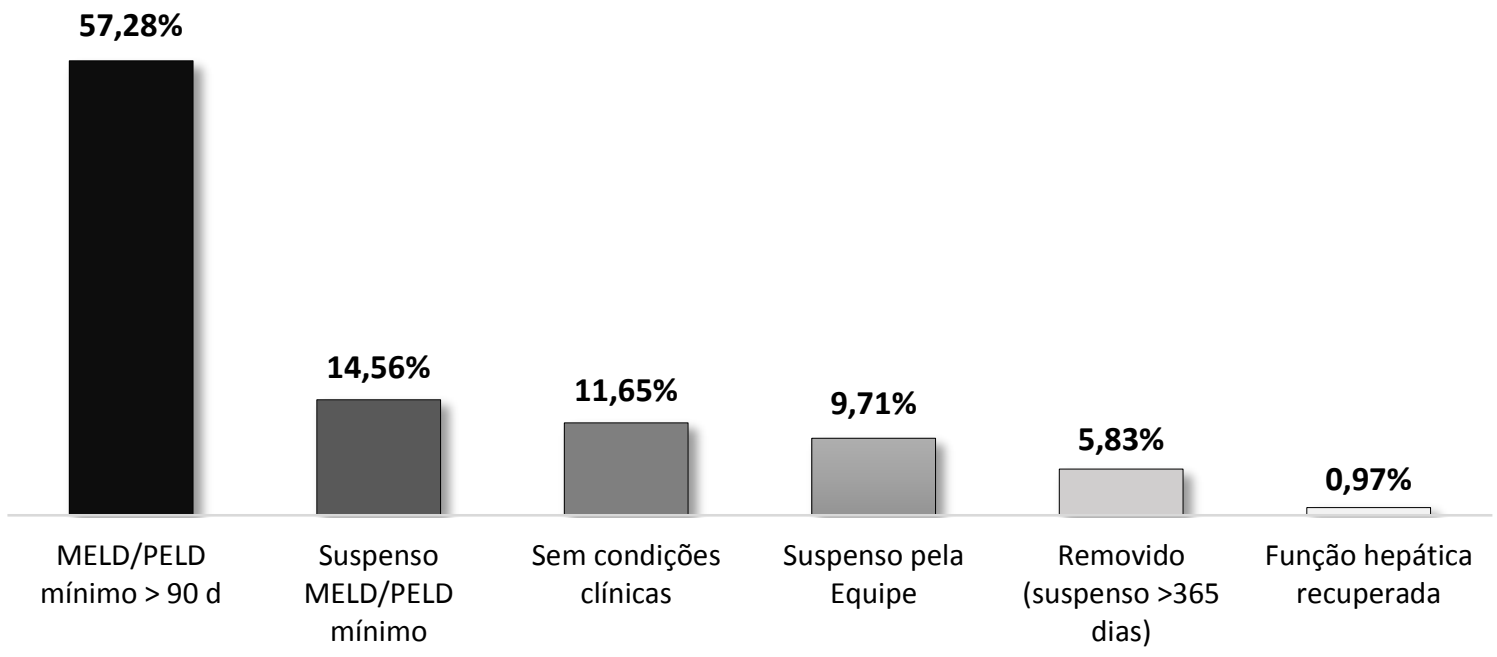

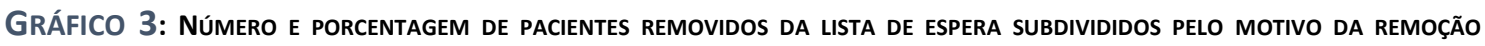
$(\mathrm{N}=103)$

\subsubsection{DADOS CLíNICOS E DEMOGRÁFICOS}

Os dados clínicos, demográficos, tempo de espera em lista, tempo de internações e procedimentos realizados pelos pacientes conforme divisão dos grupos pelo desfecho estão apresentados na tabela 4. 
TABela 4: Dados clínicos, diagnósticos e procedimentos Realizados por todos os PaCIeNTES divididos por GRUPo de DESFECHO. ( $N=492$ ). DAdOS EM NÚMEROS TOTAIS E PORCENTAGEM. TESTE DE FISHER

\begin{tabular}{|c|c|c|c|c|c|c|c|c|c|}
\hline & \multicolumn{2}{|c|}{$\begin{array}{c}\text { Transplantado } \\
n=134\end{array}$} & \multicolumn{2}{|c|}{$\begin{array}{c}\text { Removido } \\
n=103\end{array}$} & \multicolumn{2}{|c|}{$\begin{array}{l}\text { Óbito } \\
n=67\end{array}$} & \multicolumn{2}{|c|}{$\begin{array}{l}\text { Lista } \\
\mathrm{n}=188\end{array}$} & \multirow[b]{2}{*}{$P=$} \\
\hline & Total & $\%$ & Total & $\%$ & Total & $\%$ & Total & $\%$ & \\
\hline \multicolumn{10}{|l|}{ Sexo } \\
\hline Masculino & 63 & 52,24 & 19 & 18,45 & 57 & 85,07 & 98 & 55,06 & \multirow{2}{*}{$<0,001$} \\
\hline Feminino & 71 & 47,76 & 84 & 81,55 & 10 & 14,93 & 80 & 44,94 & \\
\hline \multicolumn{10}{|l|}{ Internações } \\
\hline Sim & 85 & 63,43 & 24 & 23,30 & 57 & 85,07 & 111 & 62,36 & \multirow[t]{2}{*}{$<0,001$} \\
\hline \multirow[t]{2}{*}{ Não } & 49 & 36,57 & 79 & 76,70 & 10 & 14,93 & 67 & 37,64 & \\
\hline & Média & $\overline{D p p}$ & Média & $\overline{D p p}$ & Média & $\overline{D p}$ & Média & $\overline{D p p}$ & \\
\hline Idade* & 50,2 & $\pm 13,5$ & 52,9 & $\pm 11,3$ & 52,9 & $\pm 12,1$ & 49,1 & $\pm 15,5$ & 0,502 \\
\hline IMC* & 25,8 & $\pm 5,8$ & 25,9 & $\pm 5,0$ & 26,49 & $\pm 4,39$ & 26,15 & $\pm 5,24$ & 0,558 \\
\hline Peso* & 73,22 & $\pm 17,41$ & 70,62 & $\pm 14,42$ & 72,23 & $\pm 15,49$ & 71,70 & $\pm 19,30$ & 0,841 \\
\hline MELD* & 29,8 & $\pm 8,3$ & 16,1 & $\pm 7,0$ & 29,1 & $\pm 9,0$ & 20,2 & $\pm 8,2$ & $<0,001$ \\
\hline Tempo de espera em lista (dias) * & 170,9 & $\pm 157,5$ & 208,9 & $\pm 134,1$ & 127,1 & $\pm 159,9$ & 450,8 & $\pm 200,9$ & $<0,001$ \\
\hline Dias de internação & 9,6 & $\pm 8,1$ & 25,4 & \pm 26 & 16,4 & $\pm 17,2$ & 9,5 & $\pm 11,4$ & $<0,001$ \\
\hline \multicolumn{10}{|l|}{ Procedimentos } \\
\hline Paracentese* & 6,63 & $\pm 9,58$ & 12,3 & 14,68 & 2,5 & $\pm 3,50$ & 6,39 & $\pm 10,56$ & 0,05 \\
\hline Diálise* & 1 & $\pm 0,1$ & 0 & 0 & 1,33 & $\pm 0,58$ & 1,63 & $\pm 1,06$ & 0,34 \\
\hline
\end{tabular}

*DADOS APRESENTADOS EM VALORES MÉDIOS E DESVIO-PADRÃO

IMC - ÍNDICE DE MASSA CORPORAL (PESO MULTIPLICADO PELA ALTURA (M) ELEVADO A SEGUNDA POTÊNCIA MELD - MODEL OF END-STAGE LIVER DISEASE 
A análise da homogeneidade e das diferenças entre os grupos pela idade, peso e IMC está apresentada no gráfico 4.

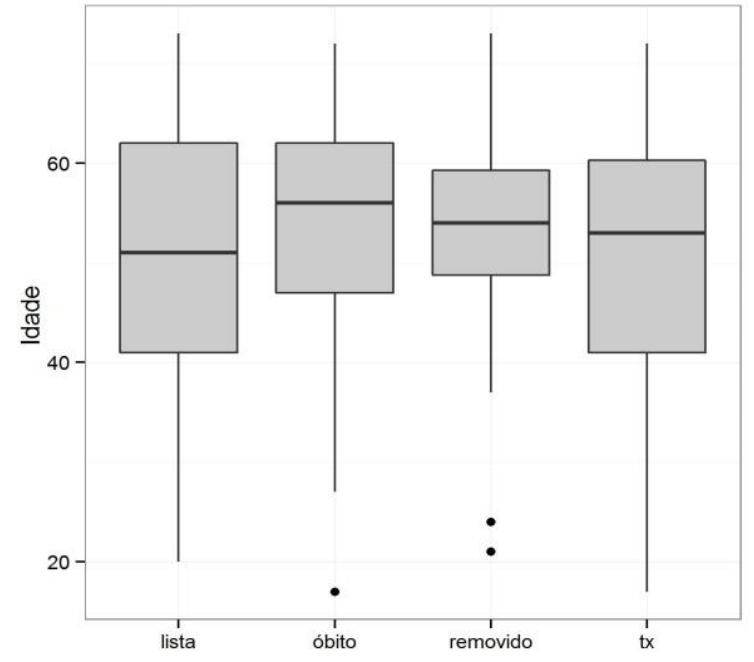

A
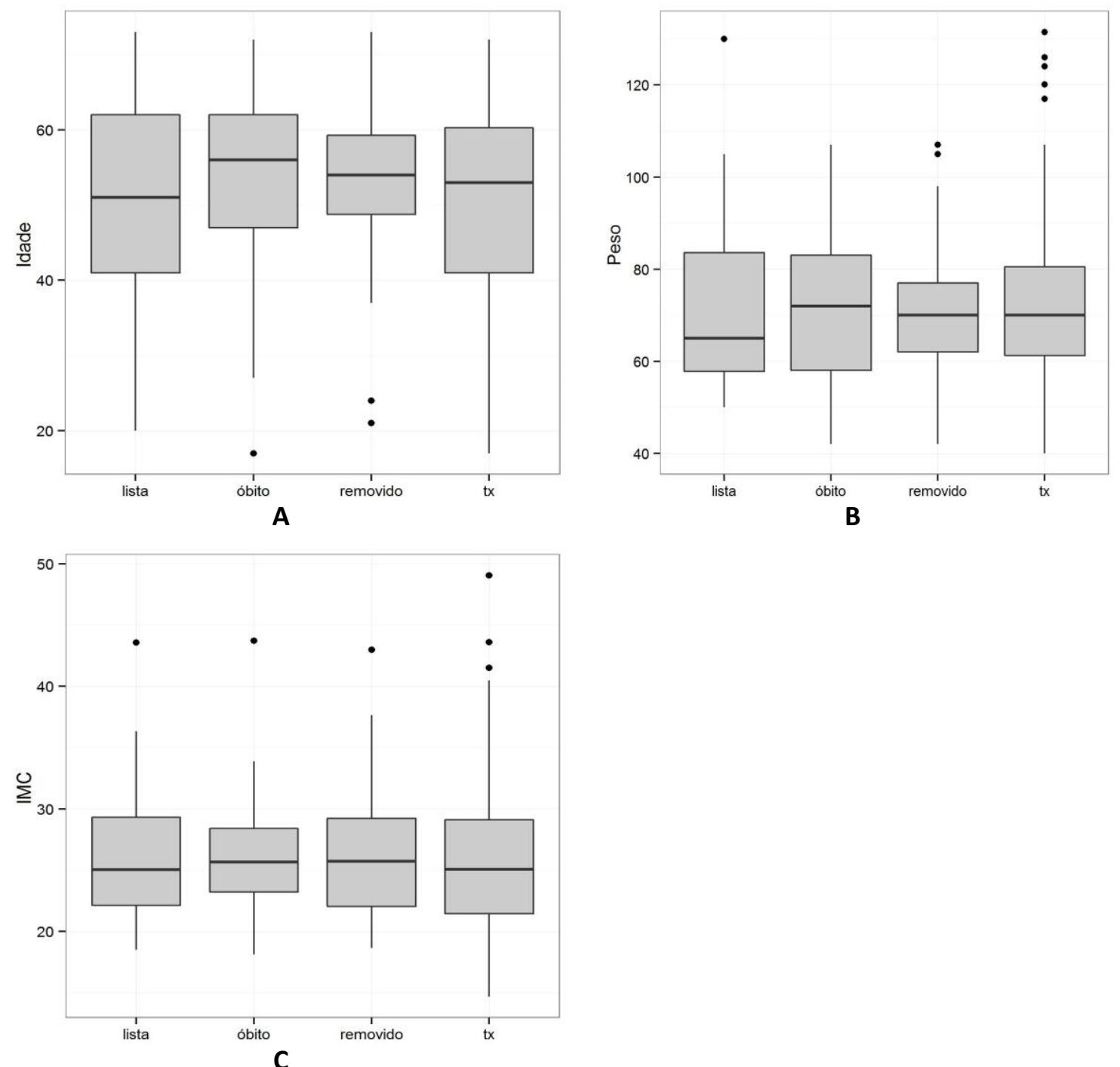

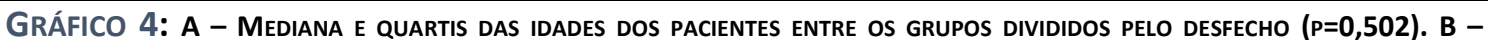
MEDIANA E QUARTIL DO PESO DOS PACIENTES ENTRE OS GRUPOS DIVIDIDOS PELO DESFECHO ( $P=0,558)$. $C$ - MEDIANA E QUARTIL DO IMC ENTRE OS GRUPOS DIVIDIDOS PELO DESFECHO $(P=0,841)$ 


\subsubsection{DIAGNÓSTICO POR GRUPO DE DESFECHO}

A frequência dos diagnósticos das etiologias entre os pacientes divididos pelo grupo de desfecho está apresentada na figura 1.

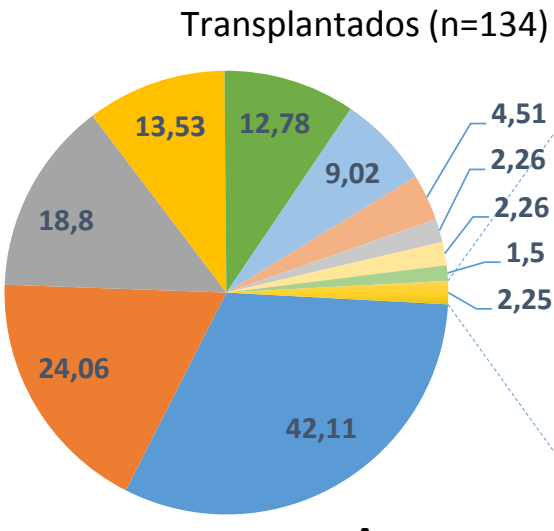

A

Óbito $(n=67)$

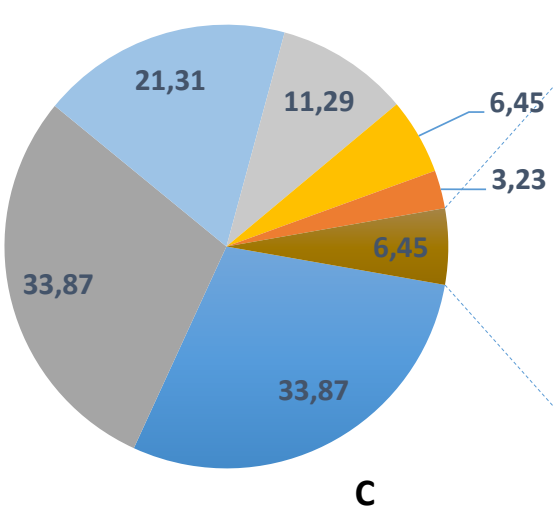

$$
\begin{aligned}
& \text { VHC } \\
& \text { HAI } \\
& \text { CEP } \\
& \text { Fulminante } \\
& \text { Carolli }
\end{aligned}
$$
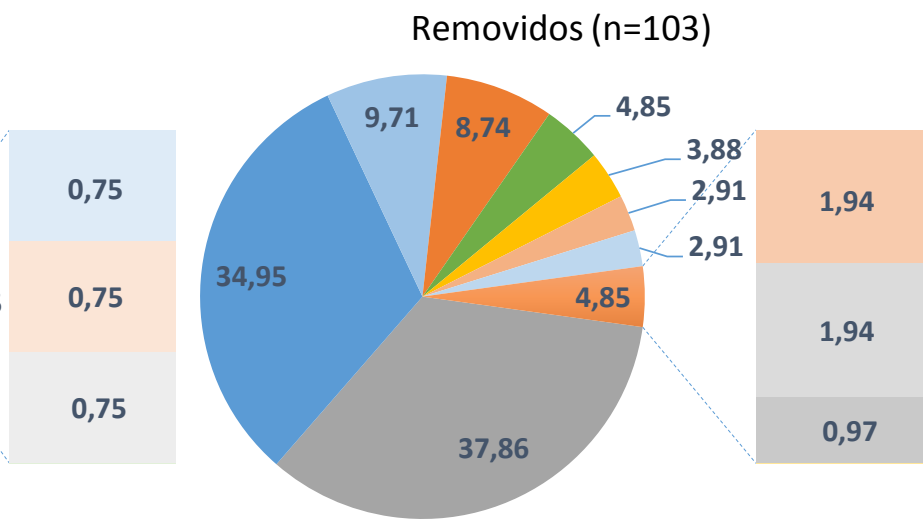

B

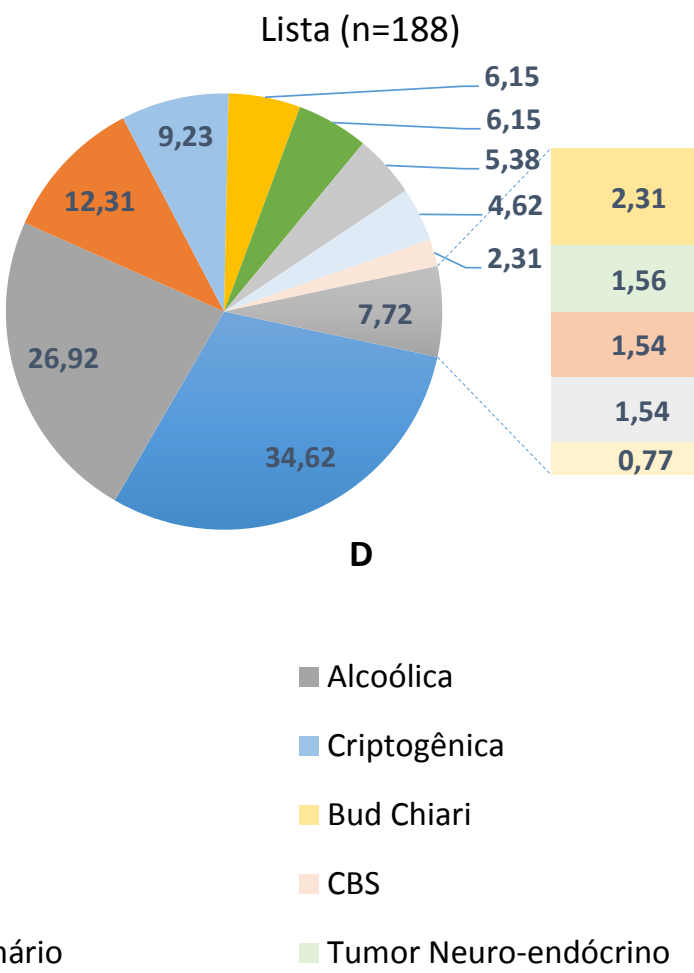

Figura 1: Frequência dos principais diagnósticos entre os grupos de pacientes cirróticos divididos por desfecho. A - Frequencia de diagnósticos nos pacientes transplantados. B - Frequencia de diagnósticos nos pacientes removidos. C - Frequencia de diagnósticos nos pacientes que falesceram. D - Frequencia de diagnósticos nos pacientes que permaneceeram em lista até o final do estudo. Valores em porcentagem. VHC - Vírus da Hepatite C; HAI - Hepatite Auto-Imune; CEP - Colangite esclerosante primária; HCC - HePATo-CELULlaR Carcinoma; VHB - Vírus da Hepatite B; NASH - Non-Alcoholic Steatosis Hepatic; CBP - Cirrose Biliar Primária; CBS - Cirrose Biliar Secundária. 
Os principais diagnósticos de hepatopatias que apresentaram diferenças significativas entre os pacientes divididos por grupo de desfecho foram o carcinoma hepatocelular $(p<0,001)$, a cirrose de etiologia alcoólica $(p=0,024)$ e NASH $(P=0,027)$. Houveram significativamente mais pacientes com $\mathrm{CHC}$ no grupo transplantado, ao passo que houveram mais pacientes com cirrose alcoólica no grupo removido e mais pacientes com o diagnóstico de NASC no grupo que veio a óbito. Os dados em porcentagem estão apresentados no gráfico 5 .

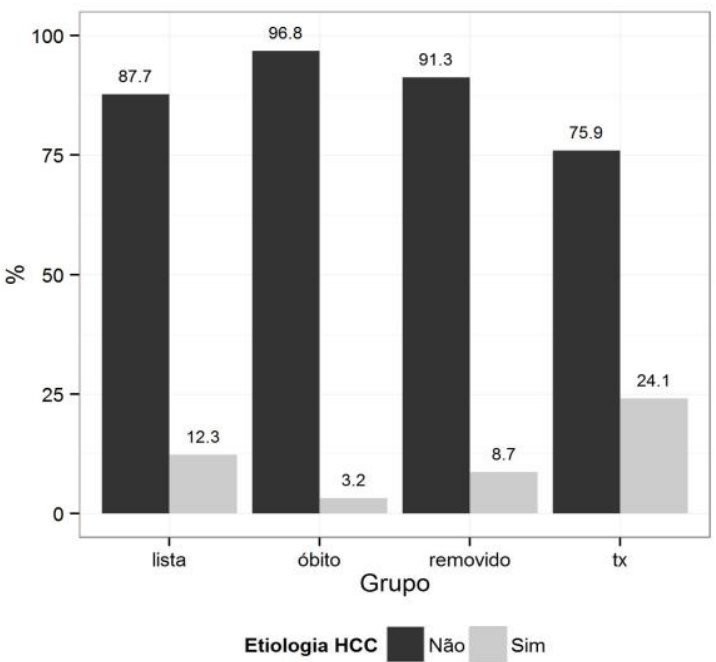

A

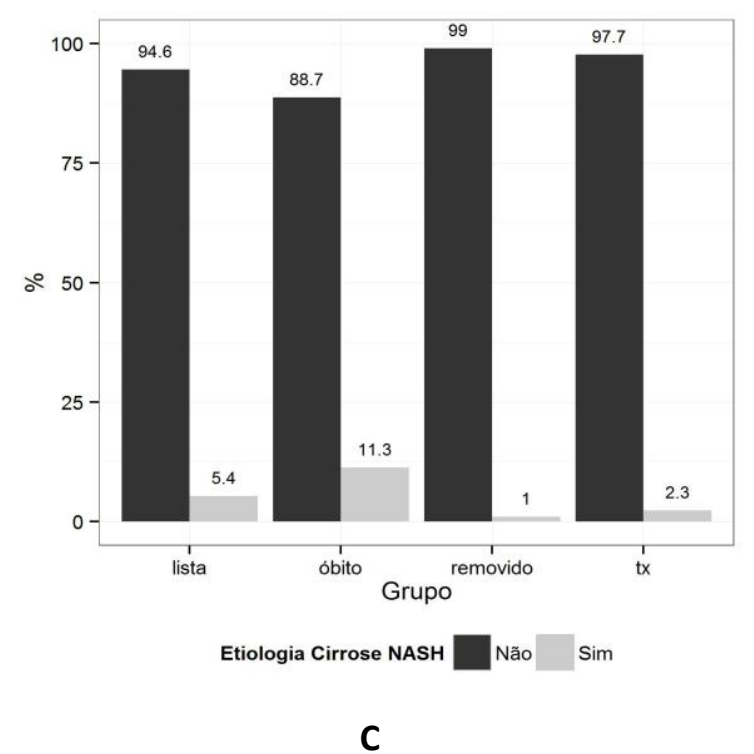

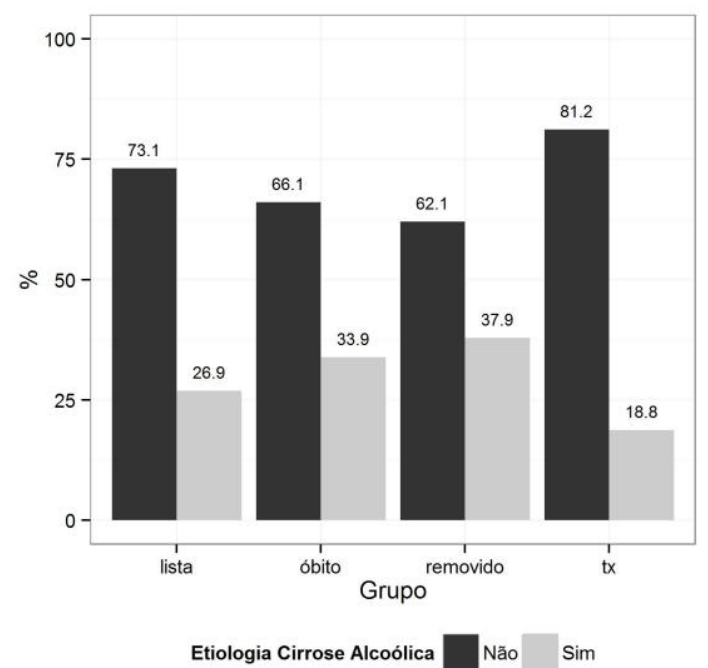

B

GRÁfico 5: A - Diagnóstico de CARCINOMA HePATOCELULAR ENTRE OS PACIENTES CIRRÓtICOS DIVIDIDOS PELO GRUPO DE DESFECHO (P<0,001). B - DiAgnÓSTICO DE CIRROSE ALCOÓlICA ENTRE OS PACIENTES DiVIDIDOS PELO GRUPO DE DESFECHO $(P=0,024)$. C - Diagnóstico DE NASH ENTRE OS PACIENTES CIRRÓTICOS DIVIDIDOS PELO GRUPO DE DESFECHO (P=0,027). DADOS EM PORCENTAGEM. 


\subsubsection{CONSULTAS AMBULATORIAIS}

Foram realizados no total 10830 consultas e atendimentos aos 492 pacientes em lista de espera. As consultas ocorridas no ICESP foram oriundas dos pacientes diagnosticados com carcinoma hepatocelular durante o período em lista de espera para o transplante hepático. 0 resultado do número de atendimentos ambulatoriais nos pacientes conforme grupo de desfecho estão na tabela 5.

TABELA 5: NÚMERO TOTAL E PORCENTAGEM DE UTILIZAÇÃo DE CONSULTAS AMBULATORIAIS DE TODOS OS PACIENTES SUBDIVIDIDOS PELO DESFECHO ( $N=492)$

\begin{tabular}{|c|c|c|c|c|c|c|c|c|c|c|c|}
\hline & \multirow{2}{*}{\multicolumn{2}{|c|}{$\begin{array}{l}\text { Todos } \\
n=492\end{array}$}} & \multirow{2}{*}{\multicolumn{2}{|c|}{$\begin{array}{l}\text { Transplantado } \\
\qquad n=134\end{array}$}} & \multirow{2}{*}{\multicolumn{2}{|c|}{$\begin{array}{l}\text { Removido } \\
n=103\end{array}$}} & \multirow{2}{*}{\multicolumn{2}{|c|}{$\begin{array}{l}\text { Óbito } \\
n=67\end{array}$}} & \multirow{2}{*}{\multicolumn{2}{|c|}{$\begin{array}{l}\text { Lista } \\
\mathrm{n}=188\end{array}$}} & \multirow[b]{3}{*}{$p=$} \\
\hline & & & & & & & & & & & \\
\hline & Total & $\%$ & Total & $\%$ & Total & $\%$ & Total & $\%$ & Total & $\%$ & \\
\hline Médico & 6142 & 56,7 & 1725 & 49,6 & 48 & 12,4 & 700 & 62,5 & 3669 & 62,8 & 0,02 \\
\hline Enfermeiro & 1457 & 13,5 & 525 & 15,1 & 15 & 3,9 & 127 & 11,3 & 790 & 13,5 & 0,47 \\
\hline Nutricionista & 571 & 5,3 & 205 & 5,9 & 5 & 1,3 & 63 & 5,6 & 298 & 5,1 & 0,42 \\
\hline Psicólogo & 1498 & 13,8 & 522 & 15,0 & 236 & 61,0 & 161 & 14,4 & 579 & 9,9 & 0,75 \\
\hline Assistente Social & 302 & 2,8 & 112 & 3,2 & 3 & 0,8 & 30 & 2,7 & 157 & 2,7 & 0,67 \\
\hline Dentista & 290 & 2,7 & 138 & 4,0 & 0 & 0,0 & 22 & 2,0 & 130 & 2,2 & $<0,05$ \\
\hline Consultas ICESP & 570 & 5,3 & 251 & 7,2 & 80 & 20,7 & 17 & 1,5 & 222 & 3,8 & 0,35 \\
\hline TOTAL & 10830 & 100,0 & 3478 & 100,0 & 387 & 100,0 & 1120 & 100,0 & 5845 & 100,0 & 0,008 \\
\hline
\end{tabular}

ICESP - INSTITUTO DO CÂNCER DO ESTADO DE SÃO PAULO

Dados do número de interconsultas e encaminhamentos para clínicas não diretamente relacionadas ao tratamento do paciente com doença hepática não foram inseridos neste estudo. Houveram pacientes com atendimentos em clinicas de Ortopedia e Ginecologia, por exemplo, mas após análise foi optado pela não inserção destes atendimentos ao número total de consultas. 


\subsubsection{EXAMES DE IMAGEM E SUPORTE AO DIAGNÓSTICO}

Foram realizados no total 3838 exames de imagem durante todo o estudo. Houveram 1195 tomografias, 723 biópsias e 431 endoscopias. O número e a porcentagem de todos os exames realizados conforme grupo de desfecho está apresentado na tabela 6 .

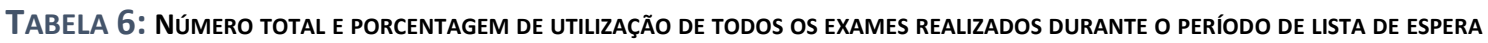
CONFORME OS GRUPOS DE DESFECHO. ( $\mathrm{N}=492)$

\begin{tabular}{|c|c|c|c|c|c|c|c|c|c|c|c|}
\hline & \multicolumn{2}{|c|}{ Todos } & \multicolumn{2}{|c|}{ Transplantados } & \multicolumn{2}{|c|}{ Removidos } & \multicolumn{2}{|c|}{ Óbito } & \multicolumn{2}{|c|}{ Lista } & \multirow[b]{2}{*}{$P=$} \\
\hline & Total & $\%$ & Total & $\%$ & Total & $\%$ & Total & $\%$ & Total & $\%$ & \\
\hline Biópsias & 723 & 45,19 & 410 & 47,45 & 79 & 42,25 & 18 & 2,61 & 216 & 10,30 & $<0,001$ \\
\hline Endoscopias & 431 & 26,94 & 146 & 16,90 & 21 & 11,23 & 59 & 8,55 & 205 & 9,78 & $<0,05$ \\
\hline Colonoscopias & 32 & 2,00 & 13 & 1,50 & 0 & 0,00 & 6 & 0,87 & 13 & 0,62 & 0,03 \\
\hline Colângiografias & 43 & 2,69 & 8 & 0,93 & 0 & 0,00 & 3 & 0,43 & 32 & 1,53 & $<0,001$ \\
\hline ECG & 89 & 5,56 & 22 & 2,55 & 3 & 1,60 & 7 & 1,01 & 57 & 2,72 & 0,006 \\
\hline US & 418 & 26,13 & 58 & 6,71 & 4 & 2,14 & 27 & 3,91 & 329 & 15,69 & $<0,001$ \\
\hline Holter & 256 & 16,00 & 55 & 6,37 & 10 & 5,35 & 59 & 8,55 & 132 & 6,29 & 0,003 \\
\hline $\mathrm{RX}$ & 381 & 23,81 & 39 & 4,51 & 12 & 6,42 & 23 & 3,33 & 307 & 14,64 & $<0,001$ \\
\hline $\mathrm{TC}$ & 1195 & 74,69 & 80 & 9,26 & 55 & 29,41 & 424 & 61,45 & 636 & 30,33 & $<0,001$ \\
\hline RNM & 270 & 16,88 & 33 & 3,82 & 3 & 1,60 & 64 & 9,28 & 170 & 8,11 & $<0,001$ \\
\hline Total & 3838 & 100,00 & 864 & 100,00 & 187 & 100,00 & 690 & 100,00 & 2097 & 100,00 & $<0,001$ \\
\hline
\end{tabular}

ECG: ELETROCARDIOGRAMA; US: ULTRASSOM; RX: RAIO-X; TC: TOMOGRAFIA COMPUTADORIZADA; RNM: RESSONÂNCIA NUCLEAR MAGNÉTICA. 


\subsubsection{INTERNAÇÕES E PROCEDIMENTOS}

Do total de 492 pacientes, 277 necessitaram de internações durante todo o período de estudo, representando $57,47 \%$ do total de pacientes participantes deste estudo. Foram considerados todas as internações anteriores ao transplante hepático. Os resultados dos pacientes que realizaram internações, analisados pelos grupos de desfecho, estão relatados na tabela 7.

TABELA 7: DiAgNóSTICOS, TEMPO, PRINCIPAIS MOTIVOS E PROCEDIMENTOS E NÚMERO TOTAL DE INTERNAÇÕES ENTRE TODOS OS PACIENTES DIVIDIDOS POR GRUPO DE DESFECHO. VALORES EM NÚMERO TOTAL E PORCENTAGEM ( $N=277$ )

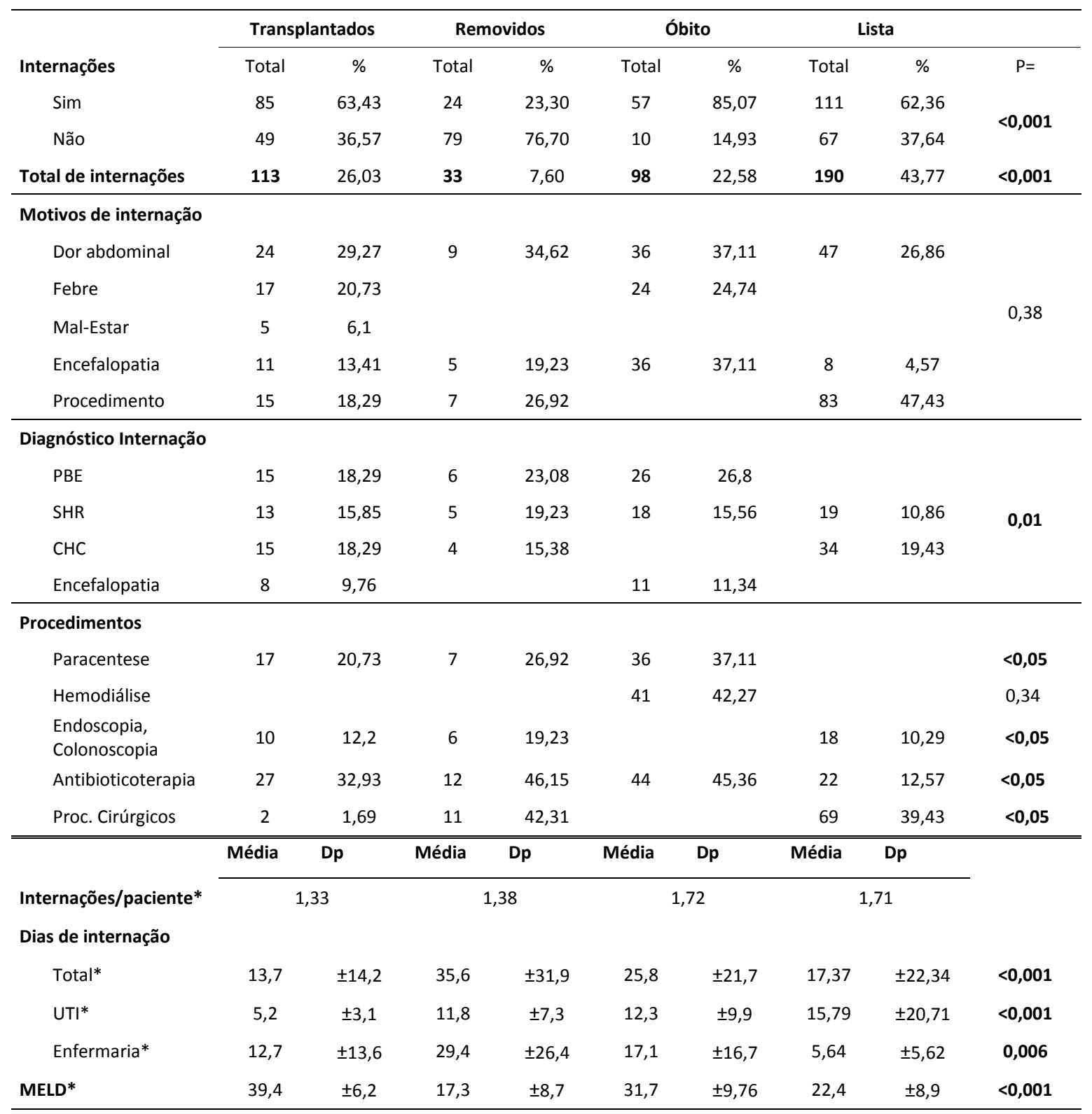

*DADOS APRESENTADOS EM VALORES MÉDIOS E DESVIO-PADRÃO. PBE: PERITONITE BACTERIANA ESPONTÂNEA; SHR: SÍNDROME HEPATORRENAL; CHC: CARCINOMA HEPATOCELULAR. 


\subsubsection{UTILIZAÇÃO DE HEMOCOMPONENTES}

No total, foram utilizados 1630 bolsas de hemocomponentes por todos os pacientes deste estudo. Foram verificadas todas as internações realizadas anteriores ao transplante hepático e sumarizados todos os hemocomponentes utilizados onde este recurso foi necessário. Os resultados da utilização de hemocomponentes pelos pacientes dividido pelo grupo de desfecho está apresentado na tabela 8.

TABELA 8: HEMOCOMPONENTES UTILIZADOS DURANTE O PERÍOdo DE INTERNAÇÃo POR TODOS OS PACIENTES DIVIDIDOS POR GRUPO DE DESFECHO. VALORES EM NÚMERO TOTAL E PORCENTAGEM ( $N=350)$

\begin{tabular}{|c|c|c|c|c|c|c|c|c|c|c|c|}
\hline & \multicolumn{2}{|c|}{ Todos } & \multicolumn{2}{|c|}{ Transplantados } & \multicolumn{2}{|c|}{ Removidos } & \multicolumn{2}{|c|}{ Óbito } & \multicolumn{2}{|c|}{ Lista } & \multirow[b]{2}{*}{$\mathrm{P}=$} \\
\hline & Total & $\%$ & Total & $\%$ & Total & $\%$ & Total & $\%$ & Total & $\%$ & \\
\hline $\mathrm{CH}$ & 289 & 17,73 & 16 & 6,58 & 37 & 25,00 & 204 & 19,23 & 32 & 17,98 & 0,22 \\
\hline $\mathrm{CHi}$ & 242 & 14,85 & 39 & 16,05 & 24 & 16,22 & 123 & 11,59 & 56 & 31,46 & 0,83 \\
\hline PFC & 576 & 35,34 & 83 & 34,16 & 40 & 27,03 & 394 & 37,13 & 59 & 33,15 & 0,37 \\
\hline CRIO & 174 & 10,67 & 59 & 24,28 & 0 & 0,00 & 115 & 10,84 & 0 & 0,00 & 0,79 \\
\hline CP & 51 & 3,13 & 6 & 2,47 & 17 & 11,49 & 28 & 2,64 & 0 & 0,00 & 0,99 \\
\hline CPi & 229 & 14,05 & 24 & 9,88 & 25 & 16,89 & 158 & 14,89 & 22 & 12,36 & 0,75 \\
\hline Aférese & 69 & 4,23 & 16 & 6,58 & 5 & 3,38 & 39 & 3,68 & 9 & 5,06 & $<0,001$ \\
\hline Total & 1630 & 100,00 & 243 & 100,00 & 148 & 100,00 & 1061 & 100,00 & 178 & 100,00 & $<0,001$ \\
\hline $\begin{array}{l}\text { Média por } \\
\text { paciente }\end{array}$ & \multicolumn{2}{|c|}{5,9} & \multicolumn{2}{|c|}{2,9} & \multicolumn{2}{|c|}{6,2} & \multicolumn{2}{|c|}{18,6} & \multicolumn{2}{|c|}{1,6} & $<0,001$ \\
\hline
\end{tabular}

CH - Concentrado de Hemácias; Chi - Concentrado de Hemácias irradiado; PfC - Plasma Fresco Concentrado; CRiO -

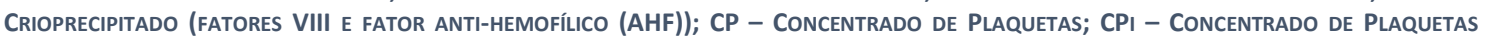
IRRADIADO; AFÉRESE - CONCENTRADO PLAQUETÁRIO OBTIDO DIRETAMENTE DO DOADOR. 


\subsubsection{PACIENTES COM CARCINOMA HEPATOCELULAR ATENDIDOS PELO ICESP}

Os pacientes diagnosticados com carcinoma hepatocelular foram avaliados com relação à necessidade de internação junto ao Hospital do Câncer do Estado de São Paulo para a realização de procedimentos como Quimioembolização Transarterial (TACE) ou Ablação por radiofrequência (RFA). Não foram observados dados referentes ao registro de procedimentos de alcoolização durantes as internações.

Foram ao total 83 pacientes diagnosticados com $\mathrm{CHC}$, dos 492 pacientes em lista $(17,22 \%)$. Este grupo de pacientes foi formado por 40 pacientes do grupo transplantado (48,19\%), 11 pacientes do grupo removido (13,25\%), 3 pacientes do grupo óbito $(3,61 \%)$ e 29 pacientes que permaneceram em lista de espera (34,94\%). Deste total de 83 pacientes diagnosticados com HCC houveram 50 pacientes que necessitaram de internação no ICESP, com 283 internações no total. Houveram no total, 643 dias de internação no ICESP, sendo 580 em enfermaria e 87 em UTI. O número de internações e principais motivos estão resumidos na tabela 9.

TABELA 9: NúMERO TOTAL DE INTERNAÇÕES E PRINCIPAIS PROCEDIMENTOS REALIZADOS NOS PACIENTES DIAGNOSTICADOS COM CHC ATENDIDOS NO ICESP ( $\mathrm{N}=83$ ) E TOTAL DE 350 INTERNAÇõES. VALORES EM NÚMERO TOTAL E PORCENTAGEM

\begin{tabular}{|c|c|c|c|c|c|c|c|c|}
\hline & \multicolumn{2}{|c|}{$\begin{array}{l}\text { Transplantados } \\
\qquad(\mathrm{n}=40)\end{array}$} & \multicolumn{2}{|c|}{$\begin{array}{l}\text { Removidos } \\
\qquad(n=11)\end{array}$} & \multicolumn{2}{|c|}{$\begin{array}{l}\text { Óbito } \\
(n=3)\end{array}$} & \multicolumn{2}{|c|}{$\begin{array}{l}\text { Lista } \\
(n=29)\end{array}$} \\
\hline & Total & $\%$ & Total & $\%$ & Total & $\%$ & Total & $\%$ \\
\hline Total TACE & 30 & 18,5 & 9 & 25,0 & 0 & 0 & 15 & 15,8 \\
\hline Total RFA & 15 & 9,3 & 4 & 11,1 & 0 & 0 & 7 & 7,4 \\
\hline $\begin{array}{l}\text { Internações para outros } \\
\text { procedimentos }\end{array}$ & 117 & 72,2 & 23 & 63,9 & 0 & 0 & 73 & 76,8 \\
\hline Total Internações & 162 & 100,0 & 36 & 100 & 0 & 0 & 95 & 100 \\
\hline
\end{tabular}

TACE: TRANSARTERIAL CHEMOEMBOLIZATION; RFA: RADIOFREQUENCY ABLATION 
A frequência de consultas no ICESP e os principais procedimentos realizados pelos pacientes diagnosticados com Carcinoma Hepatocelular e sua diferença estatística está apresentado no gráfico 6.

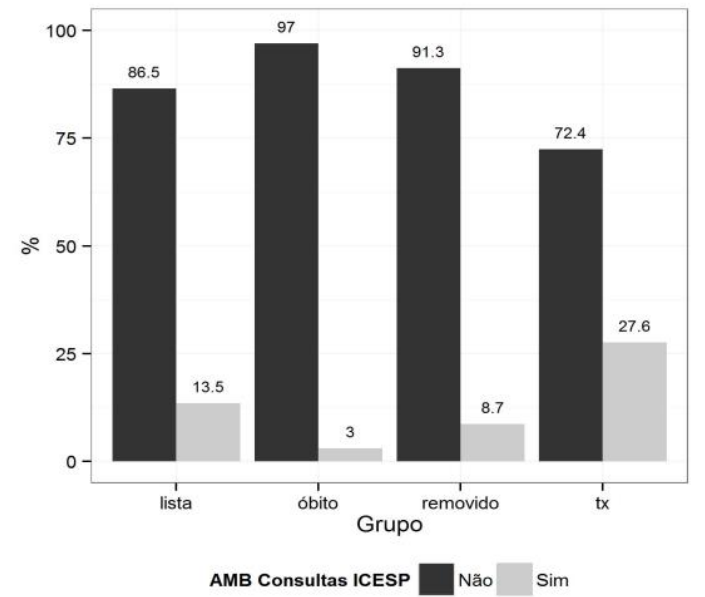

A

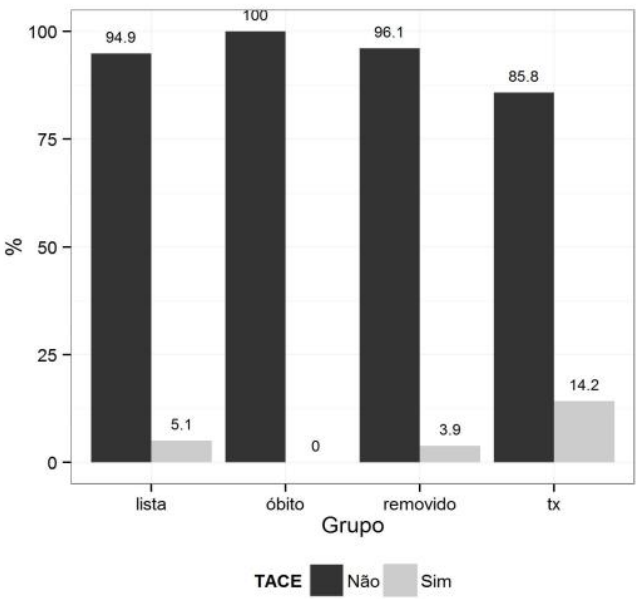

B

gráfico 6: A - FrequênCIA de utILIZAÇÃo de CONSULtAS No ICESP ENTRE OS PACIENTES COM CHC DIVIDIDOS PELO GRUPO DE DESFECHO $(P<0,001)$. B - FREQUÊNCIA DE REALIZAÇÃo de TACE ENTRE OS PACIENTES COM CHC DIVIDIDOS PELO GRUPO DE DESFECHO $(\mathrm{P}<0,001)$ 


\subsection{RESULTADOS POR GRUPO DE MELD}

Foram formados quatro grupos entre os pacientes em lista de espera para o transplante hepático divididos pela gravidade do estado clínico segundo o cálculo do escore de MELD individual. Foi utilizado o valor de MELD obtido segundo os dados dos exames de entrada em lista de cada indivíduo e valores de MELD no dia da internação para aqueles que tiveram alguma intercorrência. Estes grupos foram formados seguindo divisão pelo quartil dos valores de MELD, dado que na literatura existe uma heterogeneidade e subjetividade muito grande de divisões, foi decidido utilizar valores científicos e matemáticos para esta divisão.

Foram formados grupos com valores de MELD <=17, MELD 18-24, MELD 25-30 e MELD maior que 30. Pacientes em situação especial, como os diagnosticados com CHC tiveram seu MELD calculado de acordo com a pontuação atribuída a estes pacientes. A distribuição dos valores de custo por faixa de MELD está apresentado na figura 2.

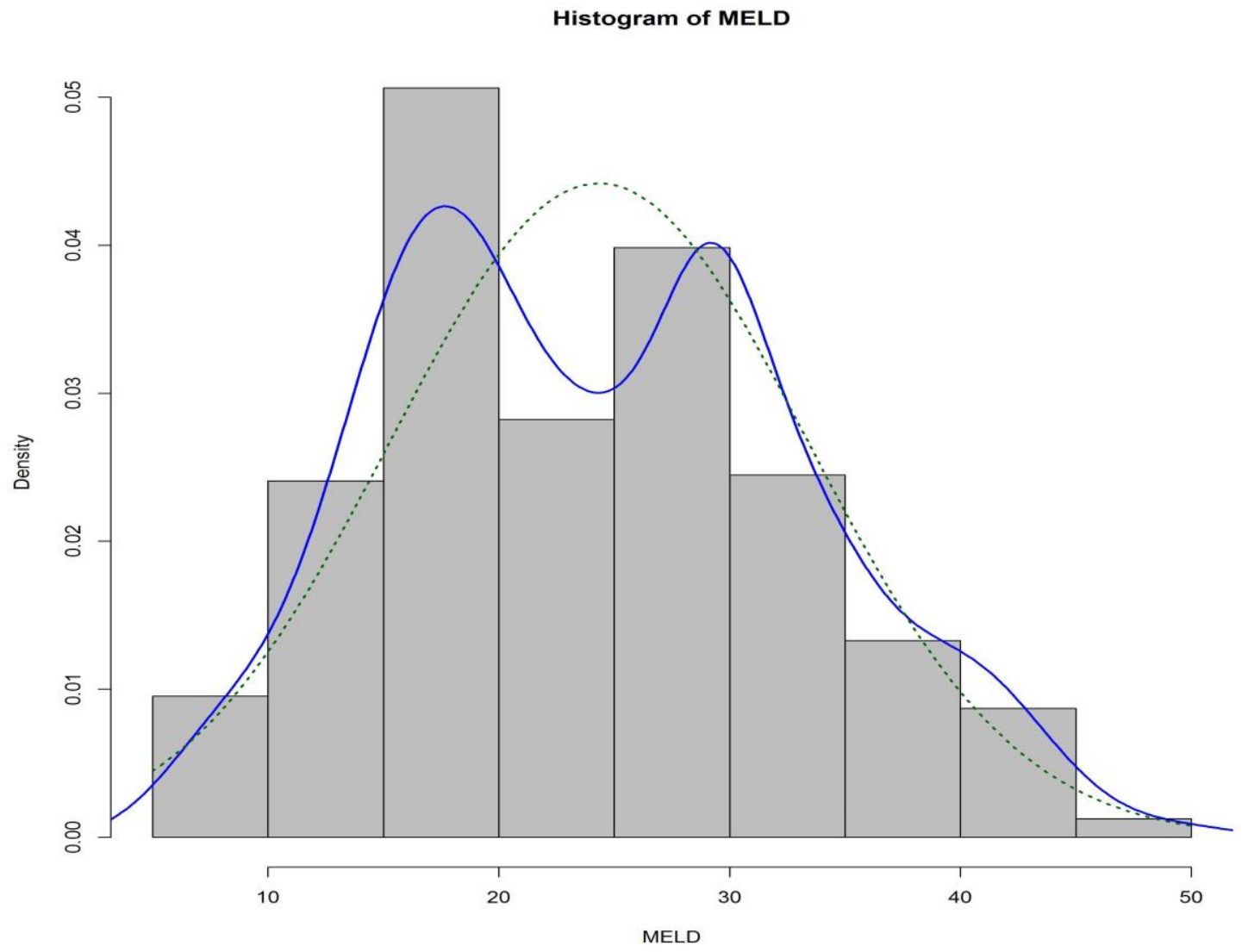

FIgURA 2: HISTOGRAMA DA FREQUÊNCIA DE DISTRIBUIÇÃo DOS VALORES DE CUSTO POR FAIXA DE MELD (N=492) 


\subsubsection{NÚMERO DE PACIENTES POR GRUPO DE MELD}

O grupo com MELD <= 17 foi formado por 132 pacientes, sendo 4 pacientes do grupo transplantado (3,03\%), 60 do grupo removido (45,45\%), 4 do grupo óbito $(3,03 \%)$ e 64 pacientes que permaneceram em lista $(48,48 \%)$.

O grupo com MELD 18-24 foi formado por 122 pacientes, sendo 22 pacientes do grupo transplantado (18,03\%), 24 do grupo removido (19,67\%), 17 do grupo óbito $(13,93 \%)$ e 59 pacientes que permaneceram em lista $(48,36 \%)$.

O grupo com MELD 25-30 foi formado por 113 pacientes, sendo 49 pacientes do grupo transplantado (43,36\%), 16 do grupo removido (14,16\%), 11 do grupo óbito $(9,73 \%)$ e 37 pacientes do grupo que permaneceu em lista $(32,74 \%)$.

O grupo com MELD acima de 30 foi formado por 115 pacientes, sendo 59 do grupo transplantado (51,3\%), 5 do grupo removido (4,35\%), 50 do grupo óbito $(43,48 \%)$ e 1 do grupo que permaneceu em lista (0,87\%). A composição de pacientes transplantados, removidos, óbito e lista de cada grupo de MELD está apresentada no gráfico 7.

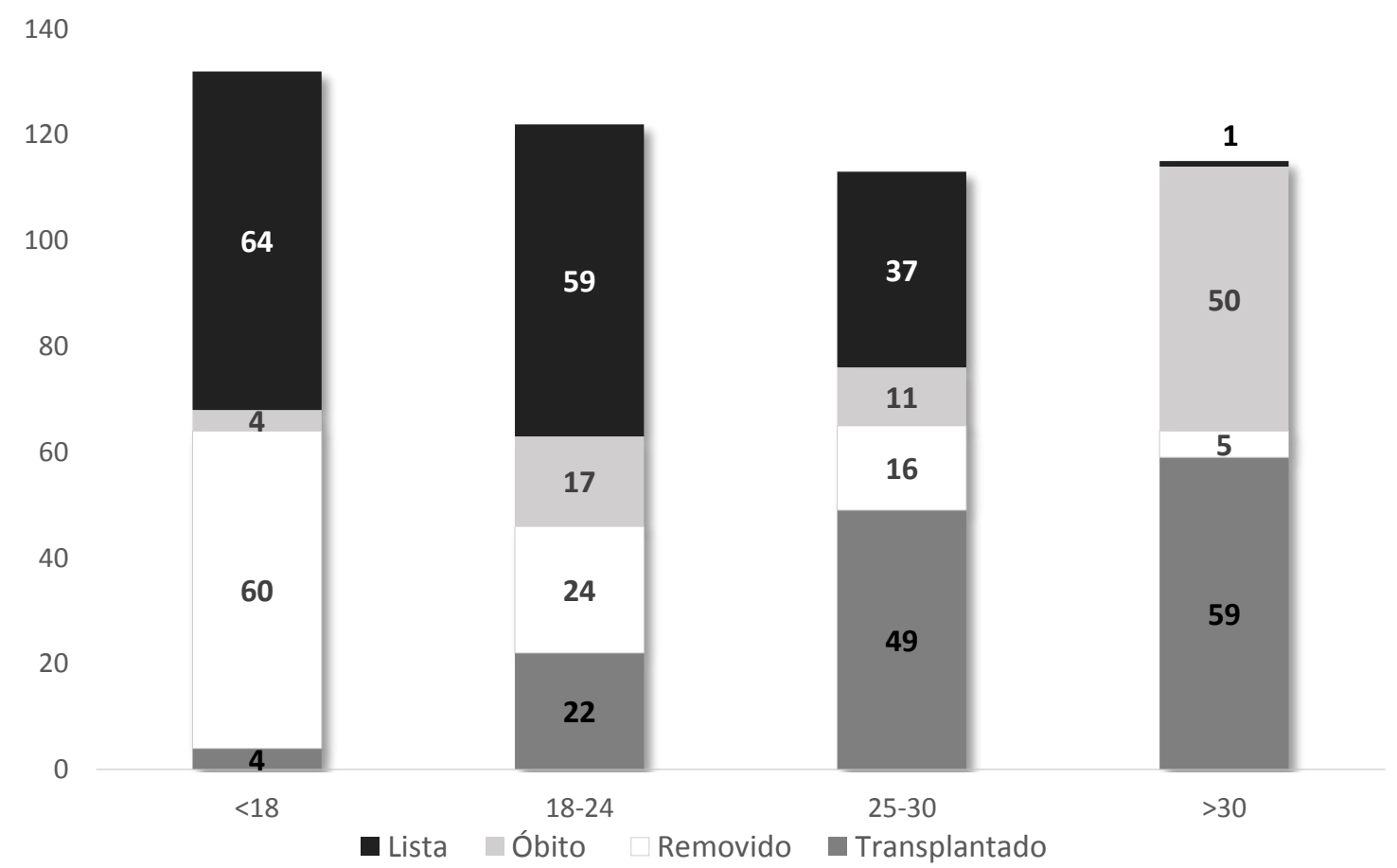

GRÁFICO 7: NúMERo TOtAL de PACIENTES EM CADA GRUPO dE MELD DIVIDIDOS PELO DESFECHO. 


\subsubsection{DADOS CLÍNICOS E DEMOGRÁFICOS POR GRUPO DE MELD}

Os dados clínicos, demográficos, tempo de espera até o transplante (para os pacientes que chegaram a este desfecho), tempos de espera para os demais desfechos e tempo de internações conforme divisão dos grupos pelo MELD estão apresentados na tabela 10.

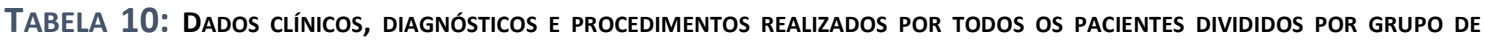
MELD. $(\mathrm{N}=492)$

\begin{tabular}{|c|c|c|c|c|c|c|c|c|c|}
\hline & \multicolumn{2}{|c|}{$\begin{array}{c}\text { MELD }<=17 \\
(n=132) 27,39 \%\end{array}$} & \multicolumn{2}{|c|}{$\begin{array}{c}\text { MELD } 18 \text { - } 24 \\
(n=122) 25,31 \%\end{array}$} & \multicolumn{2}{|c|}{$\begin{array}{c}\text { MELD 25-30 } \\
(n=113) 23,44 \%\end{array}$} & \multicolumn{2}{|c|}{$\begin{array}{c}\text { MELD }>30 \\
(n=115) 28,32 \%\end{array}$} & \multirow[b]{2}{*}{$\mathbf{P}$} \\
\hline & Total & $\%$ & Total & $\%$ & Total & $\%$ & Total & $\%$ & \\
\hline \multicolumn{10}{|l|}{ Desfecho } \\
\hline Transplantado & 4 & 3,03 & 22 & 18,03 & 49 & 43,36 & 59 & 51,3 & \multirow{4}{*}{$<0,001$} \\
\hline Removido & 60 & 45,45 & 24 & 19,67 & 16 & 14,16 & 5 & 4,3 & \\
\hline Óbito & 4 & 3,03 & 17 & 13,93 & 11 & 9,73 & 50 & 43,5 & \\
\hline Lista & 64 & 48,48 & 59 & 48,36 & 37 & 32,74 & 1 & 0,9 & \\
\hline \multicolumn{10}{|l|}{ Internações } \\
\hline Sim & 42 & 31,8 & 70 & 57,4 & 82 & 72,6 & 86 & 74,8 & \multirow{2}{*}{$<0,001$} \\
\hline \multirow[t]{2}{*}{ Total } & 90 & 68,2 & 52 & 42,6 & 31 & 27,4 & 29 & 25,2 & \\
\hline & Média & Dp & Média & Dp & Média & Dp & Média & Dp & $\mathbf{P}$ \\
\hline MELD* & 13,8 & $\pm 3,1$ & 20,8 & $\pm 2,1$ & 28,2 & \pm 1.6 & 36,5 & $\pm 4,4$ & $<0,001$ \\
\hline Idade* & 52,5 & $\pm 13,5$ & 51,8 & $\pm 14,1$ & 55,6 & $\pm 10,7$ & 50,2 & $\pm 13,5$ & 0,203 \\
\hline Peso* & 69,2 & $\pm 14,9$ & 70,7 & $\pm 14,8$ & 72,4 & $\pm 17,6$ & 74,6 & $\pm 17,4$ & 0,474 \\
\hline IMC* & 25,6 & $\pm 5,1$ & 25,5 & $\pm 4,5$ & 25,9 & $\pm 5,1$ & 26,5 & $\pm 5,9$ & 0,601 \\
\hline $\begin{array}{l}\text { Tempo de espera até } \\
\text { Transplante (dias) * } \\
\text { Tempo de espera até } \\
\text { desfechos (dias) }\end{array}$ & \multicolumn{8}{|c|}{$\begin{array}{l}\text { Tempo de espera até } \\
\text { desfechos (dias) }\end{array}$} & $<0,001$ \\
\hline Remoção* & 198,4 & $\pm 136,6$ & 204,9 & $\pm 135,5$ & 197,1 & $\pm 118,6$ & 135,1 & $\pm 37,8$ & 0,21 \\
\hline Óbito* & 77,1 & $\pm 85,7$ & 182,3 & $\pm 174,9$ & 85,1 & $\pm 74,2$ & 100,1 & $\pm 122,5$ & 0,47 \\
\hline Lista* & 462,1 & $\pm 167,1$ & 381,1 & $\pm 192,4$ & 192,4 & $\pm 174,6$ & 509,6 & $\pm 225,1$ & 0,03 \\
\hline \multicolumn{10}{|l|}{ Dias de internação } \\
\hline UTI e Enfermaria* & 13,2 & $\pm 16,2$ & 20,4 & $\pm 22,9$ & 21,46 & $\pm 23,6$ & 19,5 & $\pm 19,1$ & $<0,001$ \\
\hline
\end{tabular}

*DADOS APRESENTADOS EM VALORES MÉDIOS E DESVIO-PADRÃO 
A análise das diferenças entre os grupos em relação ao Tempo de espera em lista, MELD, Idade e IMC está apresentado no gráfico 8.

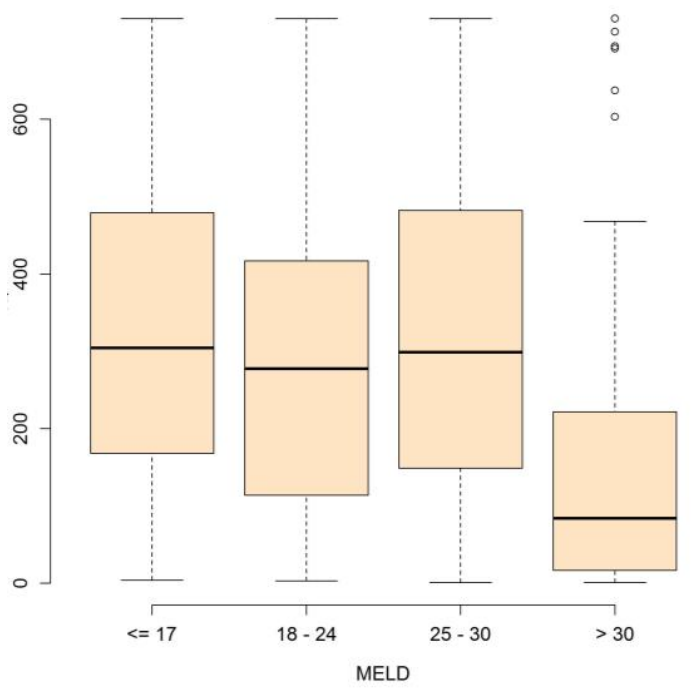

A

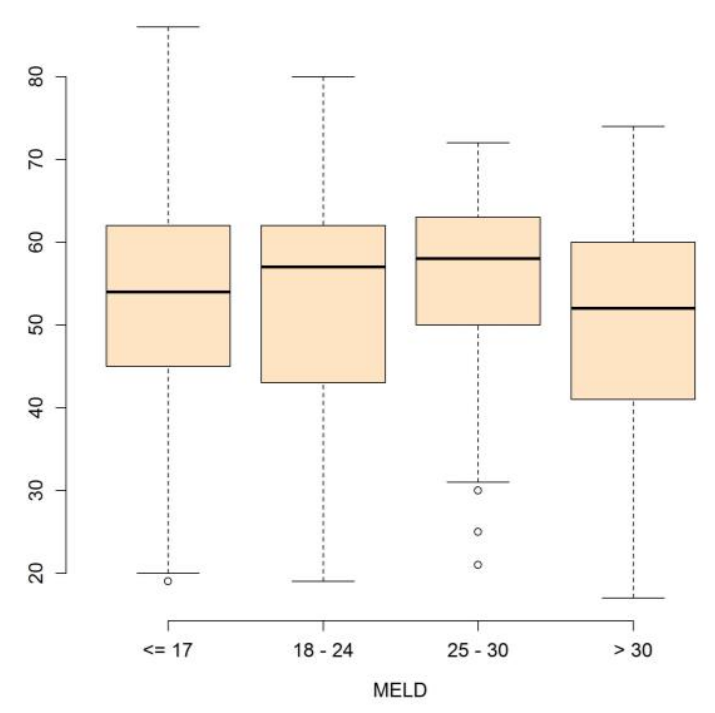

C

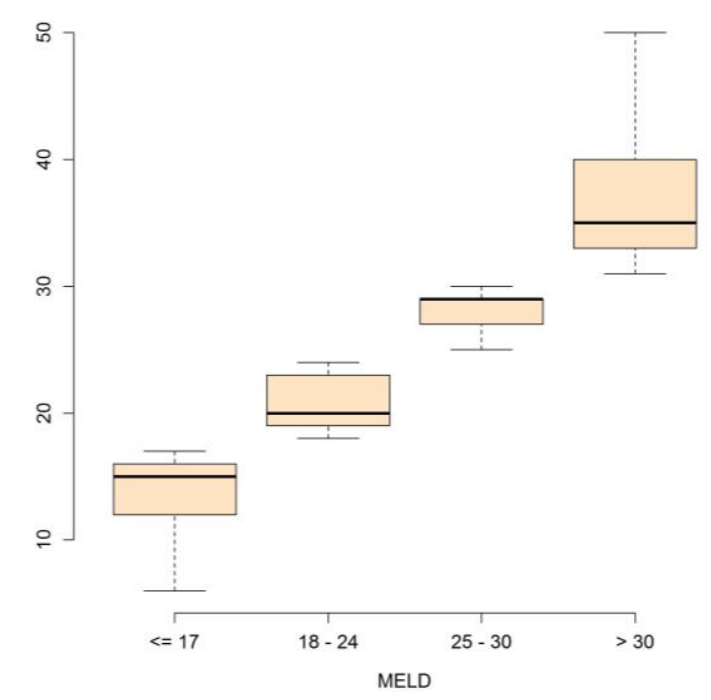

B

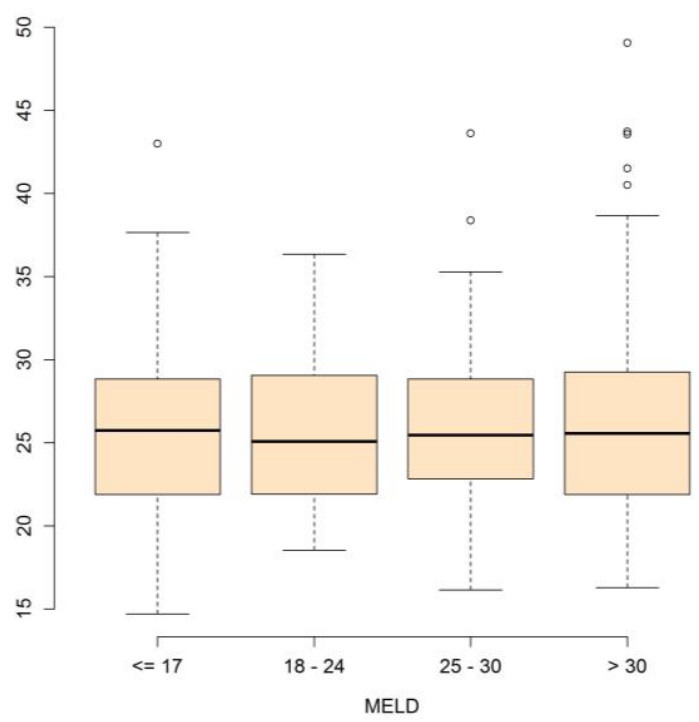

GRÁFICO 8: A - Média e quartis do tempo de espera em lista entre os grupos divididos por faixa de MELD ( $p<0,001$ entre os grupos MELD <=17 e MELD>30). B - Média e quartil do MELD entre os grupos ( $p<0,001$ entre todos os grupos). C Média e quartil da idade entre os grupos divididos por faixa de MELD ( $p=0,007$ entre os grupos MELD 25-30 e MELD >30). $D$ - Média e quartil do IMC entre os grupos divididos por faixa de MELD $(p=0,865)$. 


\subsubsection{DiAGNÓSTICOS POR GRUPO DE MELD}

Os diagnósticos entre os pacientes divididos por grupo de MELD estão na tabela 11.

TABELA 11 - NúMERo tOtAL E PORCENTAGEM DE tOdOS OS DIAGNÓSTICOS DOS PACIENTES EM LISTA DE ESPERA PARA O TRANSPLANTE HEPÁTICO DIVIDIDOS PELO GRUPO DE MELD.

\begin{tabular}{|c|c|c|c|c|c|c|c|c|}
\hline & \multicolumn{2}{|c|}{$<=17(N=132)$} & \multicolumn{2}{|c|}{$18-24(N=122)$} & \multicolumn{2}{|c|}{$25-30(N=113)$} & \multicolumn{2}{|c|}{$>30(\mathrm{~N}=115)$} \\
\hline & Total & $\%$ & Total & $\%$ & Total & $\%$ & Total & $\%$ \\
\hline Adenomatose & & & & & 1 & 0,88 & & \\
\hline Câncer Primário & 1 & 0,76 & 1 & 0,82 & 1 & 0,88 & & \\
\hline CEP & 4 & 3,03 & 1 & 0,82 & 3 & 2,65 & 3 & 2,61 \\
\hline $\mathrm{CEP}+\mathrm{HAl}$ & & & & & 1 & 0,88 & & \\
\hline $\mathrm{CEP}+\mathrm{HCC}$ & & & & & & & 1 & 0,87 \\
\hline Cirrose Biliar Primária & 4 & 3,03 & 1 & 0,82 & & & 3 & 2,61 \\
\hline Cirrose Biliar Secundária & 2 & 1,52 & 2 & 1,64 & & & & \\
\hline Cirrose Criptogênica & 12 & 9,09 & 14 & 11,48 & 7 & 6,19 & 10 & 8,70 \\
\hline Cirrose Criptogênica + HCC & & & & & & & 1 & 0,87 \\
\hline Cirrose Criptogênica + NASH & & & 1 & 0,82 & & & & \\
\hline Cirrose Criptogênica + OH & & & & & & & 1 & 0,87 \\
\hline Doença de Carolli & 4 & 3,03 & 1 & 0,82 & 1 & 0,88 & & \\
\hline Fístula Biliar & & & & & 1 & 0,88 & & \\
\hline Glicogenose tipo III & & & 1 & 0,82 & & & & \\
\hline Hepatite Autoimune & 5 & 3,79 & 6 & 4,92 & 5 & 4,42 & 10 & 8,70 \\
\hline Carcinoma hepatocelular & & & 1 & 0,82 & 4 & 3,54 & 1 & 0,87 \\
\hline $\mathrm{HCC}+\mathrm{OH}$ & & & 1 & 0,82 & 5 & 4,42 & 4 & 3,48 \\
\hline Hepatite Ductopênica & & & & & & & 1 & 0,87 \\
\hline Hepatite Fulminante & & & 1 & 0,82 & 1 & 0,88 & 7 & 6,09 \\
\hline NASH & 4 & 3,03 & 8 & 6,56 & 2 & 1,77 & 5 & 4,35 \\
\hline $\mathrm{OH}$ & 49 & 37,12 & 20 & 16,39 & 14 & 12,39 & 19 & 16,52 \\
\hline $\mathrm{OH}+\mathrm{HAl}$ & & & 1 & 0,82 & & & & \\
\hline PAF & 1 & 0,76 & & & 1 & 0,88 & & \\
\hline Pancreatite aguda & & & 1 & 0,82 & & & & \\
\hline Síndrome de Budd-Chiari & & & 3 & 2,46 & 2 & 1,77 & 2 & 1,74 \\
\hline Tumor Neuroendócrino & 2 & 1,52 & & & & & & \\
\hline VHB & 4 & 3,03 & 4 & 3,28 & & & 2 & 1,74 \\
\hline VHB + Fulminante & & & & & & & 1 & 0,87 \\
\hline $\mathrm{VHB}+\mathrm{HCC}$ & & & 1 & 0,82 & 5 & 4,42 & 2 & 1,74 \\
\hline $\mathrm{VHB}+\mathrm{HCC}+\mathrm{OH}$ & & & & & 1 & 0,88 & 1 & 0,87 \\
\hline $\mathrm{VHB}+\mathrm{OH}$ & & & 3 & 2,46 & 1 & 0,88 & & \\
\hline $\mathrm{VHC}$ & 29 & 21,97 & 26 & 21,31 & 27 & 23,89 & 21 & 18,26 \\
\hline $\mathrm{VHC}+\mathrm{HCC}$ & 1 & 0,76 & 9 & 7,38 & 21 & 18,58 & 12 & 10,43 \\
\hline $\mathrm{VHC}+\mathrm{HCC}+\mathrm{HAl}$ & & & & & & & 1 & 0,87 \\
\hline $\mathrm{VHC}+\mathrm{HCC}+\mathrm{OH}$ & & & 1 & 0,82 & 4 & 3,54 & 2 & 1,74 \\
\hline $\mathrm{VHC}+\mathrm{OH}$ & 9 & 6,82 & 7 & 5,74 & 4 & 3,54 & 3 & 2,61 \\
\hline $\mathrm{VHC}+\mathrm{VHB}$ & 1 & 0,76 & 7 & 5,74 & & & 2 & 1,74 \\
\hline $\mathrm{VHC}+\mathrm{VHB}+\mathrm{HCC}$ & & & & & 1 & 0,88 & & \\
\hline
\end{tabular}




\subsubsection{Consultas ambulatoriais por grupo de MELD}

No total, foram realizados 10830 consultas e atendimentos aos 492 pacientes em lista de espera. Os resultados de atendimentos ambulatoriais nos pacientes conforme grupo dividido por MELD estão na tabela 12.

TABELA 12: NúMERO TOTAL E PORCENTAGEM DE UTILIZAÇÃo DE CONSULTAS AMBULATORIAIS DE TODOS OS PACIENTES SUBDIVIDIDOS PELO GRUPO DE MELD ( $\mathrm{N}=492)$

\begin{tabular}{|c|c|c|c|c|c|c|c|c|c|}
\hline & \multicolumn{2}{|c|}{$\begin{array}{c}\text { MELD }<=17 \\
(n=132) 27,39 \%\end{array}$} & \multicolumn{2}{|c|}{$\begin{array}{c}\text { MELD } 18-24 \\
(n=122) 25,31 \%\end{array}$} & \multicolumn{2}{|c|}{$\begin{array}{c}\text { MELD } 25-30 \\
(n=113) 23,44 \%\end{array}$} & \multicolumn{2}{|c|}{$\begin{array}{c}\text { MELD > } 30 \\
(n=115) 28,32 \%\end{array}$} & \multirow[b]{2}{*}{$\mathbf{P}$} \\
\hline & Total & $\%$ & Total & $\%$ & Total & $\%$ & Total & $\%$ & \\
\hline Médicas & 1289 & 61,91 & 1758 & 58,06 & 1703 & 48,27 & 1254 & 57,21 & $<0,001$ \\
\hline Enfermagem & 279 & 13,40 & 461 & 15,22 & 442 & 12,53 & 347 & 15,83 & $<0,05$ \\
\hline Nutricionista & 121 & 5,81 & 147 & 4,85 & 235 & 6,66 & 97 & 4,43 & 0,24 \\
\hline Psicologia & 266 & 12,78 & 377 & 12,45 & 603 & 17,09 & 260 & 11,86 & $<0,001$ \\
\hline Assistente Social & 59 & 2,83 & 81 & 2,68 & 99 & 2,81 & 73 & 3,33 & $<0,001$ \\
\hline Odontologia & 38 & 1,83 & 87 & 2,87 & 120 & 3,40 & 50 & 2,28 & 0,138 \\
\hline ICESP & 30 & 1,44 & 117 & 3,86 & 326 & 9,24 & 111 & 5,06 & 0,6 \\
\hline TOTAL & 2082 & 100 & 3028 & 100,00 & 3528 & 100,00 & 2192 & 100,00 & $<0,05$ \\
\hline
\end{tabular}




\subsubsection{EXAMES DE IMAGEM E SUPORTE AO DIAGNÓSTICO POR GRUPO DE MELD}

Foram realizados no total 3838 exames de imagem entre todos os pacientes durante $o$ tempo de estudo. A distribuição de todos os exames realizados conforme grupo de MELD está apresentado na tabela 13.

TABELA 13: NúMERO TOTAL E PORCENTAGEM DE UTILIZAÇÃo DE TOdOS OS EXAMES REALIZADOS DURANTE O PERÍOdO DE LISTA DE ESPERA CONFORME OS GRUPOS DIVIDIDOS PELO VALOR DE MELD. ( $N=492)$

\begin{tabular}{|c|c|c|c|c|c|c|c|c|c|}
\hline & \multicolumn{2}{|c|}{$\begin{array}{c}\text { MELD }<=17 \\
(n=132) 27,39 \%\end{array}$} & \multicolumn{2}{|c|}{$\begin{array}{c}\text { MELD } 18 \text { - } 24 \\
(n=122) 25,31 \%\end{array}$} & \multicolumn{2}{|c|}{$\begin{array}{c}\text { MELD } 25-30 \\
(n=113) 23,44 \%\end{array}$} & \multicolumn{2}{|c|}{$\begin{array}{c}\text { MELD > } 30 \\
(n=115) 28,32 \%\end{array}$} & \multirow[b]{2}{*}{$\mathbf{P}$} \\
\hline & Total & $\%$ & Total & $\%$ & Total & $\%$ & Total & $\%$ & \\
\hline Biópsias & 7 & 0,7 & 109 & 11,4 & 351 & 26,1 & 136 & 16,6 & 0,51 \\
\hline Endoscopias* & 139 & 14,4 & 118 & 12,3 & 105 & 7,8 & 128 & 15,7 & $<0,005$ \\
\hline Colonoscopias & 11 & 1,1 & 6 & 0,6 & 8 & 0,6 & 8 & 1,0 & 0,831 \\
\hline ECG & 7 & 0,7 & 25 & 2,6 & 26 & 1,9 & 26 & 3,2 & 1 \\
\hline US & 218 & 22,5 & 193 & 20,1 & 165 & 12,3 & 119 & 14,6 & $<0,005$ \\
\hline Holter & 10 & 1,0 & 10 & 1,0 & 20 & 1,5 & 6 & 0,7 & 0,222 \\
\hline $\mathrm{RX}$ & 379 & 39,2 & 318 & 33,2 & 315 & 23,4 & 317 & 38,8 & $<0,001$ \\
\hline TC & 134 & 13,8 & 121 & 12,6 & 134 & 10,0 & 64 & 7,8 & $<0,001$ \\
\hline RNM & 13 & 1,3 & 9 & 0,9 & 71 & 5,3 & 12 & 1,5 & 1 \\
\hline Total & 918 & 94,8 & 909 & 94,8 & 1195 & 88,8 & 816 & 99,9 & $<0,05$ \\
\hline
\end{tabular}

*ENDOSCOPIAS: FORAM SOMADOS TODOS OS PROCEDIMENTOS ENDOSCÓPICOS COMO ENDOSCOPIAS SIMPLES, ENDOSCOPIAS PARA LIGADURA ELÁSTICA, ENDOSCOPIAS PARA BIÓPSIAS E ENDOSCOPIAS PARA PASSAGEM DE SONDA NASO-ENTERAL.

ECG: ELETROCARDIOGRAMA; US: ULTRASSOM; RX: RAIO-X; TC: TOMOGRAFIA COMPUTADORIZADA; RNM: RESSONÂNCIA NUCLEAR MAGNÉTICA. 


\subsubsection{INTERNAÇÕES E PROCEDIMENTOS POR GRUPO DE MELD}

No grupo de pacientes com MELD <= 17, 61 pacientes necessitaram internações com 42 internações no total. No grupo dos pacientes com MELD entre 18 e 24, 70 pacientes necessitaram de internações com 105 internações no total. No grupo dos pacientes com MELD entre 25 a 30, 82 pacientes necessitaram de internações com 105 internações no total e entre os pacientes com MELD acima de 30, 86 pacientes necessitaram de internações, com 111 internações no total. Os principais motivos de internação, diagnósticos, procedimentos, valor de MELD no momento da entrada em internação o número de dias totais, em enfermaria e em UTI estão apresentados na tabela 14. 
TABELA 14: Diagnósticos, TEMPO, MOTIVOS, PROCEDIMENTOS E NÚMERO DE INTERNAÇões ENTRE TOdOS OS PACIENTES DIVIDIDOS PELO GRUPO DE MELD ( $\mathrm{N}=\mathbf{2 7 7}$ )

\begin{tabular}{|c|c|c|c|c|c|c|c|c|c|}
\hline & \multicolumn{2}{|c|}{$\begin{array}{l}\text { MELD < } 17 \\
n=61(16 \%)\end{array}$} & \multicolumn{2}{|c|}{$\begin{array}{l}\text { MELD } 18 \text { - } 24 \\
n=105(27,5 \%)\end{array}$} & \multicolumn{2}{|c|}{$\begin{array}{c}\text { MELD 25-30 } \\
n=105(27,5 \%)\end{array}$} & \multicolumn{2}{|c|}{$\begin{array}{c}\text { MELD > } 30 \\
n=111(29,1 \%)\end{array}$} & \multirow[b]{2}{*}{$\mathbf{P}$} \\
\hline & Total & $\%$ & Total & $\%$ & Total & $\%$ & Total & $\%$ & \\
\hline \multicolumn{10}{|l|}{ Internações } \\
\hline Sim & 42 & 68,9 & 70 & 66,7 & 82 & 78,1 & 86 & 77,5 & \multirow{2}{*}{$<0,001$} \\
\hline Não & 19 & 31,1 & 35 & 33,3 & 23 & 21,9 & 25 & 22,5 & \\
\hline Número de internações & 61 & 16,0 & 105 & 27,5 & 105 & 27,5 & 111 & 29,1 & 0,02 \\
\hline \multicolumn{10}{|l|}{ Motivos de internação } \\
\hline Procedimento & 22 & 36,1 & 41 & 39,0 & 28 & 26,7 & 19 & 17,1 & \multirow{7}{*}{0,999} \\
\hline Dor abdominal & 13 & 21,3 & 18 & 17,1 & 18 & 17,1 & 28 & 25,2 & \\
\hline Encefalopatia & 5 & 8,2 & 16 & 15,2 & 15 & 14,3 & 13 & 11,7 & \\
\hline HDA & 4 & 6,6 & 2 & 1,9 & 1 & 1,0 & 8 & 7,2 & \\
\hline Exame & 4 & 6,6 & 13 & 12,4 & 8 & 7,6 & 10 & 9,0 & \\
\hline Febre e mal-estar & 7 & 11,5 & 4 & 3,8 & 19 & 18,1 & 14 & 12,6 & \\
\hline Outros & 6 & 9,8 & 11 & 10,5 & 16 & 15,2 & 19 & 17,1 & \\
\hline \multicolumn{10}{|l|}{ Diagnóstico Internação } \\
\hline HDA & 5 & 8,2 & 1 & 1,0 & 1 & 1,0 & 3 & 2,7 & \multirow{7}{*}{0,997} \\
\hline $\mathrm{EH}$ & 6 & 9,8 & 4 & 3,8 & 7 & 6,7 & 2 & 1,8 & \\
\hline CHC/Adenocarcinoma & 9 & 14,8 & 11 & 10,5 & 27 & 25,7 & 9 & 8,1 & \\
\hline PBE/infeção & 15 & 24,6 & 34 & 32,4 & 26 & 24,8 & 38 & 34,2 & \\
\hline Piora função hepática/renal & 8 & 13,1 & 26 & 24,8 & 22 & 21,0 & 37 & 33,3 & \\
\hline Hérnia & 4 & 6,6 & 10 & 9,5 & 7 & 6,7 & 6 & 5,4 & \\
\hline Outros & 14 & 23,0 & 19 & 18,1 & 15 & 14,3 & 16 & 14,4 & \\
\hline \multicolumn{10}{|l|}{ Procedimentos } \\
\hline Paracentese & 11 & 18,0 & 19 & 17,1 & 9 & 8,6 & 6 & 5,7 & \multirow{6}{*}{0,902} \\
\hline ATB & 13 & 21,3 & 14 & 12,6 & 13 & 12,4 & 16 & 15,2 & \\
\hline Procedimentos Cirúrgicos & 11 & 18,0 & 26 & 23,4 & 40 & 38,1 & 41 & 39,0 & \\
\hline Hemodiálise & 6 & 9,8 & 7 & 6,3 & 4 & 3,8 & 4 & 3,8 & \\
\hline Realização de exames - observação & 16 & 26,2 & 34 & 30,6 & 29 & 27,6 & 30 & 28,6 & \\
\hline \multirow[t]{2}{*}{ Outros } & 4 & 6,6 & 11 & 9,9 & 10 & 9,5 & 8 & 7,6 & \\
\hline & Média & Dp & Média & Dp & Média & Dp & Média & Dp & \multirow[b]{2}{*}{$\mathbf{P}$} \\
\hline MELD* & 26,1 & $\pm 5,4$ & 26,3 & $\pm 5,5$ & 27,0 & $\pm 6,1$ & 29,5 & $\pm 6,4$ & \\
\hline \multicolumn{10}{|l|}{ Dias de internação } \\
\hline Total* & 8,7 & $\pm 10,1$ & 12,6 & $\pm 13,8$ & 12,6 & $\pm 19,3$ & 14,1 & $\pm 12,6$ & 0,02 \\
\hline UTI* & 5,5 & $\pm 6,3$ & 6,7 & $\pm 4,7$ & 9,1 & $\pm 10,7$ & 10,6 & $\pm 7,9$ & 0,02 \\
\hline Enfermaria* & 7,3 & $\pm 7,8$ & 10,8 & $\pm 12,0$ & 10,4 & $\pm 15,1$ & 10,7 & $\pm 9,3$ & 0,03 \\
\hline
\end{tabular}

* DAdOS APRESENTADOS EM VAlORES MÉDIOS E DESVIO-PADRÃo.

HDA: hemorRagia digestiva alta; EH: encefalopatia hepática; CHC: CARCinoma hepatocelular; PBE: PERItonite BACTERIANA ESPONTÂNEA; ATB: ANTIBIOTICOTERAPIA. 


\subsubsection{UTILIZAÇÃO DE HEMOCOMPONENTES POR GRUPO DE MELD}

No total, foram utilizados 1630 bolsas de hemocomponentes por todos os pacientes deste estudo. As quantidades de cada hemocomponente, totais, porcentagens e média de utilização por paciente divididos por grupo de MELD estão resumidos na tabela 15.

TABELA 15: HEMOCOMPONENTES UTILIZAdOS EM INTERNAÇÃO. QUANTIDADES TOTAIS, PORCENTAGENS E MÉDIA DE UTILIZAÇÃO POR PACIENTE DIVIDIDOS POR GRUPO DE MELD (N=277; COM 434 INTERNAÇÕES NO TOTAL).

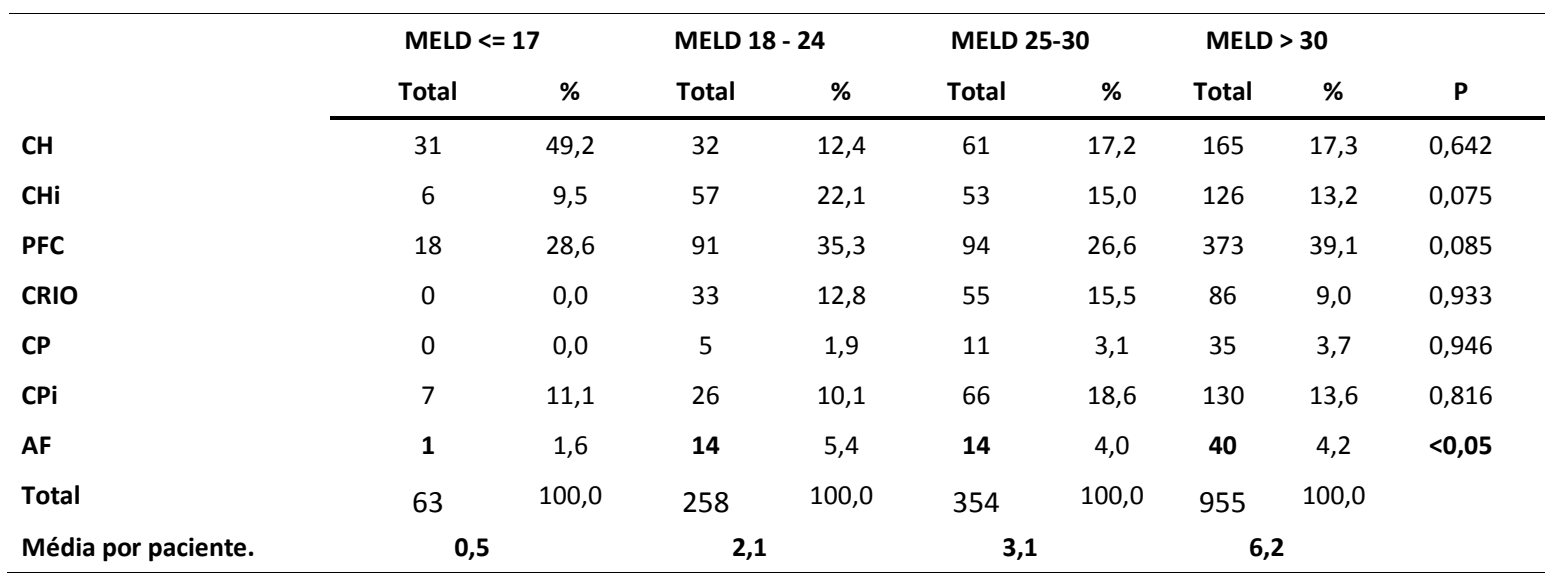




\subsubsection{PACIENTES COM CARCINOMA HEPATOCELULAR ATENDIDOS PELO ICESP POR GRUPO DE MELD}

Os pacientes diagnosticados com carcinoma hepatocelular foram avaliados com relação ao número de internações junto ao Hospital do Câncer do Estado de São Paulo para a realização de procedimentos como a Quimioembolização Transarterial (TACE), para a Ablação por radiofrequência (RFA) ou internações por outros motivos.

Estes pacientes foram avaliados com relação ao número de internações, dias de internação em enfermaria e UTI e procedimento realizado e seus dados foram analisados de maneira específica neste estudo. Estes dados foram analisados minuciosamente e individualmente para cada período de internação e posteriormente somados ao total de cada paciente.

Foram ao total 80 pacientes diagnosticados com $\mathrm{CHC}$, dos 492 pacientes em lista $(17,22 \%)$, sendo 1 paciente do grupo com MELD <=17 (1,25\%), 13 pacientes com MELD entre 18 e 24 (16,25\%), 43 pacientes do grupo com MELD entre 25 e $30(53,75 \%)$ e 23 pacientes do grupo com MELD acima de 30 (28,75\%). O número de internações e principais procedimentos realizados estão resumidos na tabela 16.

TABELA 16: NúMERO TOTAL E FREQUÊNCIA DE INTERNAÇÕES DOS PACIENTES COM CHC ATENDIDOS NO ICESP ( $\mathrm{N=80}$ ).

\begin{tabular}{|c|c|c|c|c|c|c|c|c|c|}
\hline & \multicolumn{2}{|c|}{$\begin{array}{c}\text { MELD }<=17 \\
N=1\end{array}$} & \multicolumn{2}{|c|}{$\begin{array}{c}\text { MELD } 18 \text { - } 24 \\
n=13\end{array}$} & \multicolumn{2}{|c|}{$\begin{array}{c}\text { MELD 25-30 } \\
n=43\end{array}$} & \multicolumn{2}{|c|}{$\begin{array}{c}\text { MELD > } 30 \\
n=23\end{array}$} & \multirow[b]{2}{*}{$\mathbf{P}$} \\
\hline & Total & $\%$ & Total & $\%$ & Total & $\%$ & Total & $\%$ & \\
\hline Internações para TACE & - & - & 17 & 26,2 & 27 & 14,1 & 12 & 24,0 & 0,82 \\
\hline Internações para RFA & - & - & 5 & 7,7 & 12 & 6,3 & 9 & 18,0 & 0,64 \\
\hline Internações outros motivos & 1 & 100,0 & 43 & 66,2 & 153 & 79,7 & 29 & 58,0 & 0,14 \\
\hline Total Internações & 1 & 100,0 & 65 & 100,0 & 192 & 100,0 & 50 & 100,0 & 0,05 \\
\hline
\end{tabular}




\section{Resultado dA ANÁlise de Custo}

O custo total de todos os itens e recursos utilizados durante todo o período em lista de espera para o transplante hepático foi de RS\$ 14.065.914,56. O custo total em consultas e procedimentos ambulatoriais foi RS\$ $4.157 .792,93$ e o custo total em internações foi de RS\$ 9.908.121.63. Os principais valores totais e porcentagens com relação ao custo total estão resumidos na tabela 17.

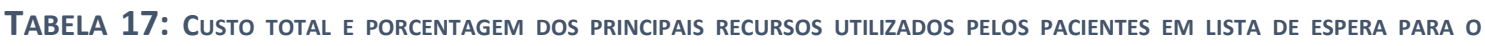
TRANSPLANTE HEPÁtico (N=492). VALORES EM REAIS.

\begin{tabular}{lcccc}
\hline & Total & $\%$ & Por paciente & dp \\
\cline { 2 - 5 } Custo total & $\mathbf{1 4 . 0 6 5 . 9 1 4 , 5 6}$ & $\mathbf{1 0 0}$ & $\mathbf{2 9 . 1 1 4 , 7 7}$ & $\mathbf{3 1 . 5 4 1 , 4 0}$ \\
$\begin{array}{l}\text { Custo em } \\
\text { ambulatório }\end{array}$ & $4.157 .792,93$ & 29,63 & $8.626,13$ & $10.541,70$ \\
Custo em internação & $9.908 .121 ; 63$ & 70,37 & $20.488,64$ & $29.622,62$ \\
\hline \hline Medicamentos & $3.766 .995,66$ & 26,78 & $6.538,46$ & $9.295,79$ \\
Recursos humanos & $3.142 .805,26$ & 22,34 & $6.740,24$ & $7.758,50$ \\
Exames laboratoriais & $2.562 .799,80$ & 18,22 & $2.686,37$ & $3.563,51$ \\
Materiais & $1.244 .870,99$ & 8,85 & $2.292,25$ & $2.615,72$ \\
Total ICESP & $822.730,04$ & 5,85 & $18.307,70$ & $17.013,02$ \\
Exames de imagem & $789.974,49$ & 5,62 & $1.618,80$ & $2.105,85$ \\
Quimioembolizações & $641.592,68$ & 4,59 & $12.831,85$ & $9.731,70$ \\
Hemoterapia & $641.585,38$ & 4,56 & $5.886,10$ & $5.739,63$ \\
Paracenteses & $535.305,50$ & 3,81 & $2.052,38$ & $3.806,04$ \\
Diálises & $290.697,10$ & 2,07 & 701,23 & $10.902 ; 53$ \\
Nutrição & $267.871,37$ & 1,90 & 843,70 \\
\hline
\end{tabular}

Os gastos com recursos humanos, incluindo consultas ambulatoriais, atendimentos em internações, honorários médicos e da equipe somaram $\mathrm{R} \$ 3.142 .805,26$, representando $22,34 \%$ dos gastos totais de todos os pacientes. 


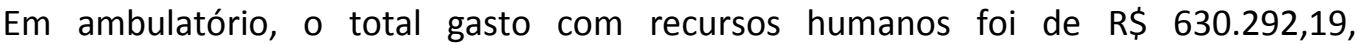
representando $15,16 \%$ do total gasto e nas internações o total gasto com recursos humanos foi de $\mathrm{R} \$ 2.512 .513,07$, representando $25,36 \%$ do total. Figura 3 .

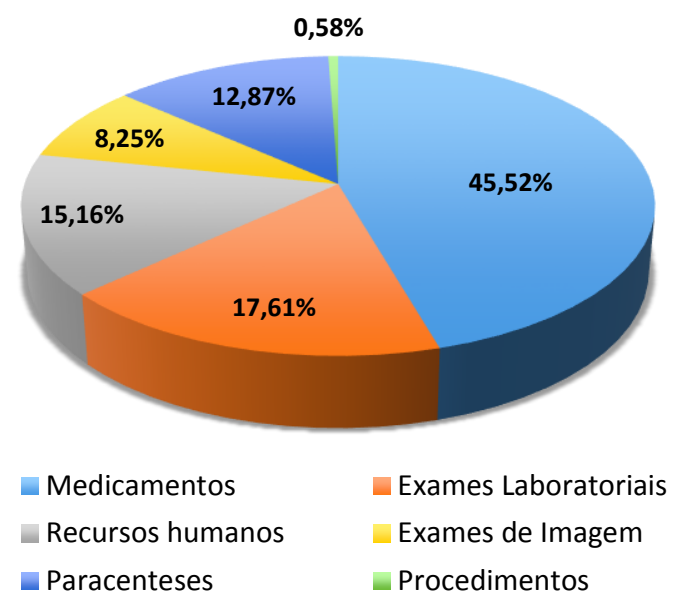

A

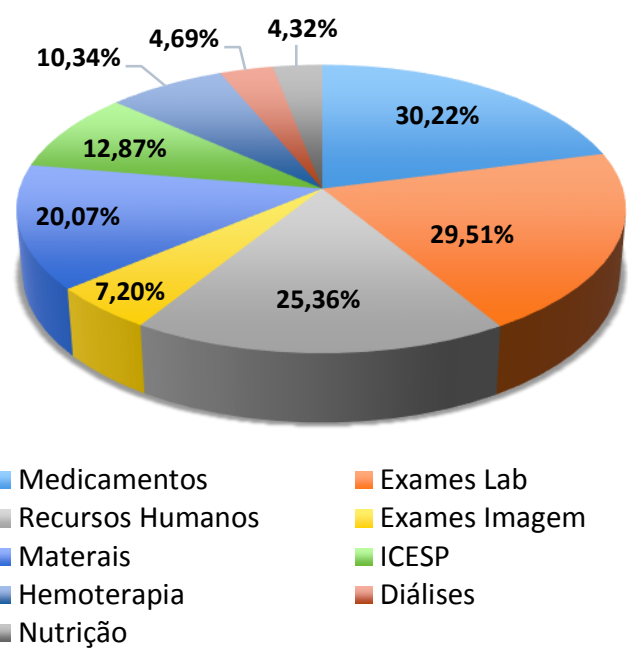

B

Figura 3: A - Porcentagem de gastos ambulatorials por ReCURso utilizado em Relação ao custo total. B PORCENTAGEM DE GASTOS EM INTERNAÇõES POR RECURSO UTILIZADO EM RELAÇÃo AO CUSTO TOTAL.

O número de pacientes em lista de espera distribuídos em relação ao custo total está resumida no gráfico 9.

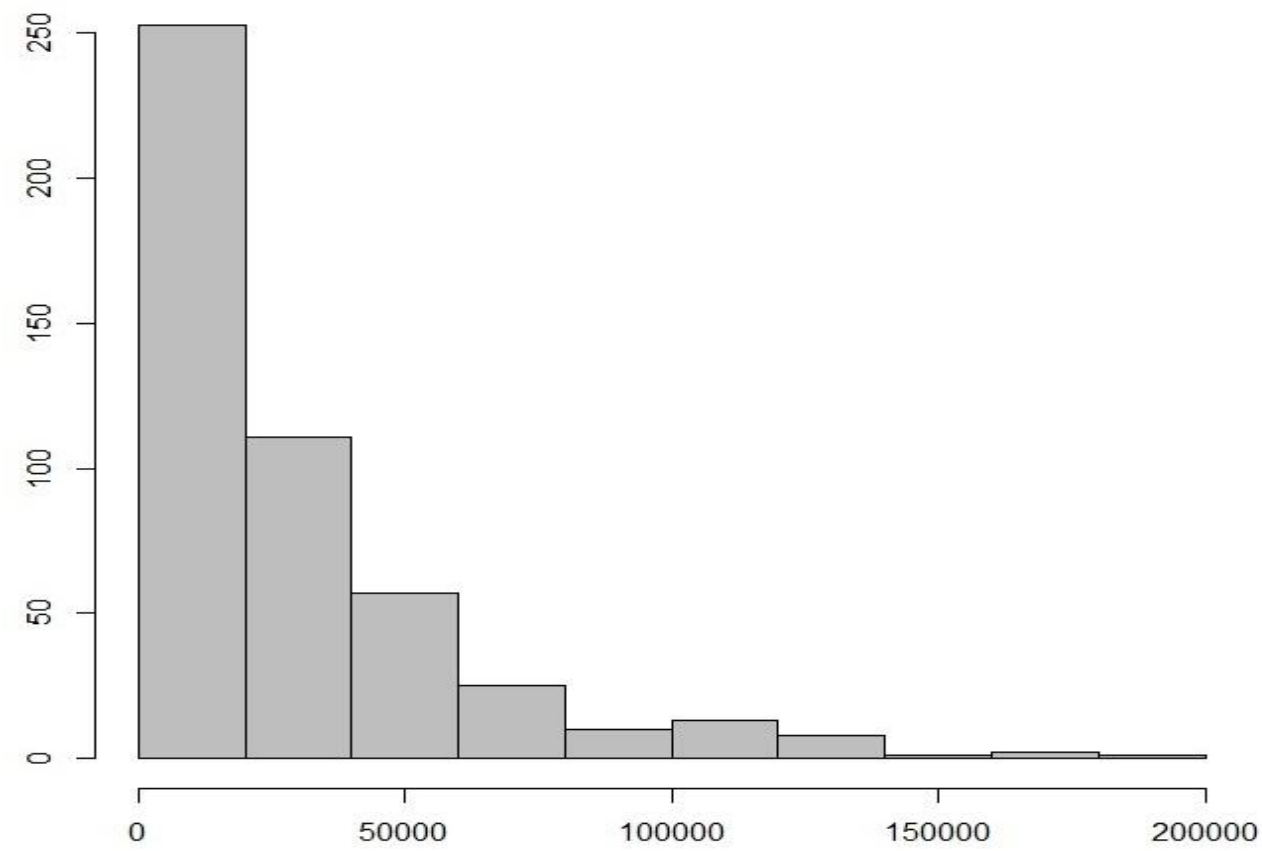

GRÁFICO 9: FREQUÊNCIA de distribUIÇÃo dos PACIENTES COM RELAÇão AOS VALORES dE CUSTO. VALORES EM REAIS 


\subsection{CUSTO TOTAL POR GRUPO DE DESFECHO}

O custo total dos pacientes chamados ao transplante $(n=134)$ foi de RS\$ $2.339 .982,87$ representando $23,69 \%$ do custo total de todos os pacientes.

O custo total de todos os indivíduos que foram removidos ( $n=103)$ foi de RS\$ 1.993.470,67, representando $14,21 \%$ do custo total de todos os pacientes.

O custo total dos pacientes que vieram a óbito $(n=67)$ foi de RS\$ $3.293 .873,64$, representando $23,47 \%$ do custo total de todos os pacientes.

O custo total de todos os pacientes que permaneceram em lista de espera até o final do estudo ( $n=178$ ), foi de RS\$ 4.399.649,33, representando 31,35 \% do custo total de todos os pacientes $(p<0,001)$.

Os valores médios de cada paciente divididos por grupo de desfecho estão apresentados no gráfico 10 .

60000,00

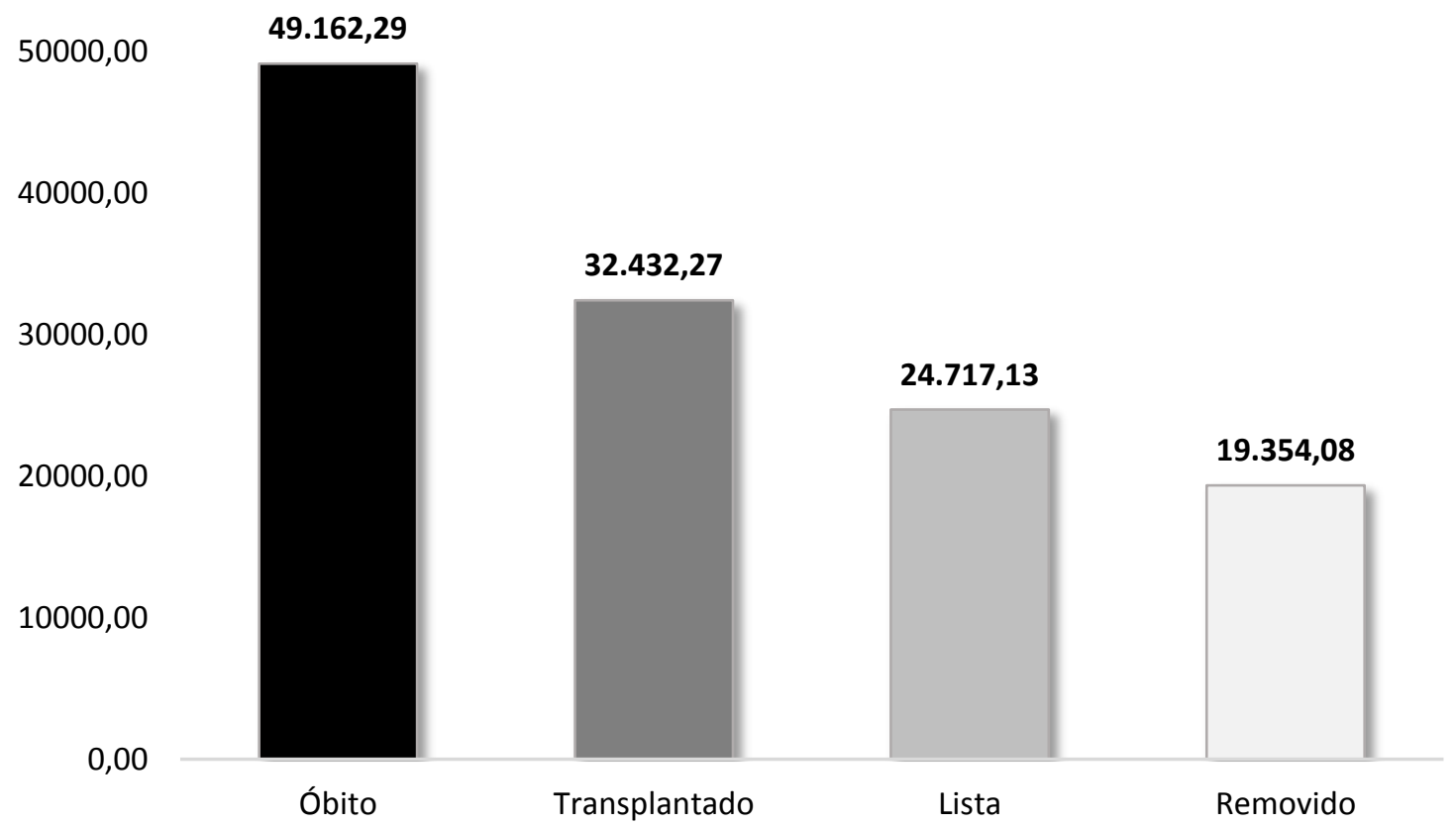

GRÁFICO 10: CUSTO TOTAL do PACIENTE CIRRÓtICO EM LISTA DE ESPERA PARA O TRANSPLANTE HEPÁTICO DIVIDIDO PELO GRUPO DE DESFECHO. VALORES MÉDIOS POR PACIENTE EM REAIS. 
Os demais valores dos recursos utilizados pelos pacientes divididos pelo grupo de desfecho estão resumidos na tabela 18.

TABELA 18: ANÁLISE DOS PRINCIPAIS RECURSOS E COMPONENTES DE CUSTOS UTILIZADOS DIVIDIDOS PELO GRUPO DE DESFECHO. ( $\mathrm{N}=492$ ) VALORES EM REAIS.

\begin{tabular}{|c|c|c|c|c|c|c|c|c|c|}
\hline & \multicolumn{2}{|c|}{$\begin{array}{c}\text { Transplantado } \\
n=134\end{array}$} & \multicolumn{2}{|c|}{$\begin{array}{c}\text { Removido } \\
n=103\end{array}$} & \multicolumn{2}{|c|}{$\begin{array}{l}\text { Óbito } \\
n=67\end{array}$} & \multicolumn{2}{|c|}{$\begin{array}{l}\text { Lista } \\
n=178\end{array}$} & \multirow[b]{2}{*}{$P$} \\
\hline & Média & $\mathrm{Dp}$ & Média & $\mathrm{dp}$ & Média & $\mathrm{dp}$ & Média & $\mathrm{dp}$ & \\
\hline Custo total ${ }^{1}$ & 17462,6 & 20087,99 & 19354,1 & 35001,14 & 49162,3 & 37511,10 & 24717,13 & 28571,05 & $<0,001$ \\
\hline Custo dia ${ }^{2}$ & 189,82 & 150,34 & 197,95 & 261,04 & 386,77 & 234,47 & 142,15 & 54,83 & $<0,001$ \\
\hline Ambulatório $^{3}$ & 14972,7 & 12878,17 & 5887,33 & 8767,52 & 3757,97 & 4877,39 & 7265,56 & 8860,65 & $<0,001$ \\
\hline Internação ${ }^{4}$ & 17462,6 & 20087,99 & 13466,7 & 31594,89 & 45404,3 & 36780,38 & 17451,57 & 26866,79 & 0,001 \\
\hline Internação/dia 5 & 1273,31 & 1409,63 & 377,75 & 989,52 & 1760,67 & 1693,74 & 1105,48 & 1297,53 & $<0,001$ \\
\hline Materiais $^{6}$ & 1524,57 & 1584,73 & 3367,17 & 3730,65 & 3115,66 & 2613,84 & 2183,42 & 2796,30 & 0,043 \\
\hline Medicamentos ${ }^{7}$ & 3994,88 & 5118,67 & 8231,80 & 8540,69 & 10288,64 & 9483,33 & 6344,78 & 8739,01 & 0,017 \\
\hline Exames Laboratoriais $^{8}$ & 4390,22 & 3989,53 & 2744,00 & 4193,57 & 5090,06 & 3478,52 & 3588,62 & 4371,39 & 0,020 \\
\hline Exames Imagem $^{9}$ & 1160,25 & 1302,18 & 2560,15 & 3058,40 & 2381,66 & 2093,52 & 1758,09 & 2229,09 & 0,035 \\
\hline Hemocomponentes ${ }^{10}$ & 5485,57 & 5512,2 & 4691,39 & 3610,85 & 8888,94 & 6327,12 & 2456,38 & 3020,78 & 0,008 \\
\hline Internações ICESP & 17327,23 & 19581,49 & 26835,57 & 12023,70 & 16692,80 & - & 17599,05 & 12752,28 & 0,092 \\
\hline TACE e RFAs & 12425,15 & 5959,14 & 16217,28 & 9008,38 & 10647,86 & - & 1239,40 & 11483,15 & 0,423 \\
\hline
\end{tabular}

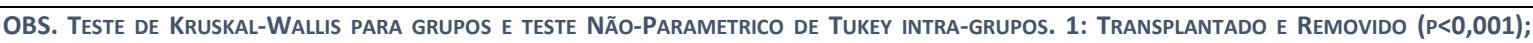
TRANSPLANTADO E ÓBITO ( $P=0,041)$; TRANSPLANTADO E LISTA ( $P=0,002)$; REMOVIDO E ÓBITO ( $P<0,001)$; REMOVIDO E LISTA (P<0,001); ÓBITO E LISTA $(P<0,001)$. 2: TRANSPLANTAdO E REMOVIDO (P<0,001); TRANSPLANTADO E LISTA ( $<<0,001)$; ReMOVIDO E ÓBITO (P<0,001); ÓBITO E LISTA (P<0,001).

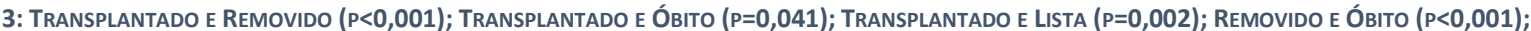
REMOVIDO E LISTA ( $P<0,001)$; ÓBITO E LISTA ( $P<0,001)$. 4: TRANSPLANTADO E ÓBITO ( $<<0,001)$; ÓBITO E LISTA (P<0,001). 5: TRANSPLANTADO E ÓBITO $(P<0,001)$; TRANSPLANTAdo E LISTA ( $P<0,001)$; ReMOVIDO E ÓBITO $(P<0,001)$; REMOVIDO E LISTA ( $<<0,001)$; ÓBITO E LISTA (P<0,001). 6 : TRANSPLANTADO E ÓBITO ( $P<0,001)$; Ó BITO E LISTA ( $P=0,003)$. 7: TRANSPLANTADO E ReMOVIDO ( $P=0,013$ ); TRANSPLANTADO E ÓBITO (P<0,001); ÓBITO E LISTA ( $P=0,002)$. 8: ÓBITO E LISTA ( $P=0,012)$. 9: TRANSPLANTADO E ÓBITO $(P<0,001)$; ÓBITO E LISTA $(P=0,009)$. 10: ÓBITO E LISTA ( $P<0,001)$. 
As principais diferenças estatísticas entre os grupos em relação ao custo total, custo em internação e custo ambulatorial entre os pacientes divididos pelo desfecho está apresentado no gráfico 11.

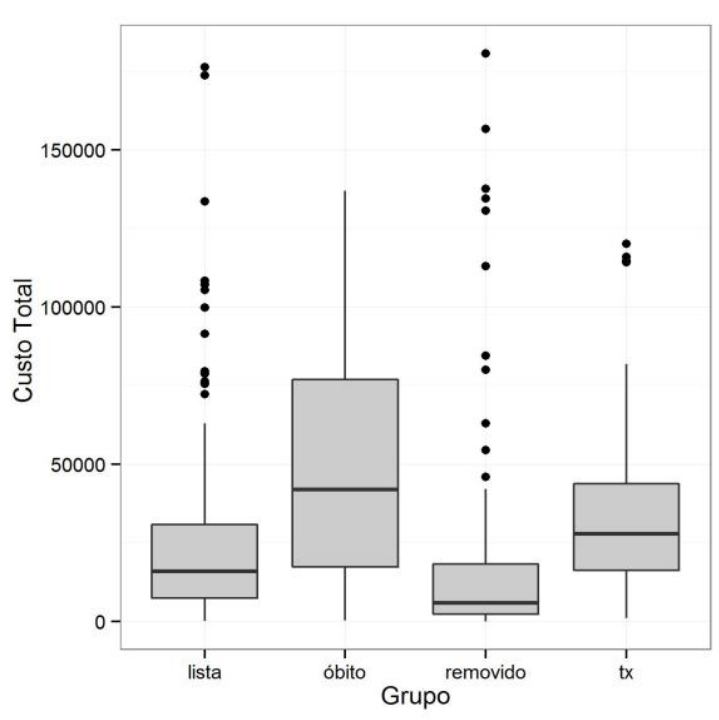

A

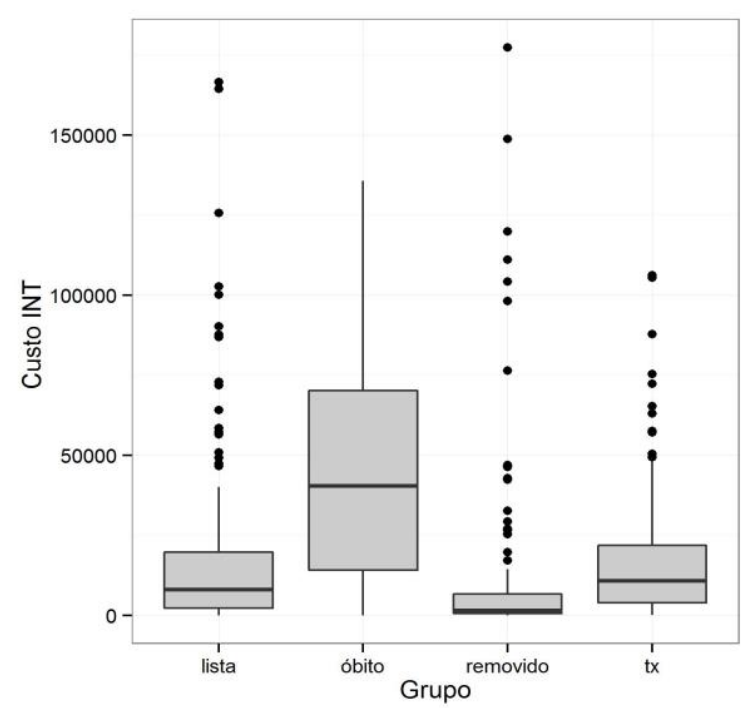

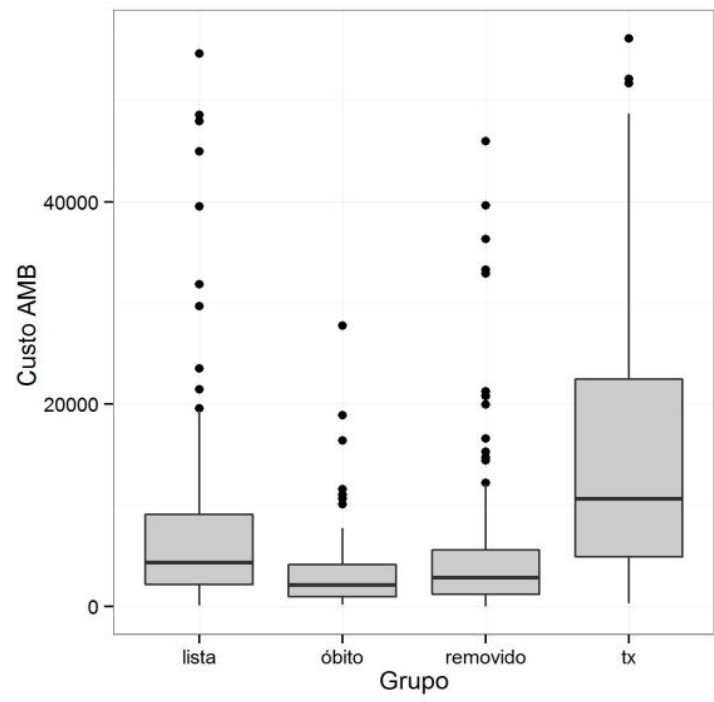

B

\section{C}

Gráfico 11: A - Mediana e quartis do custo total dos paCientes divididos Pelo gRUPO de desfecho $(P<0,001)$. B - MEDIANA E QUARTIS DO CUSTO AMBULATORIAL DOS PACIENTES DIVIDIDOS PELO GRUPO DE DESFECHO $(P<0,001)$. C - MEdIANA E QUARTIS DO CUSTO EM INTERNAÇÃo DOS PACIENTES DIVIDIDOS PELO GRUPO DE DESFECHO $(P<0,001)$.

O gráfico 12 apresenta as diferenças estatísticas entre os principais componentes de custo e recursos utilizados entre os pacientes divididos pelo grupo de desfecho. 


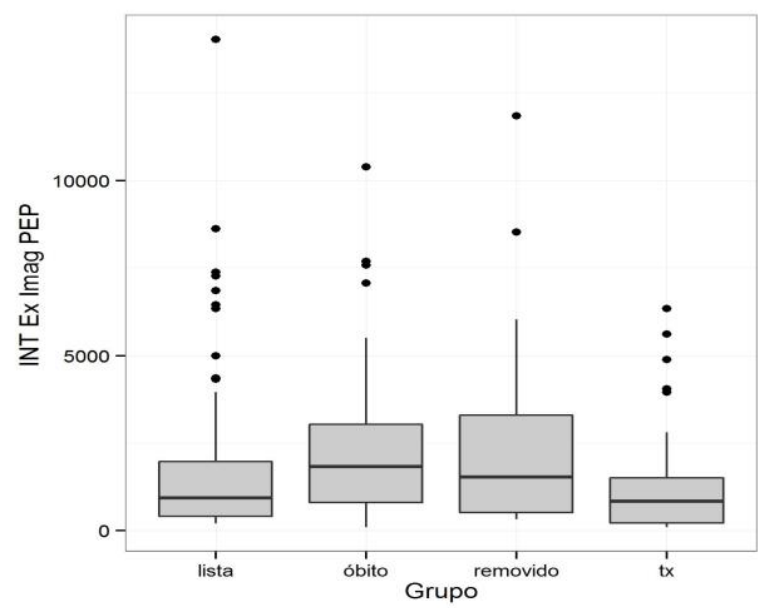

A

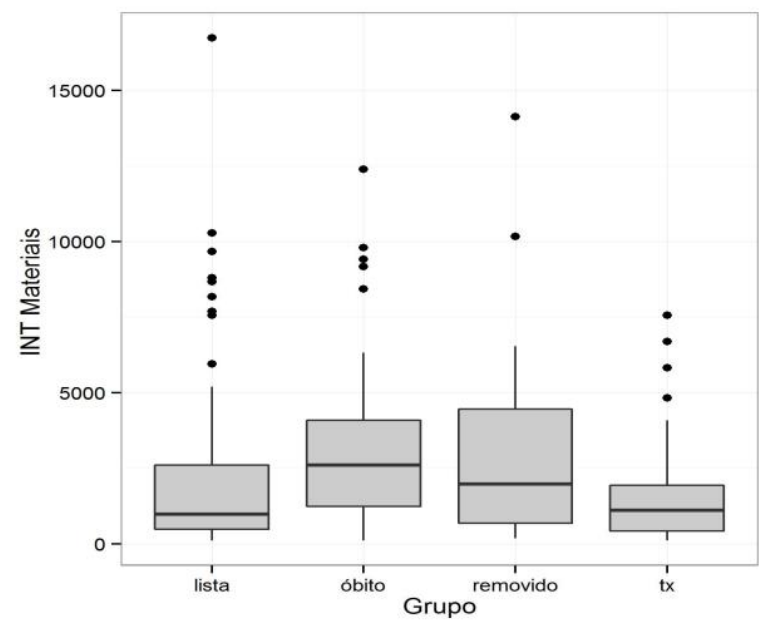

C

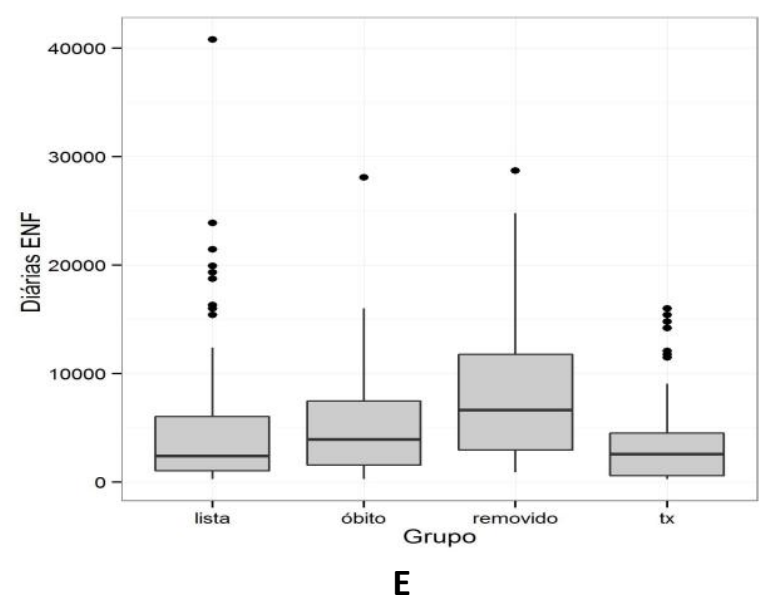

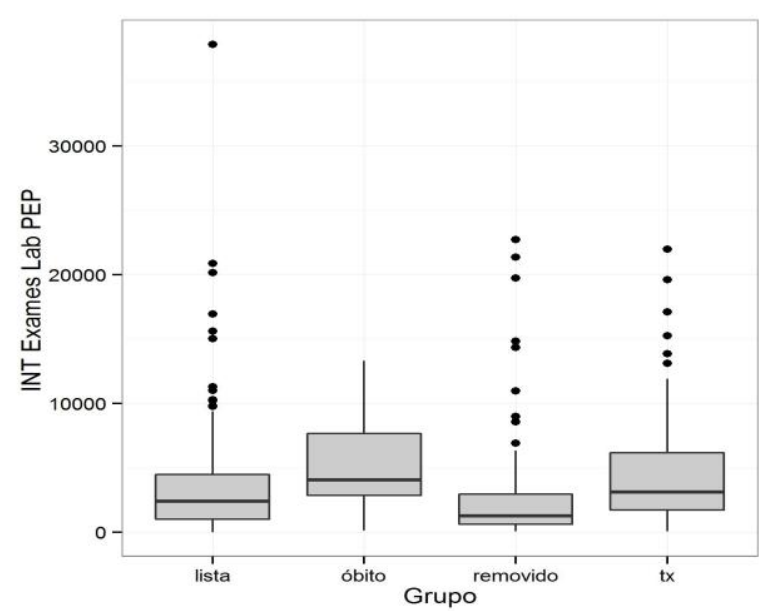

B

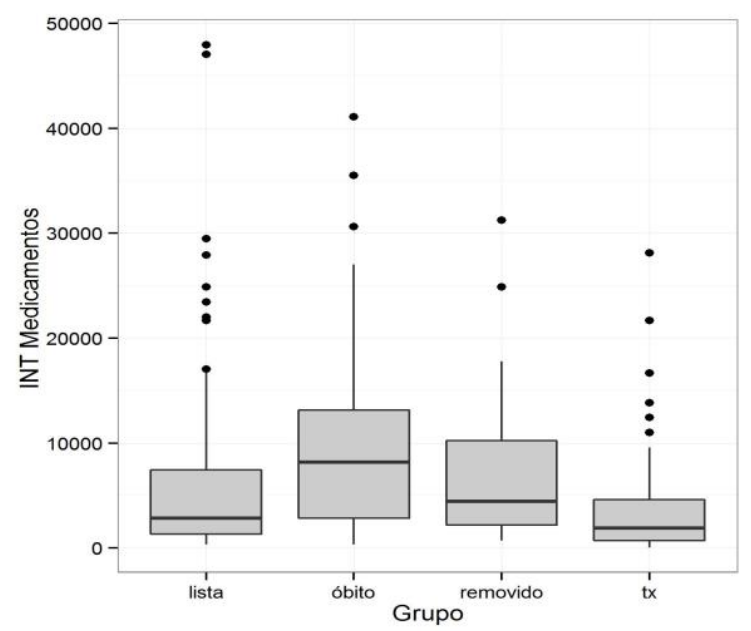

D

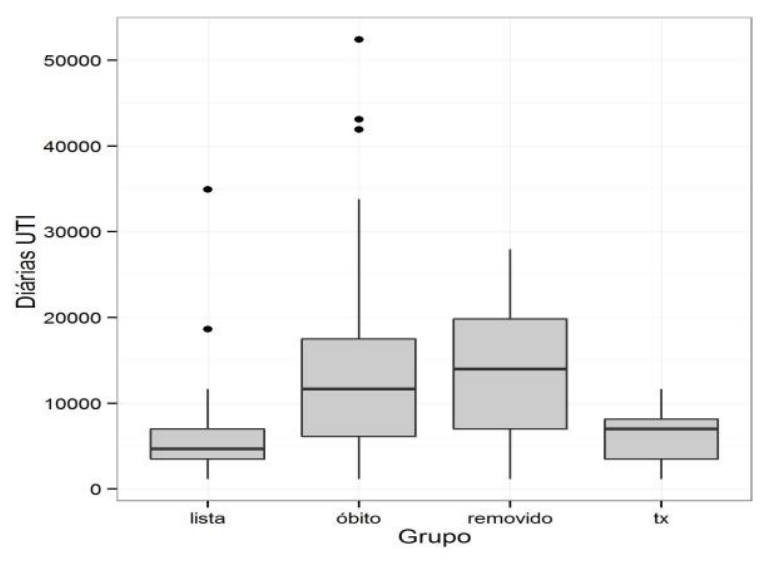

F

GRÁfICO 12: A - MEDIANA E QUARTIS DO CUSTO DOS EXAMES DE IMAGEM DOS PACIENTES DIVIDIDOS PELO GRUPO DE DESFECHO ( $P=0,003)$. B - MEDIANA E QUARTIS DO CUSTO COM EXAMES LABORATORIAIS DOS PACIENTES DIVIDIDOS PELO GRUPO DE DESFECHO ( $P=0,001)$. C - MEDIANA E QUARTIS DO CUSTO COM MATERIAIS UTILIZADOS DOS PACIENTES DIVIDIDOS PELO GRUPO DE DESFECHO $(P=0,001)$. D - MEDIANA E QUARTIS DO CUSTO COM MEDICAMENTOS DOS PACIENTES DIVIDIDOS PELO GRUPO DE DESFECHO ( $P=0,001)$. E - MEDIANA E QUARTIS DO CUSTO COM DIÁRIAS EM ENFERMARIA DOS PACIENTES DIVIDIDOS PELO GRUPO DE DESFECHO (P=0,001). F - MEDIANA E QUARTIS DO CUSTO COM DIÁRIAS EM UTI DOS PACIENTES DIVIDIDOS PELO GRUPO DE DESFECHO (P=0,001). 
A análise do custo total do atendimento no ICESP aos pacientes com CHC e do custo com hemocomponentes destes pacientes está apresentado no gráfico 13.
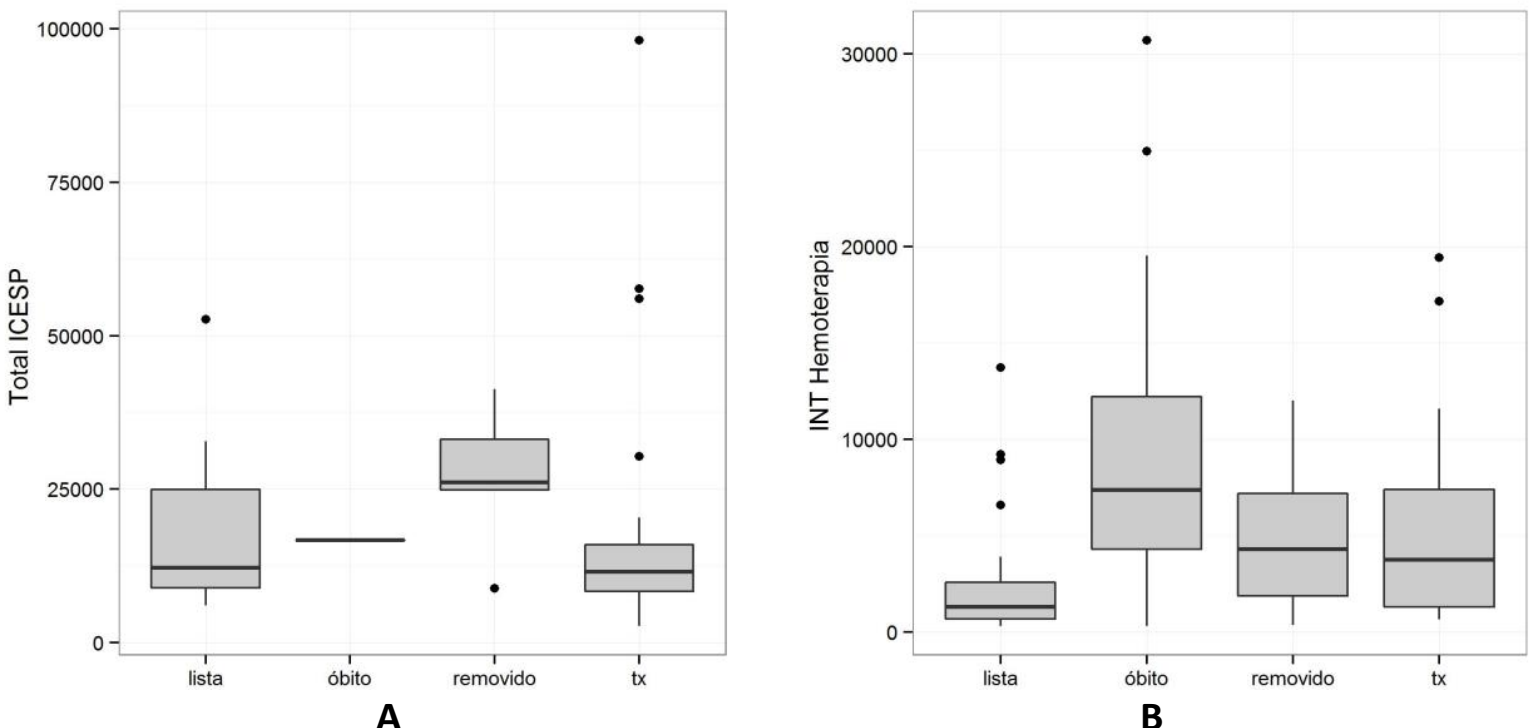

Gráfico 13: A - Mediana e quartis do custo total utilizados Pelos PaCientes diagnosticados com CHC que Realizaram INTERNAÇõES E PROCEDIMENTOS NO ICESP DIVIDIDOS PELO GRUPO DE DESFECHO $(P=0,718)$. B - MEDIANA E QUARTIS DO CUSTO TOTAL UTILIZADO COM HEMOCOMPONENTES ENTRE OS PACIENTES DIVIDIDOS PELO GRUPO DE DESFECHO $(\mathrm{p}<0,001)$. 


\subsection{CUSTO TOTAL POR GRUPO DE MELD}

O custo total do paciente em lista de espera com MELD $<=17(n=132)$ foi de $R \$$ $1.726 .765,33$, representando $12,88 \%$ dos custos totais de todos os pacientes, com custo total médio de $\mathrm{R} \$ 12.604,13 \pm 20.594,28$ por paciente. O custo total do paciente em lista de espera com MELD entre 18 e 24 ( $n=122)$ foi de $R \$ 3.327 .016,58$, representando $24,82 \%$ dos custos totais de todos os pacientes, com média de $\mathrm{R} \$ 26.830,78 \pm 30.991,55$ por paciente.

O custo total do paciente em lista de espera com MELD entre 25 e $30 \quad(n=113)$ foi de RS\$ 4.240.933,60, representando $31,64 \%$ dos custos totais de todos os pacientes, com média de RS\$ $36.877,68 \pm 35.592,11$ por paciente. O custo total do paciente em lista de espera com MELD maior que $30(n=115)$ foi de RS\$ 4.108.904,67, representando $30,66 \%$ dos custos totais de todos os pacientes, com média de RS\$35.421,59 $\pm 29.527,50$ por paciente.

O gráfico 14 mostra a dispersão dos valores de custo total de todos os pacientes segundo o escore de MELD.

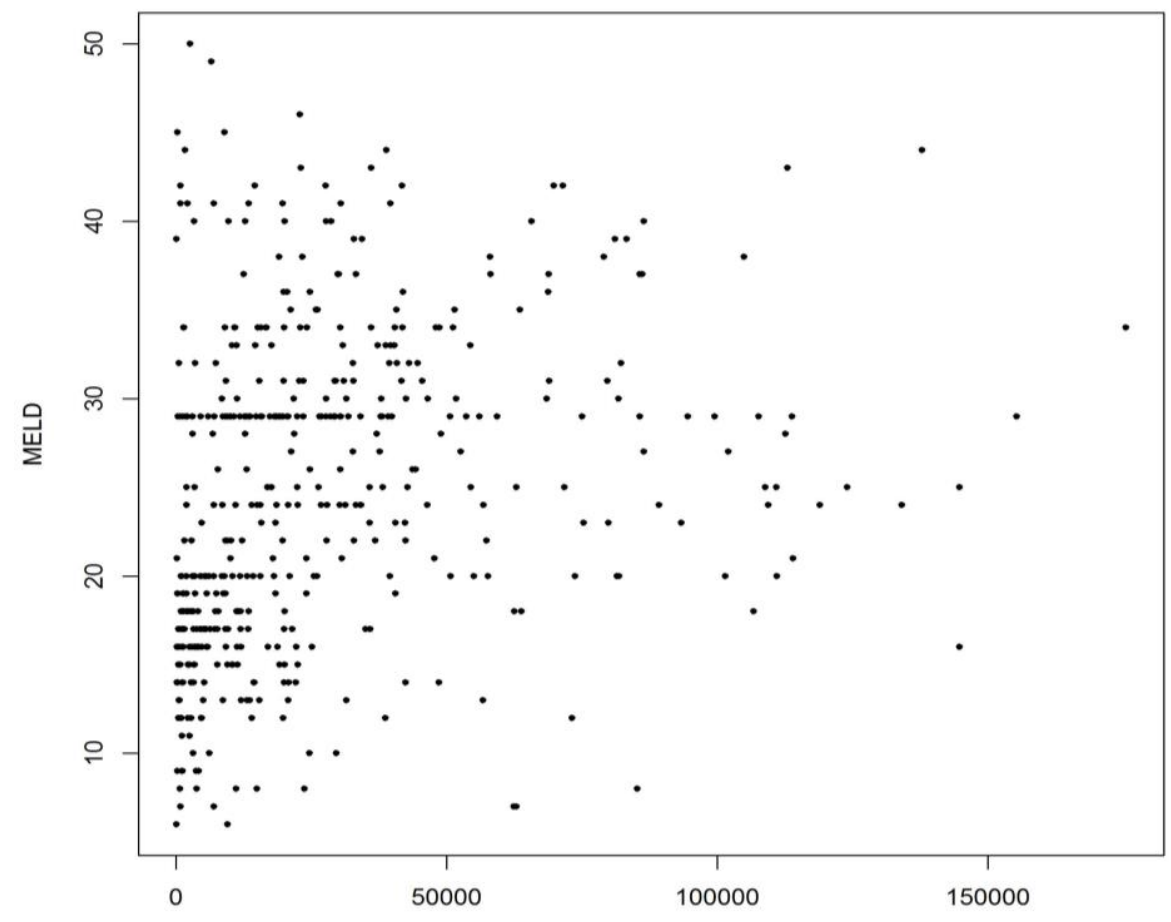

GRÁFICO 14 - GRÁFICO dE DISPERSÃo de TODOS OS PACIENTES SEGUNDO CUSTO TOTAL E ESCORE DE MELD (N=492). VALORES EM REAIS 
Os principais gastos de todos os pacientes divididos por faixa de MELD estão resumidos na Tabela 19.

TABELA 19: ANÁlISE dos PRINCIPAIS RECURSOS E COMPONENTES DE CUSTOS UTILIZADOS, DIVIDIDOS PELO GRUPO DE MELD (N=492). VALORES EM REAIS (R\$).

\begin{tabular}{|c|c|c|c|c|c|c|c|c|c|}
\hline & \multicolumn{2}{|c|}{$\begin{array}{c}\text { MELD }<=17 \\
(n=132) \quad 27,39 \%\end{array}$} & \multicolumn{2}{|c|}{$\begin{array}{c}\text { MELD } 18 \text { - } 24 \\
(n=122) 25,31 \%\end{array}$} & \multicolumn{2}{|c|}{$\begin{array}{c}\text { MELD } 25-30 \\
(n=113) 23,44 \%\end{array}$} & \multicolumn{2}{|c|}{$\begin{array}{c}\text { MELD > } 30 \\
(n=115) 28,32 \%\end{array}$} & \multirow[b]{2}{*}{$P$} \\
\hline & Média & $\mathrm{dp}$ & Média & $\mathrm{dp}$ & Média & $\mathrm{dp}$ & Média & $\mathrm{dp}$ & \\
\hline Custo total $^{1}$ & 12604,13 & 20594,28 & 26830,78 & 30991,55 & 36877,68 & 35592,11 & 35421,59 & 29527,50 & $<0,001$ \\
\hline Custo dia ${ }^{2}$ & 131,54 & 669,43 & 290,65 & 1010,67 & 1512,74 & 12457,28 & 1251,58 & 2395,45 & $<0,001$ \\
\hline Custo em ambulatório 3 & 5993,08 & 9923,61 & 9267,12 & 12275,16 & 11247,49 & 11635,47 & 9262,67 & 10723,31 & 0,005 \\
\hline Custo em internação ${ }^{4}$ & 20495,12 & 27944,02 & 31563,67 & 30973,36 & 35511,71 & 35949,06 & 35690,82 & 30251,14 & 0,002 \\
\hline Custo internação/dia & 1773,99 & 911,82 & 1850,48 & 1371,50 & 2146,55 & 1403,95 & 2317,20 & 1507,96 & 0,921 \\
\hline Custo Materiais & 1643,95 & 1994,05 & 2535,73 & 2819,14 & 2474,62 & 3011,05 & 2364,48 & 2405,48 & 0,614 \\
\hline Custo medicamentos & 4277,30 & 6910,76 & 8824,85 & 11600,30 & 9582,93 & 11036,57 & 12094,58 & 11416,10 & 0,748 \\
\hline Exames laboratoriais ${ }^{5}$ & 2066,30 & 2140,37 & 4051,56 & 4137,64 & 5523,63 & 6064,44 & 4916,87 & 4403,07 & $<0,001$ \\
\hline Exames de imagem & 2438,14 & 3416,35 & 2780,05 & 3181,08 & 5249,92 & 7393,50 & 3114,64 & 3964,42 & 0,532 \\
\hline Hemocomponentes $^{6}$ & 2849,89 & 3174,43 & 4250,69 & 4338,82 & 4801,14 & 4620,43 & 8289,46 & 6735,88 & 0,05 \\
\hline Internações ICESP7 & $6.079,14$ & - & 23654,48 & 15897,55 & 15812,13 & 11939,47 & 17057,08 & 25321,14 & 0,02 \\
\hline TACE e RFAs & 6079,14 & - & 18053,30 & 8347,78 & 11694,97 & 7616,26 & 15078,22 & 21444,45 & 0,66 \\
\hline
\end{tabular}

OBS. VALOR DE $P$ UTILIZANDO TESTE DE KRUSKAL-WALLIS PARA TODOS OS GRUPOS. VALORES DE $P$ ENTRE GRUPOS UTILIZANDO TESTE NÃO-PARAMETRICO DE TUKEY. 1. MELD <=17 E MELD 18-24 (P<0,001); MELD <=17 E MELD 25-30 ( $<<0,001)$; MELD <=17 E MELD >=30 (P<0,001); MELD 18-24 E MELD 25-30 ( $\mathrm{p=0,002);} \mathrm{MELD} \mathrm{18-24} \mathrm{E} \mathrm{MELD} \mathrm{>=30} \mathrm{(} \mathrm{P=0,001).} \mathrm{2:} \mathrm{MELD} \mathrm{<=17} \mathrm{E} \mathrm{MELD} \mathrm{18-24} \mathrm{(} \mathrm{P=0,005);} \mathrm{MELD} \mathrm{<=17} \mathrm{E} \mathrm{MELD}$ 25-30 ( $P<0,001)$; MELD <=17 E MELD >=30 ( $P<0,001)$. 3: MELD <=17 E MELD 18-24 ( $P=0,018)$; MELD <=17 E MELD 25-30 ( $P<0,001)$; MELD <=17 E MELD >=30 ( $P=0,024)$; MELD 18-24 E MELD 25-30 ( $\mathrm{p=0,029).} \mathrm{4:} \mathrm{MELD} \mathrm{<=17} \mathrm{E} \mathrm{MELD} \mathrm{25-30} \mathrm{(} \mathrm{P=0,004);} \mathrm{MELD} \mathrm{<=17} \mathrm{E}$ MELD >=30 ( $\mathrm{p}<0,001)$. 5: MELD <=17 E MELD 25-30 ( $\mathrm{p=0,001);} \mathrm{MELD} \mathrm{<=17} \mathrm{E} \mathrm{MELD} \mathrm{>=30} \mathrm{(} \mathrm{P}<0,001) .6:$ MELD <=17 E MELD >=30

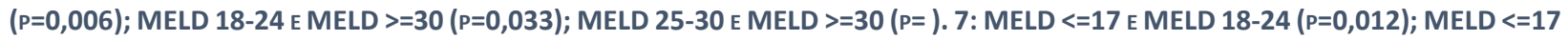
E MELD 25-30 ( $\mathrm{P=0}, 001)$; MELD <=17 E MELD >=30 ( $\mathrm{P}<0,001)$.

As principais diferenças estatísticas com relação ao custo total, custo em internação, custo ambulatorial, custo dos hemocomponentes utilizados, custo total em internações no ICESP e o custo total em exames laboratoriais entre os pacientes divididos pelo grupo de MELD estão apresentadas no gráfico 15. 


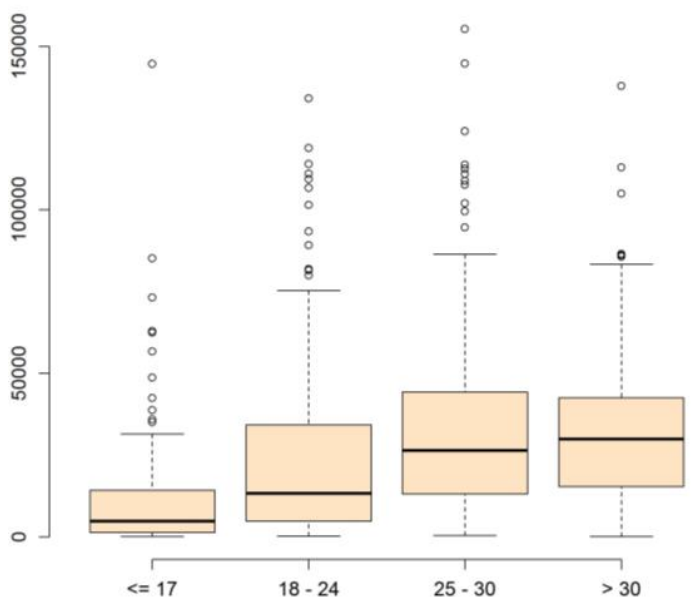

A

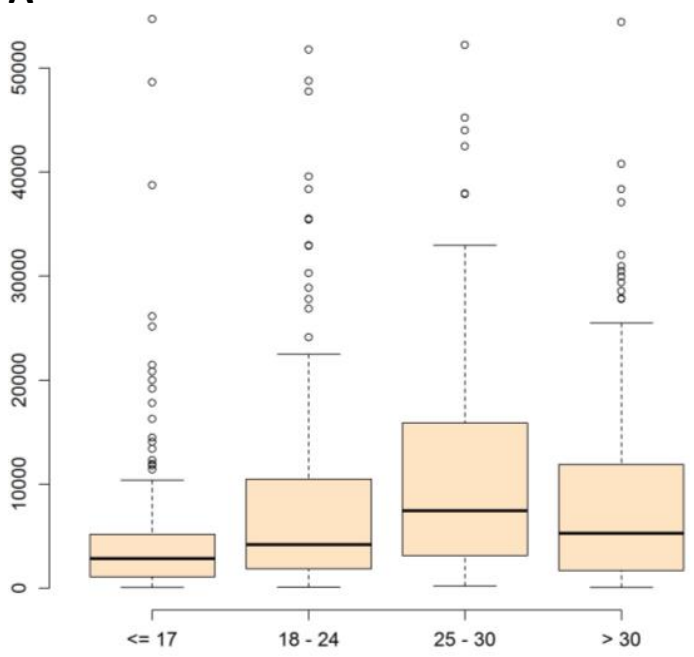

C

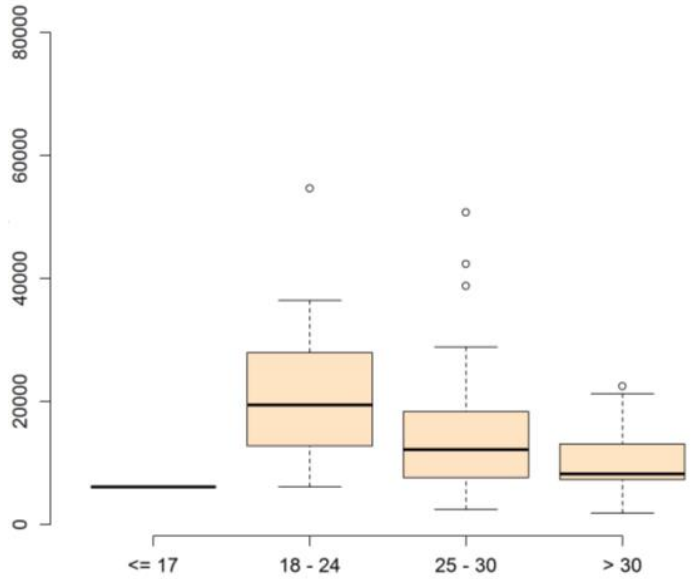

E

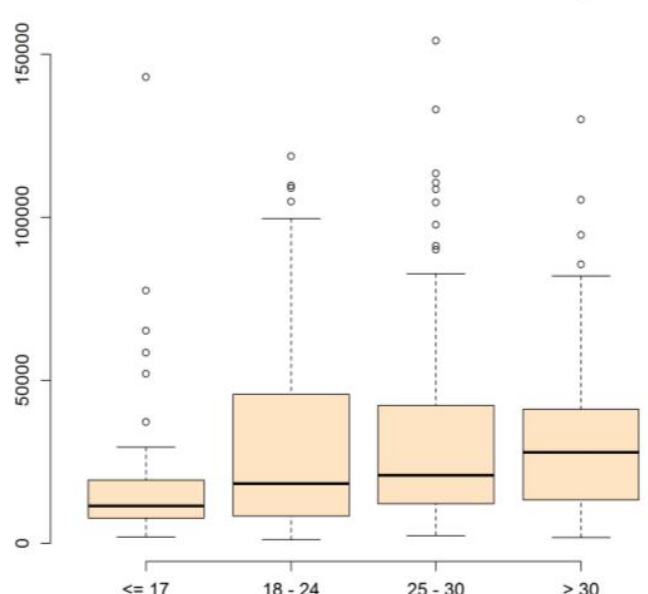

B

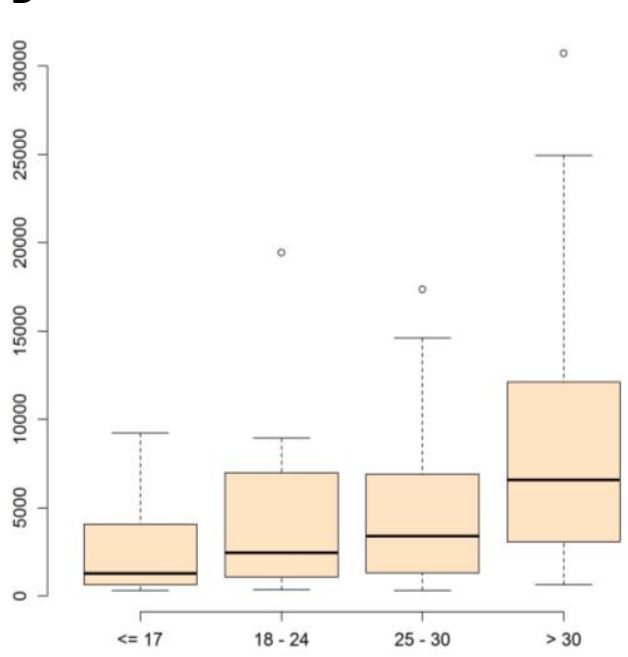

D

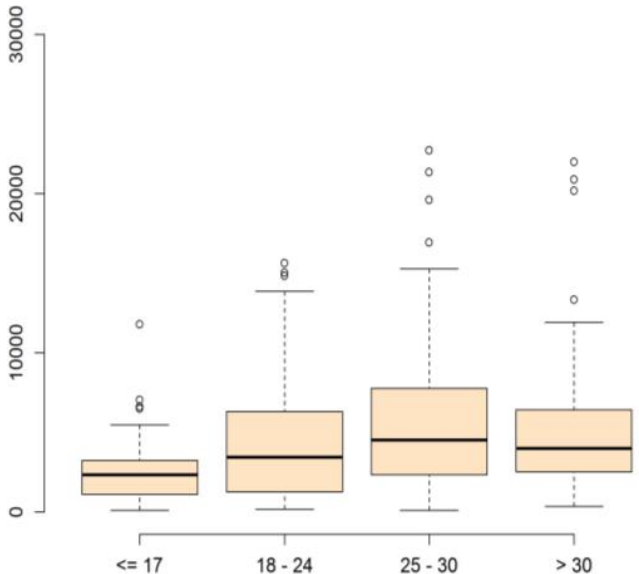

$\mathbf{F}$

GRÁFICO 15: A -- MEDIANA E QUARTIS DO CUSTO DO CUSTO TOTAL DIVIDIDO PELO GRUPO DE MELD $(p=0,614)$. B - MEDIANA E QUARTIS DO CUSTO EM INTERNAÇÃo DIVIDIDO POR GRUPO DE MELD $(p=0,748)$. $C$ - MEDIANA E QUARTIS DO CUSTO AMBULATORIAL DIVIDIDO POR GRUPO DE MELD $(P=0,02)$. $D$ - MEDIANA E QUARTIS DO CUSTO DOS HEMOCOMPONENTES UTILIZADOS DIVIDIDO POR GRUPO DE MELD ( $P=0,532)$. E - MEDIANA E QUARTIS DO CUSTO EM INTERNAÇÕES NO ICESP DIVIDIDO POR GRUPO DE MELD ( $P<0,001)$. $F$ - MEDIANA E QUARTIS DO CUSTO EM EXAMES LABORATORIAIS DIVIDIDO POR GRUPO DE MELD $(p=0,05)$ VALORES EM REAIS. 


\subsection{DETERMINAÇÃO dOS COST DRIVERS}

Foi realizada uma regressão logística para variáveis dicotômicas para determinação dos principais fatores preditivos para o alto custo em lista de espera para o transplante hepático. Para determinar os principais cost drivers fori realizado uma comparação entre grupos classificados como de alto custo e outro de baixo custo. Os grupos foram criados a partir do custo total divididos pelo terceiro quartil. A divisão pelo terceico quartil dos custo da amostra se mostrou mais robusta estatisticamente pois os valores encontrados pelo segundo quartil (mediana) teriam uma dispersão bastante elevada, com valores muito discrepantes.

Todas as variáveis contínuas e categóricas foram analisadas com o objetivo de verificar os principais recursos determinantes do alto custo em lista de espera. Foram realizadas análises de regressão logística simples para verificação dos principais fatores preditivos associados ao custo elevado em lista de espera e em seguida foi realizada análise de regressão múltipla determinando os principais cost drivers para o alto custo em lista de espera.

Os principais fatores preditivos para o alto custo em lista, agrupados pela análise univariada estão apresentados na tabela 20. 
TABELA 20: ANÁLISE UNIVARIADA DOS PRINCIPAIS FATORES DETERMINANTES DO ALTO CUSTO EM LISTA DE ESPERA PARA O TRANSPLANTE HEPÁTICO

\begin{tabular}{|c|c|c|c|c|}
\hline Fator & Estimativa & Dp & OR - IC (95\%) & $\mathbf{P}$ \\
\hline Internação & 2,693 & 0,362 & $14,78(7,27-30,04)$ & $<0,001$ \\
\hline MELD > 30 & 2,099 & 0,395 & $8,16(3,76-17,69)$ & $<0,001$ \\
\hline MELD 25-30 & 2,013 & 0,397 & $7,49(3,44-16,3)$ & $<0,001$ \\
\hline ECG & 2 & 1,178 & $7,39(0,73-74,36)$ & 0,09 \\
\hline Grupo Óbito & 1,562 & 0,31 & $4,77(2,6-8,75)$ & $<0,001$ \\
\hline Colonoscopia & 1,451 & 1,152 & $4,27(0,45-40,81)$ & 0,208 \\
\hline MELD 18-24 & 1,45 & 0,406 & $4,26(1,92-9,45)$ & $<0,001$ \\
\hline Colângiografia & 1,338 & 0,831 & $3,81(0,75-19,43)$ & 0,108 \\
\hline RFA & 1,124 & 0,562 & $3,08(1,02-9,26)$ & 0,045 \\
\hline TACE & 1,06 & 0,428 & $2,89(1,25-6,68)$ & 0,013 \\
\hline Holter & 0,74 & 0,246 & $2,1(1,29-3,39)$ & 0,003 \\
\hline RM & 0,726 & 0,252 & $2,07(1,26-3,39)$ & 0,004 \\
\hline Endoscopia SNE & 0,712 & 1,08 & $2,04(0,25-16,93)$ & 0,51 \\
\hline Número de dias em UTI & 0,396 & 0,089 & $1,49(1,25-1,77)$ & $<0,001$ \\
\hline Grupo Transplantado & 0,378 & 0,27 & $1,46(0,86-2,48)$ & 0,161 \\
\hline Tomografia computadorizada & 0,323 & 0,066 & $1,38(1,21-1,57)$ & $<0,001$ \\
\hline Diálises em UTI & 0,241 & 0,72 & $1,27(0,31-5,22)$ & 0,738 \\
\hline Utilização de Raios X & 0,202 & 0,068 & $1,22(1,07-1,4)$ & 0,003 \\
\hline Endoscopia com Biópsia & 0,193 & 0,27 & $1,21(0,71-2,06)$ & 0,475 \\
\hline Internação ICESP & 0,163 & 0,085 & $1,18(1-1,39)$ & 0,055 \\
\hline Atendimentos Enfermagem & 0,157 & 0,079 & $1,17(1-1,37)$ & 0,047 \\
\hline Biópsias & 0,135 & 0,051 & $1,14(1,04-1,26)$ & 0,008 \\
\hline Total de dias em internação & 0,12 & 0,016 & $1,13(1,09-1,16)$ & $<0,001$ \\
\hline Número de dias em enfermaria & 0,11 & 0,016 & $1,12(1,08-1,15)$ & $<0,001$ \\
\hline Número de consultas ICESP & 0,083 & 0,051 & $1,09(0,98-1,2)$ & 0,101 \\
\hline Atendimentos Enfermagem & 0,075 & 0,025 & $1,08(1,03-1,13)$ & 0,003 \\
\hline Endoscopia LEVE & 0,06 & 0,247 & $1,06(0,65-1,72)$ & 0,807 \\
\hline Paracenteses & 0,054 & 0,025 & $1,06(1,01-1,11)$ & 0,027 \\
\hline Atendimentos Nutrição & 0,052 & 0,071 & $1,05(0,92-1,21)$ & 0,467 \\
\hline Holter em internação & 0,048 & 0,016 & $1,05(1,02-1,08)$ & 0,003 \\
\hline Número de atendimentos médicos & 0,034 & 0,008 & $1,03(1,02-1,05)$ & $<0,001$ \\
\hline Atendimentos Serviço Social & 0,02 & 0,124 & $1,02(0,8-1,3)$ & 0,873 \\
\hline Atendimentos em Psicologia & $-0,003$ & 0,03 & $1(0,94-1,06)$ & 0,918 \\
\hline Hemoterapia & $<0,001$ & $<0,001$ & $1,05(1,01-1,06)$ & 0,003 \\
\hline Atendimentos Odontologia & $-0,009$ & 0,083 & $0,99(0,84-1,17)$ & 0,913 \\
\hline Ultrassom & $-0,028$ & 0,095 & $0,97(0,81-1,17)$ & 0,773 \\
\hline Endoscopia simples & $-0,098$ & 0,247 & $0,91(0,56-1,47)$ & 0,691 \\
\hline Número de Biópsias & $-0,504$ & 0,874 & $0,6(0,11-3,35)$ & 0,564 \\
\hline Grupo Removido & $-0,556$ & 0,35 & $0,57(0,29-1,14)$ & 0,113 \\
\hline Holter & $-0,614$ & 0,685 & $0,54(0,14-2,07)$ & 0,37 \\
\hline
\end{tabular}


Os fatores determinantes para o alto custo em lista de espera (Cost Drivers) estão apresentados na tabela 21.

Fatores relacionados ao grupo de MELD foram comparados com o MELD de referência $<=17$. Pacientes com MELD 25-30 tem 3,25 (225\%) vezes mais chance de tem um alto custo em lista e pacientes com MELD 18-24 tem 2,56 (156\%) mais chance de alto custo.

Os demais dados tem como referência o fator custo. Para cada real gasto com internações, aumentam em 5,48 vezes (448\%) as chances do paciente ter alto custo em lista. Para cada real gasto em RFAs aumentam em 1,47 vezes (47\%) as chances do paciente ter alto custo e para cada real gasto em hemoterapia aumentam em $0,35 \%$ as chances do paciente ter alto custo em lista de espera.

Como os valores gastos nestes procedimentos são da ordem de milhares de reais, as chances de alto custo destes pacientes são elevados.

TABELA 21. ANÁlise multivariada dos PRINCIPAIS FATORES DETERMINANTES do ALTO CUSTO EM LISTA DE ESPERA PARA O TRANSPLANTE HEPÁTICO.

\begin{tabular}{|c|c|c|c|c|}
\hline Fator & Estimativa & OR & $\mathrm{Cl} 95 \%$ & P-value \\
\hline Internação & 1,70239 & 5,48706 & $(2,55-11,79)$ & $<0,001$ \\
\hline MELD 25 - 30 & 1,18055 & 3,25618 & $(1,34-7,94)$ & 0,00945 \\
\hline MELD 18 - 24 & 0,94277 & 2,56708 & $(1,05-6,27)$ & 0,03862 \\
\hline MELD > 30 & 0,78203 & 2,1859 & $(0,88-5,46)$ & 0,09399 \\
\hline RFAs & 0,38761 & 1,47345 & $(1,11-1,96)$ & 0,00781 \\
\hline TACE & 0,06801 & 1,07038 & $(0,71-1,61)$ & 0,74264 \\
\hline Hemoterapia & 0,00035 & 1,00351 & $(1,11-1,17)$ & $<0,001$ \\
\hline
\end{tabular}




\section{DISCUSSÃO}

Trata-se do primeiro estudo de microcusteio, prospectivo, nacional, para análise de custos do paciente cirrótico em lista de espera para transplante hepático.

A principal contribuição científica do estudo é determinar os custos reais do paciente cirrótico listado para transplante hepático e tratado em hospital público no Brasil.

A determinação desses custos é de suma importância para organização de políticas públicas em saúde. O paciente cirrótico está envolvido num contesto que incluí desde programas de vacinação, como para hepatite B e programas de combate ao consumo de álcool; até políticas de financiamento de procedimentos de alta complexidade, como o transplante hepático, tratamento do carcinoma hepatocelular e o da hepatite C.

Determinando quais os fatores clínicos relacionam-se com maiores custos poderemos otimizar o financiamento dos transplantes hepáticos no Brasil. É possível que uma melhor seleção do doente seja fator determinante, ou então a melhora da técnica cirúrgica e dos cuidados clínicos pós-operatórios. Em um país onde os recursos para saúde pública são ainda limitados, é de suma importância determinar onde a aplicação dos mesmos resultará em maior impacto nos resultados de sobrevida.

Além disso, estamos desenvolvendo e aprimorando tecnologia para análise de microcustos hospitalares, através do desenvolvimento de software para coleta de dados. Assim, utilizamos ao máximo a informatização e a tecnologia para garantir determinações fidedignas de valores, otimizando a utilização de recursos humanos. O aprimoramento dessa tecnologia permitirá a replicação do método para análise de custos no SUS, baseados tanto em procedimentos como em diagnósticos. Dessa forma, torna-se possível realização de estudos de custo-efetividade e custo-eficiência baseados em dados nacionais, atualmente pouco disponíveis.

Os primeiros resultados mostram que o custo do tratamento do paciente cirrótico em lista de espera cresce juntamente com o aumento da gravidade do paciente, do tratamento das co-morbidades e internações. A progressão da doença pode ser lenta, com custos estimados pouco elevados e a maior parte dos atendimentos em nível ambulatorial, 
permanecendo o paciente em lista por longos períodos ou rápida, levando o paciente a um elevado número de internações, procedimentos ao elevado consumo de recursos hospitalares como exames, medicamentos, bolsas de sangue e consequentemente alto custo ou em lista.

O impacto econômico do paciente cirrótico em lista de espera tem grande importância para os gerenciadores de políticas públicas para saúde e para o equilíbrio financeiro do hospital ou centro de transplantes. Estes profissionais necessitam de informações sólidas a respeito dos custos desta doença, das progressões dos estados de saúde dos pacientes e todas as possíveis intervenções a que estes possam vir a requerer, em vista do possível impacto orçamentário que isto leva. Se subestimado, pode levar a crença errônea de que o paciente em lista exige poucos recursos, diminuindo o fluxo de investimentos no tratamento, ocasionando um aumento do tempo de espera e, consequentemente da gravidade destes pacientes.

Este balanço entre o custo do tratamento e as consequências da gravidade da doença e sua progressão são fundamentais para que possamos entender qual a melhor alternativa de tratamento, a melhor fase para que o transplante seja efetuado e o menor custo com melhor resultado clínico, ou seja a cura do paciente.

Os dados clínicos e demográficos dos pacientes que fizeram parte deste estudo foram bastante similares aos estudos abrangendo o transplante hepático. Observamos primeiramente que pouco menos de dois terços dos pacientes em lista de espera para o transplante hepático foram do sexo masculino, cerca de 34\% tiveram principal diagnóstico a hepatite $C$, seguido por cirrose alcoólica. O carcinoma hepatocelular como indicação do transplante foi o terceiro diagnóstico mais frequente, e o tempo de espera em lista foi de pouco mais de 12 meses. Embora alguns estudos mostrem maior frequência de cirrose de etiologia alcoólica como mais predominante, os dados encontrados em nosso estudo estão de acordo com a maioria dos dados publicados até o momento. ${ }^{102,164}$

O sexo masculino ser mais predominante é um dado bastante encontrado na literatura. Existem mais pacientes cirróticos masculinos, com grande predominância entre os de etiologia alcoólica. Vários trabalhos citam este dado, mesmo sem a devida discussão sobre este achado, sendo que podemos citar a exposição a fatores de risco como utilização de drogas ou maior quantidade de co-morbidades. ${ }^{68,69,127} \mathrm{Em}$ um amplo trabalho de Teh et al ${ }^{138}$, verificou-se que pacientes do sexo masculino tem entre $45 \%$ e $79 \%$ maior probabilidade de 
complicações e risco de morte do que pacientes do sexo feminino. Silveira et al ${ }^{101}$, em um estudo nacional encontrou $85 \%$ de pacientes do sexo masculino em lista de espera para o transplante hepático.

Apesar da quase inexistência de estudos com pacientes cirróticos em lista de espera, observamos que, com relação à frequência de internações, encontramos dados que mostram que mais da metade dos pacientes em nosso trabalho necessitou de ao menos uma internação durante o período do estudo, sendo que o período médio foi de aproximadamente 20 dias de internação se considerarmos múltiplas internações somadas

Como previsto em nossa metodologia, a formação dos grupos pelo desfecho foi sendo feita de acordo com a evolução clínica do próprio paciente. Após os 24 meses de acompanhamento, pouco mais de um quarto dos pacientes foram chamados ao transplante hepático. Os três quartos restantes não chegaram ao transplante e permaneceram em lista, foram removidos ou faleceram.

Segundo dados internacionais sobre número de transplantes efetuados e o número de pacientes ativos em listas de espera, observamos que há um número cada vez maior de pacientes em lista, porém, dados observados nos maiores centros de informação sobre o transplante hepático como OPTN e Eurotransplant mostram uma taxa de cerca de $40 \%$ a $45 \%$ de pacientes transplantados, dados que estão acima dos dados encontrados em nosso estudo. $11,88,89$

O tempo de espera, de cerca de pouco mais de um ano está de acordo com dados internacionais de agências de transplantes hepáticos, porém, em nosso estudo há um corte no seguimento acompanhado com 24 meses, o que pode ser um viés que deverá ser, futuramente melhor avaliado. ${ }^{87,89,97}$

A maior parte dos pacientes permaneceram em lista de espera e cerca de $15 \%$ faleceram durante este período. Segundo alguns estudos já publicados, a mortalidade em lista é de cerca de $21 \%$ a $25 \% .{ }^{165}$ Fink et al ${ }^{94}$, encontraram um mortalidade de apenas $10,2 \%$ utilizando dados da UNOS entre 1988 e 2004. Os dados encontrados neste estudo mostram uma mortalidade em lista menor, porém seguindo a tendência encontrada em todos os estudos acerca de pacientes cirróticos, em lista ou transplantados com o número de óbitos crescente na medida da gravidade do MELD. Em um estudo nacional de Nader et al ${ }^{166}$, foi 
encontrada uma mortalidade em lista de espera de $41,5 \%$ e segundo dados internacionais observados por Merion et $a^{161}$, esta taxa varia segundo o score de MELD.

Observamos também uma diferença na formação dos grupos de desfecho com relação a idade e valor de MELD. Não esperávamos observar diferença significativa com relação ao sexo dos pacientes pois todos foram alocados em lista da mesma maneira, porém, encontramos uma grande quantidade de pacientes do sexo masculino nos pacientes que faleceram em lista e uma maior quantidade de pacientes do sexo feminino que foram removidas da lista de espera. Os grupos de pacientes que chegaram ao transplante ou que permaneceram em lista tiveram proporções semelhantes entre si com relação à quantidade de homens e mulheres.

O tempo de espera em lista foi heterogêneo entre os grupos. Encontramos em nosso estudo um tempo que variou entre 170 e 450 dias de espera. Os pacientes que permaneceram em lista por todo o estudo ficaram mais tempo em lista, como esperado, seguido pelos pacientes que foram removidos. A literatura, apesar de dados escassos, mostra um tempo de espera ao redor de um ano até o transplante hepático, mas em nosso estudo, o paciente que chegou até o transplante levou aproximadamente metade deste tempo, cerca de 170 dias. $^{20,95,96}$

A formação dos grupos de acordo com o escore de MELD foi bastante heterogênea. Observamos que o tempo de espera até o transplante foi menor no grupo com maior valor de MELD do que o grupo intermediário. Isto está de acordo com a prática clínica, e o esperado universalmente. Porém, observamos que o tempo de espera em dias até o transplante no grupo de menor MELD funcional foi bastante baixo. Analisando detalhadamente as planilhas de dados deste estudo, houveram somente 6 pacientes transplantados neste grupo, sendo que o menor tempo foi de 3 dias e o maior de 236 dias, com os demais 4 pacientes com tempo menor que 30 dias. Dois pacientes foram transplantados com doadores vivos (parentes doadores) e um deles foi diagnosticado com hepatite autoimune, sendo transplantada em 11 dias. As demais diferenças de tempo de transplante podem ter ocorrido devido ao paciente pertencer aos grupos sanguíneos $B$ ou $A B$.

O tempo de remoção, óbito e espera em lista está de acordo com o esperado. Pacientes mais graves permanecem menos tempo em lista de espera, o mesmo ocorreu com 
os menos graves, pois são excluídos. Pacientes com MELD intermediário permanecem longo período em lista.

A frequência dos diagnósticos das etiologias entre os pacientes divididos pelo grupo de desfecho foi bem homogênea com relação à cirrose por vírus $C$ e alcoólica. A hepatite relacionada ao vírus $\mathrm{C}$ ainda é predominante nos pacientes transplantados, seguido pelos pacientes com carcinoma hepatocelular e cirrose alcoólica. Importante observar que a cirrose de etiologia alcoólica supera a cirrose por vírus $C$ entre os pacientes removidos e os que faleceram em lista. Estes dados confirmam alguns dados internacionais que mostram que a cirrose alcoólica já está superando a cirrose por vírus $C$ em alguns países. ${ }^{10,11,167}$

Observamos também que o diagnóstico de hepatocarcinoma esteve significativamente mais presente nos pacientes que foram transplantados. Segundo classificação pelo Critério de Milão estes pacientes ganham pontos na classificação por MELD e desta maneira são chamados mais rapidamente para o transplante. Cerca de um quarto dos pacientes transplantados foram diagnosticados com o $\mathrm{CHC}$, sendo este dado possivelmente um dos fatores que auxiliaram na redução do tempo de espera destes pacientes. De fato, pacientes com o carcinoma hepatocelular tem o tempo de espera abreviado, e contam um quadro clínico mais favorável, resultando em um bom prognóstico pós-transplante.

Os atendimentos ambulatoriais somaram quase $11 \mathrm{mil}$ atendimentos aos 492 pacientes em lista de espera durante os 24 meses deste estudo. Como esperado, os pacientes que permaneceram mais tempo em lista realizaram mais atendimentos em geral. Neste grupo também houve uma maior quantidade de atendimentos no ICESP, onde verificamos que, parte dos pacientes removidos da lista foi diagnosticado com o $\mathrm{CHC}$, tendo melhora do estado de saúde

Foram realizados no total aproximadamente 4 mil exames de imagem, mais de mil tomografias, quase 800 biópsias e mais de 400 endoscopias. Analisando os grupos entre si, observamos que a utilização deste tipo de recurso foi bastante desigual. Os pacientes que permaneceram em lista representam quase $37 \%$ do total de pacientes e realizaram mais de $54 \%$ do total de exames. Os pacientes transplantados representam quase $28 \%$ dos pacientes, mas utilizaram $22,5 \%$ do total de exames, seguido pelos pacientes removidos que somaram $21,3 \%$ e utilizaram menos de $5 \%$ do total de exames e pelos pacientes que faleceram, que foram menos de $14 \%$ do total de pacientes, mas que utilizaram cerca de $18 \%$ dos exames. 
Observamos da mesma maneira, uma heterogeneidade na frequência de utilização dos exames realizados. Os pacientes dos grupos transplantados e removidos realizaram significativamente mais biópsias do que os pacientes dos outros dois grupos de desfecho, ao passo que estes últimos realizaram mais tomografias do que os primeiros. Da mesma maneira os pacientes dos grupos óbito e lista também realizaram mais exames de ressonância magnética e raios $X$ dos que os demais grupos.

Mais da metade dos pacientes, quase $60 \%$, tiveram a necessidade de internações. Do total de 492 pacientes, 277 necessitaram de internações durante todo o período, representando $57,47 \%$ do total de pacientes participantes deste estudo.

O número total de internações entre os grupos seguiu a tendência já observada com relação à quantidade de exames. O grupo mais numeroso, dos pacientes que permaneceram em lista realizou mais internações, 190 no total, seguido pelos pacientes transplantados, com 113, pelos pacientes do grupo óbito, com 98 e, por último os pacientes removidos, com 33 internações no total.

Porém, observamos uma grande heterogeneidade na frequência de internações entre os pacientes dos 4 grupos estudados. Do total de pacientes do grupo óbito mais de $85 \%$ tiveram a necessidade de realizar uma ou mais internações, ao passo que, dentre os grupos dos pacientes transplantados e em lista, houve uma distribuição quase igualitária entre internados e não. Já os pacientes que foram removidos da lista de espera, somente cerca de 15\% tiveram necessidade de internações, muito provavelmente aqueles que foram excluídos por piora do quadro clínico.

Em relação às transfusões, foram mais de 1600 bolsas de hemocomponentes utilizadas, somando-se todos os tipos verificados neste tudo. Observamos, neste dado uma expressiva utilização de hemocomponentes pelo grupo dos pacientes que vieram a óbito. Mais de $65 \%$ do total de bolsas de hemocomponentes foram utilizadas pelos pacientes deste grupo. Os outros grupos utilizaram entre $9 \%$ e $14 \%$ deste recurso. A média de bolsas de sangue e hemocomponentes foi de mais de 18 por paciente no grupo óbito, ao passo que os demais grupos tiveram utilização entre 3 e 10 vezes menor, somando-se todas as internações. Analisando especificamente o grupo óbito e observando atentamente os dados referentes a gravidade e quantidade de internações deste grupo podemos verificar uma maior quantidade de ocorrências que demandam transfusões sanguíneas como HDA, diálises e infeções. 
Da mesma maneira que a avaliação da frequência de utilização dos hemocomponentes, durante o período de estudo dos pacientes em lista, verificamos a presença de muitos pacientes diagnosticados com o carcinoma hepatocelular. Foi obtido todas as internações e o número de realizações de procedimentos como quimioembolização (TACE) e ablação por radiofrequência (RFA) ou internações por outros motivos como procedimentos cirúrgicos ou reserva de sangue e plaquetas.

Como já esperado, do total de 83 pacientes diagnosticados com o $\mathrm{CHC}$, quase a metade (48\%) pertenceu ao grupo chamado ao transplante. Deste total de pacientes diagnosticados com o CHC, 50 pacientes foram chamados para internações no ICESP, perfazendo um total de 283 internações neste hospital.

O maior número de internações foi para reserva de plaquetas e sangue do próprio paciente ou outros procedimentos, cerca de $70 \%$ do total de internações. Verificamos que, das 283 internações no ICESP, a frequência de utilização de recursos como TACE e RFA foi bastante similar e equivalente entre os grupos, sendo aproximadamente $20 \%$ para a Quimioembolização (TACE) e 10\% para a ablação por radiofrequência (RFA). Estes dados são importantes, causando um grande impacto nos custos destes doentes, o que veremos mais à frente.

Analisando a formação dos grupos pelo MELD, pudemos verificar as maiores diferenças ou heterogeneidades entre os pacientes dos quatro grupos formados. A categorização por grupo de MELD seguiu a divisão por quartis, não havendo consenso entre as divisões encontradas em outros trabalhos na literatura. Segundo a maioria dos trabalhos, os pacientes são divididos em dois ou três grupos, sendo feitas comparações entre estes. ${ }^{123,168,169}$

Com relação a formação dos grupos, dos 60 pacientes do grupo com MELD <=17 (mais de $45 \%)$ e 64 (48\%) foram pacientes removidos e que permaneceram em lista, respectivamente. Isto está de acordo com as normas seguidas para pacientes em lista vigentes atualmente.

O grupo dos pacientes com MELD entre 18 e 24 foi formado preponderantemente por indivíduos que permaneceram em lista (48\%), seguido por pacientes removidos (19\%). Isto reflete a realidade da lista de espera, pois estes dois primeiros grupos, abrangem pacientes em faixa intermediária de MELD, sendo que alguns destes já obtiveram acesso ao transplante, mesmo com índices menos elevados de MELD. 
No grupo de maior gravidade, formado por pacientes com MELD acima de 30, quase $50 \%$ dos pacientes chegaram ao transplante, porém $40 \%$ faleceram, seguido pelos pacientes que foram removidos e que permaneceram em lista com menos de $5 \%$ do total.

Analisando estas informações, percebemos que os pacientes chamados ao transplante têm, em geral, elevados valores de MELD e, conforme o valor do MELD dos pacientes vai se elevando também se eleva a porcentagem de pacientes que vem a óbito durante o período de espera em lista. Ferraz-Neto et al ${ }^{102}$, em um estudo nacional chegou a resultados semelhantes, em que observou um maior número de óbitos entre pacientes com maior escore de MELD.

O tempo de espera também refletiu a formação dos grupos segundo critérios de valores de MELD. O grupo de menor MELD teve um tempo de espera abaixo da média observada em estudos internacionais, devido a maior quantidade de pacientes removidos (56\%). O grupo de MELD mais elevado, teve tempo de espera menor do que todos os demais grupos (236 dias), provavelmente pela maior participação de pacientes chamados ao transplante (42\%). Os pacientes com faixa de MELD intermediária permaneceram em média mais tempo em lista que os demais grupos, com predominância de pacientes que permaneceram em lista e pacientes removidos.

Com relação ao diagnóstico das hepatopatias, observamos dados bastante semelhantes entre os 4 grupos de MELD mais elevado, ao contrário do observado no grupo de MELD mais baixo.

No grupo de MELD mais baixo observou-se que a cirrose de etiologia alcoólica foi diagnosticada em aproximadamente $40 \%$ dos pacientes, seguida da cirrose por vírus C com $22 \%$ dos diagnósticos. Nos demais grupos de MELD o principal diagnóstico foi a cirrose por vírus C, com frequência entre 24 e 18\%, seguidos pelo diagnóstico de cirrose alcoólica com 16\%. Apenas no grupo dos pacientes com MELD entre 25 a 29 o diagnóstico de VHC somado ao CHC foi o segundo mais diagnosticado, com pouco mais de $18 \%$, sendo a cirrose alcoólica o terceiro diagnóstico mais frequente com pouco mais de $12 \%$.

Com relação ao número de consultas ambulatoriais, observamos dados bastante semelhantes entre os 4 grupos com relação à frequência de utilização, mas com número de consultas bastante diferentes com relação as quantidades em cada especialidade. Houveram mais de 3000 consultas nos grupos de MELD entre 18 e 24 e MELD 25 a 30, porém nos grupos 
de MELD mais baixo e mais alto este número foi de aproximadamente 2000 consultas no total. Analisando estes dados junto com o tempo de permanência em lista, encontramos que pacientes que ficaram menos tempo em lista realizaram um número menor de consultas.

Em relação às internações, encontramos as maiores diferenças entre os grupos estudados. Observamos claramente uma maior frequência de internações entre os pacientes dos grupos de MELD mais elevado, ao redor de $78 \%$ dos pacientes destes grupos necessitaram de internações, contra cerca de $68 \%$ dos pacientes dos grupos de menor MELD. Com relação ao tempo de internação foi observado que os pacientes do grupo de maior MELD tem um tempo $62 \%$ maior de permanência do que os pacientes do grupo de menor MELD (14,1 dias e 8,7 dias respectivamente). 0 mesmo foi observado com relação ao tempo de permanência em UTI e em enfermaria (92\% e 46\% respectivamente). Estes dados estão em conformidade com os encontrados em outros estudos correlacionando a escala de MELD com a frequência de internações. ${ }^{170}$

Por outro lado, observamos uma grande similaridade entre os motivos que levaram os pacientes em lista a internar, entre os diagnósticos da internação e entre os procedimentos realizados durante este período, independente do MELD do paciente e do grupo.

Mais uma vez observamos uma grande diferença entre os recursos em hemocomponentes utilizados pelos pacientes com MELD mais elevado em relação aos demais grupos de pacientes.

No total, foram utilizados 1630 bolsas de hemocomponentes por todos os pacientes deste estudo, sendo que aproximadamente $58 \%$ de todos os hemocomponentes foram utilizados pelos 115 pacientes do grupo com MELD mais elevado, ao passo que os pacientes do grupo com menor MELD utilizaram menos de $5 \%$ das bolsas de hemocomponentes verificados neste estudo. Poucos estudos abordaram os custos deste tipo de recurso relacionados aos pacientes cirróticos. Não existem dados relativos ao consumo de hemocomponentes em pacientes em lista de espera. Coelho et al ${ }^{141,154}$, em dois estudos nacionais sobre os custos do transplante hepático, cita que os hemocomponentes foram os recursos mais custosos de todo o tratamento, com grande diferença entre a quantidade de bolsas utilizadas entre os pacientes mais e menos graves.

Com relação ao paciente portador do carcinoma hepatocelular, obtivemos acesso aos dados dos 83 pacientes diagnosticados com $\mathrm{CHC}$ que foram atendidos no ICESP. Como era 
esperado, mais de $50 \%$ destes pacientes estão no grupo dos pacientes com MELD entre $25-30$ e quase $30 \%$ no grupo de MELD mais elevado, ou seja, aproximadamente $80 \%$ dos pacientes com CHC estão nos grupos de maiores valores de MELD. Internações para reserva de plaquetas ou diagnósticos, que colocamos como "outros motivos" foram a maioria entre os grupos, porém, em todos os grupos internações para o procedimento de quimioembolização (TACE) e abração por radiofrequência (RFA) tiveram frequência de $20 \%$ e $8 \%$ respectivamente.

Analisando os dados de pontuação especial a que estes pacientes se enquadram observamos que os dados deste estudo estão de acordo com o que a literatura mostra, tanto em valores médios de MELD quanto aos procedimentos realizados, o que irá refletir em relação aos custos, o que veremos adiante. 


\subsection{DiSCUSSÃO DA ANÁLISE DE CUSTO}

O objetivo principal deste estudo foi, desde o início, a análise do custo total do paciente cirrótico. Toda a análise do número de procedimentos e recursos consumidos foi realizada para a tomada de parâmetros numéricos e estimativas de valores unitários, dados estes que levam ao valor total utilizado em cada um dos 492 pacientes avaliados.

Este estudo, inédito com relação a metodologia de microcusteio oferece dados primários que permitem, pela primeira vez, algumas comparações com estudos já efetuados, porém com outras metodologias, nacionais e internacionais.

Há uma quase inexistência de estudos de avaliação econômica do paciente cirrótico em lista de espera e, dos poucos trabalhos encontrados, a quase totalidade dos estudos estabelecem um objetivo bem limitado para verificação dos gastos.

Os estudos em avaliação econômica do paciente cirrótico abordam períodos limitados como a estimativa de custos da internação, de um determinado procedimento ou da utilização de um medicamento, e, além disso, utilizam dados secundários como banco de dados de agências de saúde ou de assistência de saúde complementar. ${ }^{46}$

Embora existam inúmeras metodologias de análise de custos, o que não é o foco deste trabalho, muitos estudos abordam apenas um pequeno número de fontes de recursos como estimativa dos gastos dos pacientes ou utilizam modelos dinâmicos para análises futuras a partir de dados atuais, o que é extremamente útil para analisar o impacto de alternativas de tratamento ou o custo futuro da doença hepática avançada descompensada, mas que pecam por não investigarem dados primários como dados de microcusteio. ${ }^{135,171,172}$

Alguns estudos abordam o tempo de internação a que o paciente cirrótico é submetido e, dentro da internação estimam os gastos destes pacientes pela divisão dos custos deste setor pelo número de pacientes. ${ }^{116}$ Segundo um trabalho pioneiro de Brand et al ${ }^{126}$, mais de $40 \%$ do custo total do paciente cirrótico transplantado se deu ao pré-transplante, ou seja, os custos referentes ao período em lista de espera.

Outros estudos abordam especificamente os custos de determinados procedimentos ou complicações decorrentes do VHC ou do $\mathrm{CHC}$, alcoolismo ou doenças relacionadas à 
hepatopatia. ${ }^{31,131}$ Guirguis et $a l^{11}$, abordaram os custos da cirrose de etiologia alcoólica nos EUA em gastos gerais com atendimentos hospitalares em valores relativos aos gastos anuais orçamentários do país, e não valores por paciente.

Com relação a causa da doença hepática, para o VHC e o CHC existem mais trabalhos na literatura, a grande maioria abordando complicações e tratamentos, e poucos com enfoque em custos e análises econômicas. ${ }^{50,126}$ Outros estudos analisam os custos crescentes dos pacientes, na maioria portadores do VHC, de acordo com a gravidade do quadro clínico, MELD e complicações, com uma perspectiva de crescimento destes gastos da ordem de $60 \%$ até 2032. ${ }^{4,116}$

A perspectiva do estudo também é fator de interesse. Neste estudo a perspectiva do enfoque foi o custo do hospital como pagador do atendimento ao paciente. Em muitos estudos internacionais observamos um enfoque relacionado com o sistema saúde complementar, e este como fornecedor dos valores dispendidos. Poucos estudos permitem uma análise da perspectiva diferente dos sistemas ligados a saúde complementar ou fontes governamentais. ${ }^{11,31,126}$

Também encontramos estudos nacionais com a tentativa de abordar o custo do paciente cirrótico, utilizando outras metodologias e um reduzido número de pacientes. Estes estudos utilizaram dados de repasse SUS para análise dos custos, e foram realizados de maneira retrospectiva. ${ }^{56,140,141}$

Mais de 14 milhões de reais foram gastos com os 492 pacientes estudados durante 24 meses. O custo do paciente cirrótico foi de aproximadamente 29 mil reais, mas o desvio padrão foi de mais de 31 mil reais, ou seja, há uma heterogeneidade de valores entre os pacientes.

Analisando a distribuição dos pacientes em lista, verificamos que a grande maioria dos pacientes tiveram gastos menores que 20 mil reais durante o período em lista de espera, porém, poucos pacientes foram responsáveis por gastos extremamente altos, alguns chegando a cerca de 200 mil reais.

Vonlanthen et $a l^{50}$, em um estudo com 1200 pacientes, observaram um custo de cerca de 15 mil dólares com o tratamento da fibrose hepática em pacientes sem complicações, 
chegando até mais de 150 mil dólares com pacientes mais grave, com múltiplas complicações e internações.

Um achado muito importante é a porcentagem de gastos com recursos humanos. Classicamente na literatura encontramos dados que mostram um alto custo da mão-de-obra médica em países mais desenvolvidos, em contraste com um gasto percentualmente mais baixo em países menos desenvolvidos.

Encontramos um gasto com recursos humanos da ordem de $23 \%$, sendo que em internações este valor superou um quarto do custo total. Dados internacionais, apesar de escassos mostram um comportamento semelhante. Gastos com recursos humanos compreendem a maior porcentagem dos custos destes pacientes na maioria dos trabalhos. McAdam et $a l^{4}$, encontraram valores entre 8.300 e 17.000 dólares com honorários médicos por ano de tratamento com o paciente cirrótico descompensado por vírus $\mathrm{C}$, representando entre $20 \%$ a $35 \%$ do custo total.

Percebemos uma transição neste tipo de gasto em nosso estudo. Os gastos com recursos humanos corresponderam a cerca de $32 \%$ dos gastos em média nos Estados Unidos e a cerca de $44 \%$ nos países da OCED em $2004 .{ }^{173}$. Um estudo italiano mostrou que recursos humanos representaram $23 \%$ dos custos totais de um transplante hepático, ao passo que, dois estudos com transplante hepático e gastos hospitalares, em hospital público do estado do Ceará identificou apenas $15 \%$ de gastos com recursos humanos em relação ao custo total por paciente. ${ }^{174-176}$

Dentre os recursos utilizados, observamos que os medicamentos corresponderam a mais de $26 \%$ dos custos, sendo que este valor corresponde a soma de todos os exames, de imagem e laboratoriais não chegou a $23 \%$ do total gasto com os pacientes em lista. 0 custo das internações foi equivalente a mais de $70 \%$ do total gasto. Gordon et $a l^{23}$, encontrou dados bastante semelhantes ao observados neste estudo com relação aos custos de internação. A gravidade influi diretamente nos custos, principalmente nos custos em internações, onde corresponde a aproximadamente $62 \%, 38 \%$ e $33 \%$ respectivamente entre os pacientes mais e menos graves.

Os valores gastos com as internações dos pacientes que vieram a óbito foram além do dobro dos demais pacientes, o mesmo se refletindo com relação ao custo por dia de internação, cerca de 50\% maior. Brand et al ${ }^{126}$, citam gastos em torno de US\$ 1100.00 por dia 
de internação, sendo que os valores obtidos neste estudo, convertidos para o dólar corrente no encerramento do levantamento dos custos seria de aproximadamente de 500 dólares e de, 815 dólares nos pacientes que faleceram.

Verificamos que os pacientes que faleceram em lista foram mais custosos que os demais pacientes em praticamente todos os recursos utilizados, exigiram mais dias de internação, utilizaram mais medicamentos, hemocomponentes, exames laboratoriais e de imagem e tiveram o desfecho mais desfavorável. Apenas em atendimentos ambulatoriais estes pacientes não tiveram os maiores gastos. Ou seja, foram pacientes que já entraram em lista com um quadro clinico mais grave, passando logo por períodos de tempo variáveis de internação, de maneira geral prolongado, com evolução a óbito ao final deste período

Dados semelhantes com relação aos valores crescentes desembolsados com os pacientes mais graves segundo o critério do desfecho observado foram encontrados analisando-se os dados dos pacientes agrupados por grupo de MELD. Neff et $a l^{31}$, mostraram dados similares, com acréscimo de valores gastos com o aumento da gravidade dos pacientes.

Verificamos que, pacientes com quadro clínico menos grave, ou seja, com MELD mais baixo tiveram um custo total por paciente menor, pouco mais de 12 mil reais ao longo dos 24 meses de estudo. $\mathrm{O}$ oposto aconteceu com o grupo de pacientes com valores de MELD acima de 25 . O custo médio por paciente foi mais do que o triplo do primeiro grupo, mais de 36 mil reais ao longo do período do estudo e cerca de 10 mil reais a mais do que os pacientes pertencentes ao grupo de MELD entre 18-24. Habka et al ${ }^{172}$, encontraram valores entre 49 mil dólares para os pacientes menos graves em lista de espera até 613 mil dólares para pacientes com MELD acima de 40. Este quadro mostra que, os custos totais no Brasil são bastante inferiores aos custos internacionais, levando-se em consideração a diferença entre os estudos e a perspectiva.

Observamos que os custos de internação foram todos acima de 20 mil reais, chegando a mais de 35 mil reais no grupo de maior MELD, com o custo da internação/dia ao redor de 2 mil reais. Um dado que mostrou grande variação de custo foram medicamentos e hemocomponentes. Os pacientes de MELD menor ou igual a 17 tiveram um custo, em média de pouco mais de 4 mil reais em medicamentos, porém, os pacientes com MELD maior que 30 tiveram um custo em medicamentos acima de 12 mil reais, ou seja, três vezes mais. 
O mesmo ocorreu com os custos dos hemocomponentes, mais sensíveis a gravidade do quadro clínico, principalmente em internações. Este foi um item onde houveram grandes diferenças de custo entre os pacientes menos graves, com gastos inferiores a 3 mil reais e os pacientes mais graves, com gastos superiores a 8 mil reais. Como já citado com relação à quantidade de hemocomponentes utilizados, os dados de custos foram similares a alguns estudos nacionais abordando a quantidade e os custos dos hemocomponentes utilizados.

Coelho, et al ${ }^{140,141}$, citam em dois trabalhos que hemocomponentes foram os itens mais custosos em seu estudo abordando o custo do transplante hepático. Interessante notar que, semelhante a outros estudos já mencionados, Cacciarelli et $a{ }^{177}$, citam que quanto maior a gravidade do paciente com hepatopatia, maior a quantidade de bolsas de sangue utilizadas em internações e pior a sobrevida, dados igualmente observados em nosso trabalho.

Um dos itens deste estudo que também mostrou um forte acréscimo ao custo total do paciente cirrótico foram os atendimentos realizados no ICESP. Diferentemente da quase totalidade dos itens de custo, em que pacientes com maiores valores de MELD tiveram um custo médio maior, na avaliação dos custos dos pacientes com $\mathrm{CHC}$, aqueles com MELD elevado não tiveram os maiores custos. O maior custo com estes pacientes foi observado naqueles com MELD entre 18-24, resultado principalmente do maior número de internações no ICESP para procedimentos incluindo TACE e RFAs.

O resultado é um custo quatro vezes maior do que pacientes do grupo de menor MELD e 30\% maior do que pacientes com MELD acima de 30. Este fato está efetivamente relacionado à pontuação especial destes pacientes aliado a uma condição clínica menos grave. Analisando os critérios estabelecidos e seguidos por este hospital para atendimento ao paciente portador do carcinoma hepatocelular, verificamos que estes pacientes têm seus valores de MELD acrescidos em pontos devido a este diagnóstico.

Os custos do paciente cirrótico com carcinoma hepatocelular em lista de espera ainda não foram bem estudados. Existem estudos abordando variáveis ligadas ao custo, principalmente em medicamentos ou tratamentos adjuvantes e poucos com pacientes em lista de espera. Vitale et al ${ }^{178}$, citam em um estudo com avaliação de medicamentos o custo de mais de 22 mil euros em cinco meses de tratamento no pré transplante hepático. Lim et al ${ }^{179}$, em um interessante estudo de custos em pacientes com hepatocarcinoma encontrou o custo do tratamento com quimioembolização nos Estados Unidos, Suíça e Singapura variando entre 
US\$ 39 mil e US\$ 100 mil, valores muito superiores ao encontrados neste estudo. Llovet et al ${ }^{135}$, em um outro estudo envolvendo o tratamento medicamentoso e cirúrgico encontrou um custo de US\$ 27 mil dólares no primeiro ano de atendimento a pacientes com hepatocarcinoma em lista de espera.

Encontramos em nosso estudo um custo total reduzido no atendimento ao paciente com carcinoma hepatocelular, apesar deste tratamento ser elevado, com relação ao custo total. Isto sugere que estes pacientes tem um comportamento de custo diferente dos demais pacientes diagnosticados com outras hepatopatias como VHC ou cirrose alcoólica. Estudos abordando seletivamente este grupo de pacientes podem esclarecer com mais detalhes a progressão da doença hepática e dos custos destes pacientes.

Este estudo mostra de maneira bastante objetiva, dados primários que podem ser analisados e dar suporte a múltiplos estudos envolvendo os custos do paciente cirrótico em hospital público de grande porte. 


\subsection{DISCUSSÃO DA REGRESSÃO LOGÍSTICA}

Um dos pontos de maior interesse neste estudo foi a análise de regressão logística. A busca pelos principais fatores que levam ao alto custo de qualquer tratamento, seja ele clínico ou cirúrgico é algo de grande importância nos dias atuais. Dada a enorme complexidade que envolveu todo este estudo seria impossível predizer quais seriam os principais itens que teriam maior peso na composição dos custos totais em lista de espera para o transplante hepático.

Foi feita a opção, desta maneira, de inserir e classificar praticamente todos os itens e recursos utilizados pelos pacientes em lista e assim, ter uma compreensão ampla e objetiva da estimativa de impacto que cada fator causa, com seu intervalo de confiança.

A literatura já havia descrito o elevado custo de internação para o tratamento de diversas doenças ligadas a fibrose hepática e outras doenças hepáticas avançadas, porém, em nosso estudo observamos que o fator internação tem um intervalo de confiança entre 7 e 30, ou seja, pacientes que internam tem pelo menos sete vezes mais chance de ter um custo mais elevado do que pacientes que não necessitam de internações.

Valores de MELD mais elevado também seguiram os mesmos resultados observados nos dados de internação. Os pacientes do grupo de MELD entre 25-29 e acima de 30 tem três vezes mais chance de ter custos mais elevados do que os pacientes com menores valores de MELD.

A utilização de hemocomponentes também mostrou um elevado impacto no custo total de cada paciente, porém isto não foi observado na análise de regressão logística. Diferentemente do esperado, o impacto da utilização deste recurso foi pequeno, com apenas $6 \%$ de chance dos pacientes que utilizaram este recurso estarem entre os pacientes com maior custo.

Este dado é importante pois a reposição de hemocomponentes é um item extremamente importante e muito caro, porém, como visto neste estudo não causa um alto impacto nos custos do atendimento e talvez até possa prevenir o óbito do paciente ou problemas maiores (e mais custosos), podendo e devendo ser utilizado sempre que necessário. A análise dos pacientes que utilizaram hemocomponentes e seus desfechos é um dado que deve ser melhor abordado em outros estudos. 
Sem levar em consideração os valores de gravidade averiguados pelo escore de MELD, observamos dados muito interessantes e ao mesmo tempo preocupantes. Pacientes que vieram a óbito durante o período em lista de espera tiveram 2,6 vezes aumentados os custos totais. Este dado é bastante importante e deve ser melhor investigado, principalmente nos fatores que levaram a óbito estes pacientes, qual o seu perfil etiológico e quais foram os principais procedimentos utilizados por estes pacientes. Verificamos que os custos do paciente que faleceu em lista são altos, com alto índice de internações e utilização de recursos, porém sem retorno do paciente para a sociedade, para o trabalho ou para a vida ativa.

Apesar do paciente diagnosticado com o CHC não estar entre os fatores que levam a um custo elevado em lista, encontramos que pacientes que realizaram os procedimentos de RFAs e TACE tiveram a chance de ter custo elevado em lista de até 9 e 6 vezes mais do que pacientes sem este procedimento, respectivamente. Novamente observamos que o paciente com $\mathrm{CHC}$ tem um custo elevado nestes procedimentos, mas um custo não tão elevado no total, sendo este um assunto que deve ser melhor esclarecido e aprofundado em outros estudos.

Interessante notar que alguns itens que tem custo extremamente elevado como diálises em internação, tomografias ou paracenteses não tiveram um impacto elevado nos custos totais dos pacientes que utilizaram estes recursos. Destes descritos, diálises em UTI tem um custo acima de 3 mil reais, porém o nível de utilização foi pequeno, não tendo grande impacto no custo total do paciente que utilizou este recurso. Pacientes que realizaram tomografias e paracenteses tiveram uma chance de ter custo elevado em lista de 1,2 e 1,01 respectivamente.

Após análise da regressão simples foi feito nova análise utilizando-se os mesmos fatores e estes foram agrupados segundo importância no custo total. A regressão logística múltipla mostrou os Cost Drivers, os principais fatores que causam alto custo em lista de espera para o transplante hepático. Internações, MELD 25-30, ablação por radiofrequência (RFAs) e hemoterapia tem papel de destaque nesta análise.

Isto nos mostra que pacientes com MELD elevado, com $\mathrm{CHC}$, com alto risco para internações e com elevada chance de utilização de bolsas de sangue e seus derivados tem uma tendência alta a ter um custo elevado em lista de espera para o transplante hepático. 
A importância deste estudo se baseia no impacto financeiro que o paciente em lista de espera exerce. Em um país com sérias restrições orçamentárias em saúde faz-se cada vez mais necessário o amplo conhecimento de todos os custos intrínsecos e extrínsecos utilizados na atividade de levar a saúde ou seu tratamento ao paciente.

Muitos estudos ainda devem ser feitos e amplas possibilidades surgem. Nosso país necessita urgentemente de pesquisas em Economia da Saúde

A busca não se baseia no corte de gastos, na economia de recursos ou na diminuição do orçamento em saúde. Pelo contrário, se baseia na utilização do conhecimento adquirido, no cruzamento de dados primários, na expertise formada e no exercício da medicina baseada em evidências. Evidências estas que nos fazem crer que podemos utilizar melhor os recursos em saúde investindo onde é mais necessário, na prevenção de eventos e onde sabemos que existe o risco de maiores gastos futuros se não agirmos previamente. 


\section{CONCLUSÃO}

O custo total do paciente em lista de espera para o transplante hepático é alto e está relacionado com a sua gravidade.

Internações, MELD acima de 25, procedimentos realizados em pacientes portadores de CHC (ablação por radiofrequência) e a utilização de hemocomponentes foram os recursos que isoladamente, mais elevaram os custos totais destes pacientes. 


\section{REFERÊNCIAS BIBLIOGRÁFICAS}

1. Lingala S, Ghany MG. Natural History of Hepatitis C. Gastroenterol Clin North Am 2015;44:717-34.

2. Fattovich G, Bortolotti F, Donato F. Natural history of chronic hepatitis B: special emphasis on disease progression and prognostic factors. J Hepatol 2008;48:335-52.

3. Poordad FF. Presentation and complications associated with cirrhosis of the liver. Curr Med Res Opin 2015;31:925-37.

4. McAdam-Marx C, McGarry LJ, Hane C a, Biskupiak J, Deniz B, I D. All-cause and incremental per patient per year cost associated with chronic hepatitis $C$ virus and associated liver complications in the United States: a managed care perspective. J Manag Care Pharm 2011;17:531-46.

5. GBD 2013 Mortality and Causes of Death Collaborators. Global, regional, and national age-sex specific allcause and cause-specific mortality for 240 causes of death, 1990-2013: a systematic analysis for the Global Burden of Disease Study 2013. Lancet 2015;385:117-71.

6. Lozano R, Naghavi M, Foreman K, Lim S, Shibuya K, Aboyans V, et al. Global and regional mortality from 235 causes of death for 20 age groups in 1990 and 2010: a systematic analysis for the Global Burden of Disease Study 2010. Lancet 2012;380:2095-128.

7. Kikuchi L, Oliveira CP, Carrilho FJ. Nonalcoholic fatty liver disease and hepatocellular carcinoma. Biomed Res Int 2014;2014:106247.

8. Barbosa ER, Machado AAC, Cançado ELR, Deguti MM, Scaff M. Wilson's disease: a case report and a historical review. Arq Neuropsiquiatr 2009;67:539-43.

9. Bittencourt PL, Marin MLC, Couto CA, Cançado ELR, Carrilho FJ, Goldberg AC. Analysis of HFE and non-HFE gene mutations in Brazilian patients with hemochromatosis. Clinics (Sao Paulo) 2009;64:837-41.

10. Who. Global status report on alcohol and health [Internet]. World Heal. Organ.2014;1-100. Available from: http://www.who.int/substance_abuse/publications/global_alcohol_report/msbgsruprofiles.pdf

11. Guirguis J, Chhatwal J, Dasarathy J, Rivas J, McMichael D, Nagy LE, et al. Clinical Impact of Alcohol-Related Cirrhosis in the Next Decade: Estimates Based on Current Epidemiological Trends in the United States. Alcohol Clin Exp Res 2015;39:2085-94.

12. Khungar V, Goldberg DS. Liver Transplantation for Cholestatic Liver Diseases in Adults. Clin Liver Dis 2016;20:191-203.

13. Oliveira CP, Stefano JT. Genetic polymorphisms and oxidative stress in non-alcoholic steatohepatitis 
(NASH): A mini review. Clin Res Hepatol Gastroenterol 2015;39 (Suppl):S35-40.

14. Rotily M, Vainchtock A, Jouaneton B, Wartelle-Bladou C, Abergel A. How did chronic hepatitis C impact costs related to hospital health care in France in 2009? Clin Res Hepatol Gastroenterol 2013;37:365-72.

15. Wasley A, Alter MJ. Epidemiology of hepatitis C: geographic differences and temporal trends. Semin Liver Dis 2000;20:1-16.

16. Shepard CW, Finelli L, Alter MJ. Global epidemiology of hepatitis C virus infection. Lancet Infect Dis 2005;5:558-67.

17. Razavi H, Waked I, Sarrazin C, Myers RP, Idilman R, Calinas F, et al. The present and future disease burden of hepatitis C virus (HCV) infection with today's treatment paradigm. J Viral Hepat 2014;21 (Suppl):34-59.

18. Armstrong EP, Charland SL. Burden of illness of hepatitis C from a managed care organization perspective. Curr Med Res Opin 2004;20:671-9.

19. Georgieva S, Petrova G, Dimitrova M, Peikova L, Paskalev E, Filipov J, et al. Prospective Study of the Changes in Pharmacotherapy Cost of Adult Kidney Transplant Patients in Bulgaria. Mod Econ 2013;4:82731.

20. Ferreira PRA, Brandão-Mello CE, Estes C, Júnior FLG, Coelho HSM, Razavi H, et al. Disease burden of chronic hepatitis C in Brazil. Brazilian J Infect Dis 2015;19:363-8.

21. Marcellusi A, Viti R, Capone A, Mennini FS. The economic burden of HCV-induced diseases in Italy. A probabilistic cost of illness model. Eur Rev Med Pharmacol Sci 2015;19:1610-20.

22. Mishra V, Vaaler S, Brinch L. A prospective cost evaluation related to allogeneic haemopoietic stem cell transplantation including pretransplant procedures, transplantation and 1 year follow-up procedures. Bone Marrow Transpl 2001;28:1111-6.

23. Gordon SC, Pockros PJ, Terrault N a, Hoop RS, Buikema A, Nerenz D, et al. Impact of disease severity on healthcare costs in patients with chronic hepatitis C (CHC) virus infection. Hepatology 2012;56:1651-60.

24. Heidelbaugh JJ, Bruderly M. Cirrhosis and chronic liver failure: part I. Diagnosis and evaluation. Am Fam Physician 2006;74:756-62.

25. Heidelbaugh JJ, Sherbondy M. Cirrhosis and chronic liver failure: part II. Complications and treatment. Am Fam Physician 2006;74:767-76.

26. Fattovich G, Giustina G, Degos F, Tremolada F, Diodati G, Almasio P, et al. Morbidity and mortality in compensated cirrhosis type C: a retrospective follow-up study of 384 patients. Gastroenterology 1997;112:463-72. 
27. Fattovich G, Pantalena M, Zagni I, Realdi G, Schalm SW, Christensen E. Effect of hepatitis B and C virus infections on the natural history of compensated cirrhosis: a cohort study of 297 patients. Am J Gastroenterol 2002;97:2886-95.

28. Nusrat S, Khan MS, Fazili J, Madhoun MF. Cirrhosis and its complications: evidence based treatment. World J Gastroenterol 2014;20:5442-60.

29. Zhang J, Kuai J, Jia J, Wang B, Qin C. The effect of portal hypertension on prognosis in patients with decompensated liver cirrhosis. Chinese J Hepatol 2009;17:263-5.

30. lida VH, Silva TJA da, Silva ASF da, Silva LFF da, Alves VAF. Cirrose hepática: aspectos morfológicos relacionados às suas possíveis complicações. Um estudo centrado em necropsias. J Bras Patol e Med Lab 2005;41:29-36.

31. Neff GW, Kemmer N, Duncan C, Alsina A. Update on the management of cirrhosis - focus on cost-effective preventative strategies. Clinicoecon Outcomes Res 2013;5:143-52.

32. Pedersen JS, Bendtsen F, Møller S. Management of cirrhotic ascites. Ther Adv Chronic Dis 2015;6:124-37.

33. Ripoll C, Groszmann R, Garcia-Tsao G, Grace N, Burroughs A, Planas R, et al. Hepatic venous pressure gradient predicts clinical decompensation in patients with compensated cirrhosis. Gastroenterology 2007;133:481-8.

34. Fernández-Esparrach G, Sánchez-Fueyo A, Ginès P, Uriz J, Quintó L, Ventura P-J, et al. A prognostic model for predicting survival in cirrhosis with ascites. J Hepatol 2001;34:46-52.

35. Carreiro G, Moreira A da L, Murad FF, Azevedo F, Coelho HSM. TIPS - anastomose portossistêmica intrahepática transjugular. Revisão. Arq Gastroenterol 2001;38:69-80.

36. Moore KP, Wong F, Gines P, Bernardi M, Ochs A, Salerno F, et al. The management of ascites in cirrhosis: report on the consensus conference of the International Ascites Club. Hepatology 2003;38:258-66.

37. Andrade Júnior DR de, Galvão FHF, Santos SA dos, Andrade DR de. Ascite: estado da arte baseado em evidências. Rev Assoc Med Bras 2009;55:489-96.

38. Haddad L, Conte TM, Ducatti L, Nacif L, D'Albuquerque LAC, Andraus W. MELD Score Is Not Related to Spontaneous Bacterial Peritonitis. Gastroenterol Res Pract 2015;2015:270456.

39. Guarner C, Soriano G. Spontaneous bacterial peritonitis. Semin Liver Dis 1997;17:203-17.

40. Shalimar, Acharya SK. Difficult to treat spontaneous bacterial peritonitis. Trop Gastroenterol 34:7-13.

41. Dever JB, Sheikh MY. Review article: spontaneous bacterial peritonitis--bacteriology, diagnosis, treatment, risk factors and prevention. Aliment Pharmacol Ther 2015;41:1116-31. 
42. Chugh K, Agrawal Y, Goyal V, Khatri V, Kumar P. Diagnosing bacterial peritonitis made easy by use of leukocyte esterase dipsticks. Int J Crit IIIn Inj Sci 5:32-7.

43. Nobre SR, Cabral JEP, Gomes JJF, Leitão MC. In-hospital mortality in spontaneous bacterial peritonitis: a new predictive model. Eur J Gastroenterol Hepatol 2008;20:1176-81.

44. Escorsell À, Pavel O, Cárdenas A, Morillas R, Llop E, Villanueva C, et al. Esophageal balloon tamponade Vs esophageal stent in controlling acute refractory variceal bleeding: A multicenter RCT. Hepatology 2015;63:1957-67.

45. Romero-Gómez M, Montagnese S, Jalan R. Hepatic encephalopathy in patients with acute decompensation of cirrhosis and acute-on-chronic liver failure. J Hepatol 2015;62:437-47.

46. Stepanova M, Mishra A, Venkatesan C, Younossi ZM. In-Hospital Mortality and Economic Burden Associated With Hepatic Encephalopathy in the United States From 2005 to 2009. Clin Gastroenterol Hepatol 2012;10:1034-1041.e1.

47. Ferenci P, Lockwood A, Mullen K, Tarter R, Weissenborn K, Blei AT. Hepatic encephalopathy--definition, nomenclature, diagnosis, and quantification: final report of the working party In: 11th World Congresses of Gastroenterology, Vienna, 1998. Hepatology 2002;35:716-21.

48. Durand F, Graupera I, Ginès P, Olson JC, Nadim MK. Pathogenesis of Hepatorenal Syndrome: Implications for Therapy. Am J Kidney Dis 2015;67:318-28.

49. Moore K. Diagnosis and management of ascites and hepatorenal syndrome (acute kidney injury) in cirrhosis. Medicine (Baltimore) 2011;39:612-6.

50. Vonlanthen R, Slankamenac K, Breitenstein S, Puhan M a., Muller MK, Hahnloser D, et al. The Impact of Complications on Costs of Major Surgical Procedures. Ann Surg 2011;254:907-13.

51. El-Serag HB, Mason AC. Rising incidence of hepatocellular carcinoma in the United States. N Engl J Med 1999;340:745-50.

52. Kikuchi LOO, Paranaguá-Vezozzo DC, Chagas AL, Mello ES, Alves VAF, Farias AQ, et al. Nodules less than 20 $\mathrm{mm}$ and vascular invasion are predictors of survival in small hepatocellular carcinoma. J Clin Gastroenterol 2009;43:191-5.

53. Kikuchi LOO. Survival analysis of patients with small hepatocellular carcinoma [Dissertação]. São Paulo. Faculdade de Medicina: Universidade de São Paulo; 2008.

54. Bhoori S, Mazzaferro V. Current challenges in liver transplantation for hepatocellular carcinoma. Best Pract Res Clin Gastroenterol 2014;28:867-79.

55. Silva MF, Wigg AJ. Current controversies surrounding liver transplantation for hepatocellular carcinoma. J 
Gastroenterol Hepatol 2010;25:1217-26.

56. Meirelles Júnior RF, Salvalaggio P, Rezende MB de, Evangelista AS, Guardia B Della, Matielo CEL, et al. Liver transplantation: history, outcomes and perspectives. Einstein (São Paulo, Brazil) 13:149-52.

57. Bruix J, Sherman M. Management of hepatocellular carcinoma: an update. Hepatology 2011;53:1020-2.

58. Bruix J, Llovet JM. Major achievements in hepatocellular carcinoma. Lancet (London, England) 2009;373:614-6.

59. Guerrini GP, Pinelli D, Di Benedetto F, Marini E, Corno V, Guizzetti M, et al. Predictive value of nodule size and differentiation in HCC recurrence after liver transplantation. Surg Oncol 2015;

60. Washburn K, Edwards E, Harper A, Freeman R. Hepatocellular carcinoma patients are advantaged in the current liver transplant allocation system. Am J Transplant 2010;10:1643-8.

61. Toso C, Mazzaferro V, Bruix J, Freeman R, Mentha G, Majno P. Toward a better liver graft allocation that accounts for candidates with and without hepatocellular carcinoma. Am J Transplant 2014;14:2221-7.

62. Brasil. Portaria № 1160 de 29 de maio de 2006. In: Diário Oficial da União. http://sites.unasp.edu.br/ portal/secretariageral/Documentos/DOU/2006-1/05/2006-05-31-1.pdf: 2006. page 52-3.

63. Murray KF, Carithers RL. AASLD practice guidelines: Evaluation of the patient for liver transplantation. Hepatology 2005;41:1407-32.

64. Kanwal F, Hoang T, Kramer JR, Asch SM, Goetz MB, Zeringue A, et al. Increasing prevalence of HCC and cirrhosis in patients with chronic hepatitis C virus infection. Gastroenterology 2011;140:1182-1188.e1.

65. Seeff LB. Natural history of chronic hepatitis C. Hepatology 2002;36:S35-46.

66. Murphy EL. The increasing burden of mortality from viral hepatitis in the United States. Ann Intern Med 2012;157:149-50; author reply 150.

67. Ly KN, Xing J, Klevens RM, Jiles RB, Ward JW, Holmberg SD. The increasing burden of mortality from viral hepatitis in the United States between 1999 and 2007. Ann Intern Med 2012;156:271-8.

68. Wise M, Bialek S, Finelli L, Bell BP, Sorvillo F. Changing trends in hepatitis C-related mortality in the United States, 1995-2004. Hepatology 2008;47:1128-35.

69. Vong S, Bell BP. Chronic liver disease mortality in the United States, 1990-1998. Hepatology 2004;39:47683.

70. Deuffic-Burban S, Poynard T, Sulkowski MS, Wong JB. Estimating the future health burden of chronic hepatitis C and human immunodeficiency virus infections in the United States. J Viral Hepat 2007;14:107- 
15.

71. Davis GL, Alter MJ, El-Serag H, Poynard T, Jennings LW. Aging of hepatitis C virus (HCV)-infected persons in the United States: a multiple cohort model of HCV prevalence and disease progression. Gastroenterology 2010;138:513-21.

72. Garcia E, Moreira JS, Brandão AB de M, Zille Al, Fernandes JC. Hipertensão portopulmonar. J Bras Pneumol 2005;31:157-61.

73. Medarov BI, Chopra A, Judson MA. Clinical aspects of portopulmonary hypertension. Respir Med 2014;108:943-54.

74. Runo JR, Loyd JE. Primary pulmonary hypertension. Lancet 2003;361:1533-44.

75. Ayoub T. Pulmonary hypertension in liver transplant. Curr Opin Organ Transplant 2011;16:331-7.

76. Nacif LS, Andraus W, Martino RB, Santos VR, Pinheiro RS, Haddad LBP, et al. Adoption of Meld Score Increases the Number of Liver Transplant. ABCD Arq Bras Cir Dig 2014;27:201-3.

77. Hardy KJ. Liver surgery: the past 2000 years. Aust N Z J Surg 1990;60:811-7.

78. Starzl TE. Liver transplantation. Johns Hopkins Med J 1978;143:73-83.

79. T. E. Starzl, M.D., F.A.C.S., T. L. Marchioro, M.D., K. N. Von Kaulla, M.D. G, Hermann, M.D., R. S. Brittain, M.D., and W. R. Wadell, M.D. FACS. Homotransplantation of the liver in humans. Surg Gynecol Obs 1963;13 (Suppl):S249-52.

80. Gómez MP, Pérez B, Manyalich M. International Registry in Organ Donation and Transplantation--2013. Transplant Proc 2014;46:1044-8

81. Neumann J. Dimensionamento dos Transplantes no Brasil e em cada estado (2006-2013) [Internet]. 2013;Available from: http://www.abto.org.br/abtov03/Upload/file/RBT/2013/rbt2013-parcial(1).pdf

82. Registro Brasileiro de Transplantes. Dados Númericos da doação de órgãos e transplantes realizados por estado e instituição no período: JANEIRO / MARÇO - 2014. 2014.

83. Menzin J, White LA, Nichols C, Deniz B. The economic burden of advanced liver disease among patients with hepatitis C virus: a large state Medicaid perspective. BMC 2012;12:459.

84. Todo S, Furukawa H, Jin MB, Shimamura T. Living donor liver transplantation in adults: outcome in Japan. Liver Transplant 2000;6:S66-72.

85. Halazun KJ, Patzer RE, Rana AA, Verna EC, Griesemer AD, Parsons RF, et al. Standing the test of time: outcomes of a decade of prioritizing patients with hepatocellular carcinoma, results of the UNOS natural 
geographic experiment. Hepatology 2014;60:1957-62.

86. Taylor RM, Davern T, Munoz S, Han S-H, McGuire B, Larson AM, et al. Fulminant hepatitis A virus infection in the United States: Incidence, prognosis, and outcomes. Hepatology 2006;44:1589-97.

87. Martin a. P, Bartels M, Hauss J, Fangmann J. Overview of the MELD Score and the UNOS Adult Liver Allocation System. Transplant Proc 2007;39:3169-74.

88. Kidney chapter, 2010 SRTR \& OPTN Annual Data Report [Internet]. 2011;8-10. Available from: https://www.unos.org/about/annual-report/

89. Foundation El. Eurotransplant Annual Report 2013 [Internet]. 2013 [cited 2013 Dec 31];158. Available from: https://www.eurotransplant.org/cms/mediaobject.php?file=ar20135.pdf

90. Williams I, Mclver S, Moore D, Bryan S. The use of economic evaluations in NHS decision-making: a review and empirical investigation. Health Technol Assess (Rockv) 2008;12:1-175.

91. NICE. National Institute for Health and Care Excellence (NICE). 2014;1-6.

92. do Nascimento EM, Pereira B de B, Basto ST, Ribeiro Filho J. Survival tree and MELD to predict long term survival in liver transplantation waiting list. J Med Syst 2012;36:73-8.

93. Pauly M V. Chapter 10 Insurance reimbursement. Handb Heal Econ 2000;1:537-60.

94. Fink MA, Berry SR, Gow PJ, Angus PW, Wang B-Z, Muralidharan V, et al. Risk factors for liver transplantation waiting list mortality. J Gastroenterol Hepatol 2007;22:119-24.

95. Ibáñez Samaniego L, Pérez Valderas M, Fernández Yunquera A, Rincón Rodríguez D, López Baena JA, Matilla Peña A, et al. Management of Liver Transplantation Waiting List for Decompensated Cirrhosis in a Spanish Tertiary Hospital: Differences Between Hepatitis C Virus Recipients and Other Etiologies. Transplant Proc 2014;46:3084-6.

96. Navasa M, Bruix J. Multifaceted perspective of the waiting list for liver transplantation: The value of pharmacokinetic models. Hepatology 2010;51:12-5.

97. ABTO. RBT - Registro Brasileiro de Transplantes [Internet]. 2015 [cited 2013 Dec 31];7:68-9. Available from: http://www.abto.org.br/abtov03/Upload/file/RBT/2015/anual-n-associado.pdf

98. Trotter JF, Osgood MJ. MELD scores of liver transplant recipients according to size of waiting list: impact of organ allocation and patient outcomes. JAMA 2004;291:1871-4.

99. Northup PG, Abecassis MM, Englesbe MJ, Emond JC, Lee VD, Stukenborg GJ, et al. Addition of adult-toadult living donation to liver transplant programs improves survival but at an increased cost. Liver Transplant 2009;15:148-62. 
100. Farnsworth N, Fagan SP, Berger DH, Awad SS. Child-Turcotte-Pugh versus MELD score as a predictor of outcome after elective and emergent surgery in cirrhotic patients. Am J Surg 2004;188:580-3.

101. Silveira F, Silveira FP, Macri MM, Nicoluzzi JEL. Análise da mortalidade na lista de espera de fígado no Paraná, Brasil: o que devemos fazer para enfrentar a escassez de órgãos? ABCD Arq Bras Cir Dig 2012;25:110-3.

102. Ferraz-Neto B-H, Hidalgo R, Thomé T, Melo VA, Lobue A, Zurstrassen MPVC, et al. Analysis of Model for End-Stage Liver Disease (MELD) score in a liver transplantation waiting list. Transplant Proc 2007;39:25113.

103. Cuomo O, Perrella A, Arenga G. Model for End-Stage Liver Disease (MELD) score system to evaluate patients with viral hepatitis on the waiting list: better than the Child-Turcotte-Pugh (CTP) system? Transplant Proc 40:1906-9.

104. Heuman DM, Mihas AA, Habib A, Gilles HS, Stravitz RT, Sanyal AJ, et al. MELD-XI: A rational approach to "sickest first" liver transplantation in cirrhotic patients requiring anticoagulant therapy. Liver Transplant 2007;13:30-7.

105. Buchanan P, Dzebisashvili N, Lentine KL, Axelrod DA, Schnitzler MA, Salvalaggio PR. Liver transplantation cost in the model for end-stage liver disease era: Looking beyond the transplant admission. Liver Transplant 2009;15:1270-7.

106. Andraus W, Pinheiro RS, Haddad LB, Herman P, D'Albuquerque LAC. The best approach for splenectomy in portal hypertension. Surgery 2011;149:853.

107. Vilstrup H. Liver cirrhosis and bacterial infections. Ugeskr Laeger 2005;167:739-41.

108. Cordoba J, Ventura-Cots M, Simón-Talero M, Amorós À, Pavesi M, Vilstrup H, et al. Characteristics, risk factors, and mortality of cirrhotic patients hospitalized for hepatic encephalopathy with and without acuteon-chronic liver failure (ACLF). J Hepatol 2014;60:275-81.

109. Saab S, DeRosa V, Nieto J, Durazo F, Han S, Roth B. Costs and clinical outcomes of primary prophylaxis of variceal bleeding in patients with hepatic cirrhosis: a decision analytic model. Am J Gastroenterol 2003;98:763-70.

110. Jay CL, Skaro Al, Ladner DP, Wang E, Lyuksemburg V, Chang Y, et al. Comparative effectiveness of donation after cardiac death versus donation after brain death liver transplantation: Recognizing who can benefit. Liver Transplant 2012;18:630-40.

111. Wong G, Howard K, Webster AC, Morton RL, Chapman JR, Craig JC. How is Health Economics Relevant to Transplant Clinicians? Transplantation 2014;98:124-30.

112. Rajendra A, Wong JB. Economics of chronic hepatitis B and hepatitis C. J Hepatol 2007;47:608-17. 
113. Rosenberg DM, Cook SF, Lanza LL. Health care, treatment patterns and cost of services for patients infected with chronic hepatitis C virus in a large insured New England population. J Viral Hepat 2000;7:361-7.

114. Sandler RS, Everhart JE, Donowitz M, Adams E, Cronin K, Goodman C, et al. The burden of selected digestive diseases in the United States. Gastroenterology 2002;122:1500-11.

115. Jacobson IM, Davis GL, El-Serag H, Negro F, Trépo C. Prevalence and challenges of liver diseases in patients with chronic hepatitis C virus infection. Clin Gastroenterol Hepatol 2010;8:924-33; quiz e117.

116. Myers RP, Krajden M, Bilodeau M, Kaita K, Marotta P, Peltekian K, et al. Burden of disease and cost of chronic hepatitis C infection in Canada. Can J Gastroenterol Hepatol 2014;28:243-50.

117. El Khoury AC, Wallace C, Klimack WK, Razavi H. Economic burden of hepatitis C-associated diseases: Europe, Asia Pacific, and the Americas. J Med Econ 2012;15:887-96.

118. Myers RP, Liu M, Shaheen AA. The burden of hepatitis $C$ virus infection is growing: a Canadian populationbased study of hospitalizations from 1994 to 2004. Can J Gastroenterol 2008;22:381-7.

119. Leigh JP, Bowlus CL, Leistikow BN, Schenker M. Costs of Hepatitis C. Arch Intern Med 2001;161:2231.

120. Sancho LG. Reviewing the literature of cost-effectiveness and cost-utility analysis in health. Cad Saude Publica 2008;24:2735-46.

121. Bond M, Pitt M, Akoh J, Moxham T, Hoyle M, Anderson R. The effectiveness and cost-effectiveness of methods of storing donated kidneys from deceased donors: a systematic review and economic model. Health Technol Assess 2009;13:1-156.

122. Egorova NN, Gelijns AC, Moskowitz AJ, Emond JC, Krapf R, Lazar EJ, et al. Process of care events in transplantation: effects on the cost of hospitalization. Am J Transplant 2010;10:2341-8.

123. Washburn WK, Pollock BH, Nichols L, Speeg K V, Halff G. Impact of recipient MELD score on resource utilization. Am J Transplant 2006;6:2449-54.

124. Wong JB. Cost-effectiveness of treatments for chronic hepatitis C. Am J Med 1999;107:74S-78S.

125. Wong JB. Hepatitis C: cost of illness and considerations for the economic evaluation of antiviral therapies. Pharmacoeconomics 2006;24:661-72.

126. Brand D a, Viola D, Rampersaud P, Patrick P a, Rosenthal WS, Wolf DC. Waiting for a liver--hidden costs of the organ shortage. Liver Transplant 2004;10:1001-10.

127. Mathis a S. Economic burden and current managed care challenges associated with hepatitis C. Am J Manag Care 2012;18:S350-9. 
128. Goetzmann L, Wagner-Huber R, Klaghofer R, Muellhaupt B, Clavien P a, Buddeberg C, et al. Waiting for a liver transplant: psychosocial well-being, spirituality, and need for counselling. Transplant Proc 2006;38:2931-6.

129. Miyazaki ET, Dos Santos R, Miyazaki MC, Domingos NM, Felicio HC, Rocha MF, et al. Patients on the waiting list for liver transplantation: caregiver burden and stress. Liver Transplant 2010;16:1164-8.

130. Santos R, Miyazaki MCOS, Domingos NAM, Valério NI, Silva RF, Silva RCMA. Patients Undergoing Liver Transplantation: Psychosocial Characteristics, Depressive Symptoms, and Quality of Life. Transplant Proc 2008;40:802-4.

131. Neff GW, Duncan CW, Schiff ER. The current economic burden of cirrhosis. Gastroenterol Hepatol 2011;7:661-71.

132. Zalesak M, Francis K, Gedeon A, Gillis J, Hvidsten K, Kidder P, et al. Current and future disease progression of the chronic HCV population in the United States. PLoS One 2013;8:e63959.

133. Gambato M, Lens S, Navasa M, Forns X. Treatment options in patients with decompensated cirrhosis, preand post-transplantation. J Hepatol 2014;61:S120-31.

134. Thuluvath PJ. Morbid obesity with one or more other serious comorbidities should be a contraindication for liver transplantation. Liver Transplant 2007;13:1627-9.

135. Llovet JM, Mas X, Aponte JJ, Fuster J, Navasa M, Christensen E, et al. Cost effectiveness of adjuvant therapy for hepatocellular carcinoma during the waiting list for liver transplantation. Gut 2002;50:123-8.

136. Biggins SW, Feng S. In a MELD-based economy, how can we fight off inflation? Liver Transplant 2007;13:24.

137. Åberg F, Mäklin S, Räsänen P, Roine RP, Sintonen H, Koivusalo A-M, et al. Cost of a quality-adjusted life year in liver transplantation: The influence of the indication and the model for end-stage liver disease score. Liver Transplant 2011;17:1333-43.

138. Teh SH, Nagorney DM, Stevens SR, Offord KP, Therneau TM, Plevak DJ, et al. Risk factors for mortality after surgery in patients with cirrhosis. Gastroenterology 2007;132:1261-9.

139. Wang G-S, Yang Y, Li H, Jiang N, Fu B-S, Jin H, et al. Health-related quality of life after liver transplantation: the experience from a single Chinese center. Hepatobiliary Pancreat Dis Int 2012;11:262-6.

140. Coelho JCU, Wiederkehr JC, Lacerda MA, Campos ACL, Zeni Neto C, Matias JEF, et al. Custo do transplante hepático no Hospital de Clínicas da Universidade Federal do Paraná. Rev Assoc Med Bras 1997;43:53-7.

141. Coelho J, Trubian P, Freitas A, Parolin M, Schulz G, Martins E. Comparação entre o custo do transplante hepático cadavérico e o intervivos. Rev Assoc Med Bras 2005;51:158-63. 
142. Morgan D. Focus on Health Spending-2015 [Internet]. OECD Heal. Stat. 20152015 [cited 2015 Dec 31];Available from: www.oecd.org/health/health-data.htm

143. OECD. OECD work on health [Internet]. 2015 [cited 2015 Dec 31];36. Available from: http://www.oecd.org/health/Health-Brochure.pdf

144. Drummond MF. Methods for the Economic Evaluation of Health Care Programmes, M. F. Drummond, G. L. Stoddard, and G. W. Torrance. Oxford: Oxford University Press, 1987, 182 pp., \$29.50. Int J Technol Assess Health Care 1988;4:643.

145. Drummond MF. Economic evaluation of treatment strategies in gastroenterology. Am J Gastroenterol $2005 ; 100: 2143-5$.

146. Bertocco de L, Patrícia Coelho PH, Luana Regina de S, Mendes BC. Economic Evaluation in Gastroenterology: The Brazilian Experience. J Gastrointest Dig Syst 2015;5:4-5.

147. Sartori a. MC, de Soarez PC, Novaes HMD. Cost-effectiveness of introducing the 10-valent pneumococcal conjugate vaccine into the universal immunisation of infants in Brazil. J Epidemiol Community Heal 2012;66:210-7.

148. Drummond MF, Sculpher MJ, Torrance GW, O'Brien BJ, Stoddart GL. Methods for the economic evaluation of health care programmes, second edition. By Oxford: Oxford University Press, 1997. 1999.

149. Knapp M, Kavanagh S. Economic outcomes and costs in the treatment of schizophrenia. Clin Ther 19:12838-7.

150. Liu CL, Fan ST. Adult-to-adult live-donor liver transplantation: the current status. J Hepatobiliary Pancreat Surg 2006;13:110-6.

151. Broelsch CE, Malagó M, Testa G, Valentin Gamazo C. Living donor liver transplantation in adults: outcome in Europe. Liver Transplant 2000;6:S64-5.

152. Lindner LM, Marasciulo AC, Farias MR, Grohs GEM. Economic evaluation of antipsychotic drugs for schizophrenia treatment within the Brazilian Healthcare System. Rev Saude Publica 2009;43 (Suppl):62-9.

153. Borges de Santana V, Bertocco de Paiva Haddad L, Morgado Conte T, Cortez Rizzon A, Miranda Barbosa V, Shield W, et al. MELD score and albumin replacement are related to higher costs during management of patients with refractory ascites. Transplant Proc 2014;46:1760-3.

154. Coelho JCU, Wiederkehr JC, Lacerda MA, Campos ACL, Zeni Neto C, Matias JEF, et al. Custo do transplante hepático no Hospital de Clínicas da Universidade Federal do Paraná. Rev Assoc Med Bras 1997;43:53-7.

155. de Paiva Haddad LB, Decimoni TC, Turri JAO, Leandro R, Soarez PC de. Economic evaluations in gastroenterology in Brazil: A systematic review. World J Gastrointest Pharmacol Ther 2016;7:162. 
156. Guest JF. Back to basics: an introduction to economic evaluation. J Wound Care 2013;22:100-2.

157. Camacho RR. Custeio alvo em serviços hospitalares - Um estudo sob enfoque da gestão estratégica de custos [Dissertação]. São Paulo. Faculdade de Economia, Administração e Contabilidade. Universidade de São Paulo. 2004;

158. BALAKRISHNAN R, GRUCA T, NATH D. The Effect of Service Capability on Operating Costs: An Empirical Study of Ontario Hospitals. Contemp Account Res 1996;13:177-207.

159. Chapman CS, Hopwood AG, Shields MD. Handbook of Management Accounting Research Volume 2. 1st ed. Amsterdam: Elsevier; 2007.

160. Carneiro DM. Determinantes de Custo - Uma proposta de sistematização [Dissertação]. São Paulo. Faculdade de Economia, Administração e Contabilidade. Universidade de São Paulo. 2015;

161. Merion RM, Schaubel DE, Dykstra DM, Freeman RB, Port FK, Wolfe R a. The survival benefit of liver transplantation. Am J Transplant 2005;5:307-13.

162. Schaubel DE, Sima CS, Goodrich NP, Feng S, Merion RM. The survival benefit of deceased donor liver transplantation as a function of candidate disease severity and donor quality. Am J Transplant 2008;8:41925.

163. R Core Team. R: A language and environment for statistical computing [Internet]. 2014;Available from: http://www.r-project.org

164. Guimaro MS, Lacerda SS, Karam CH, Ferraz-Neto BH, Andreoli PB a. Psychosocial Profile of Patients on the Liver Transplant List. Transplant Proc 2008;40:782-4.

165. Merion RM, Schaubel DE, Dykstra DM, Freeman RB, Port FK, Wolfe RA. The survival benefit of liver transplantation. Am J Transplant 2005;5:307-13.

166. Nader LA. Impacto das Doenças Hepáticas nas Internações Hospitalares e na Mortalidade do Sistema Único de Saúde do Brasil no Período de 2001 a 2010. [Tese]. Porto Alegre. Universidade Federal de Ciências da Saúde de Porto Alegre. 2010;

167. Testino G, Burra P, Bonino F, Piani F, Sumberaz A, Peressutti R, et al. Acute alcoholic hepatitis, end stage alcoholic liver disease and liver transplantation: an Italian position statement. World J Gastroenterol 2014;20:14642-51.

168. Benckert C, Quante M, Thelen A, Bartels M, Laudi S, Berg T, et al. Impact of the MELD allocation after its implementation in liver transplantation. Scand J Gastroenterol 2011;46:941-8.

169. Quante M, Benckert C, Thelen A, Jonas S. Experience Since MELD Implementation: How Does the New System Deliver? Int J Hepatol 2012;2012:264015. 
170. Foxton MR, Al-Freah MAB, Portal AJ, Sizer E, Bernal W, Auzinger G, et al. Increased MELD score at the time of liver transplant results in prolonged hospitalization and overall intensive care unit costs. Liver Transplant 2010;16:668-667.

171. Petta S, Cabibbo G, Enea M, Macaluso FS, Plaia A, Bruno R, et al. The socioeconomic impact of hepatitis C infection and liver transplantation in Mexico. Hepatology 2014;59:1692-705.

172. Habka D, Mann D, Landes R, Soto-Gutierrez A. Future Economics of Liver Transplantation: A 20-Year Cost Modeling Forecast and the Prospect of Bioengineering Autologous Liver Grafts. PLoS One 2015;10:e0131764.

173. Orosz E. The OECD System of Health Accounts and the US National Health [Internet]. 2005 [cited 2015 Dec 31];1-32. Available from: https://www.cms.gov/Research-Statistics-Data-and-Systems/Statistics-Trendsand-Reports/NationalHealthExpendData/downloads/confpaperorosz.pdf

174. Antonio M, Lima B De, Vinicius M, Machado V. O custeio alvo em serviços hospitalares públicos : estudo no serviço de transplante hepático do Hospital Universitário Walter Cantídio da Universidade Federal do Ceará ( HUWC / UFC ) [Internet]. XVII Congr. Bras. Custos - Belo Horiz. - MG, Bras. 3 a 5 novembro 20102010 [cited Dec 2015 31];6:2004. Available from: http://www.revista.ufpe.br/ricontabeis/index.php/contabeis/article/viewFile/345/313

175. Passarani S, De Carlis L, Maione G, Alberti AB, Bevilacqua L, Baraldi S. Cost analysis of living donor liver transplantation: the first Italian economical data. Minerva Anestesiol 2007;73:491-9.

176. Portela MP, Neri EDR, Fonteles MMF, Garcia JHP, Fernandes MEP. O custo do transplante hepático em um hospital universitário do Brasil. Rev Assoc Med Bras 2010;56:322-6.

177. Cacciarelli T V. Effect of Intraoperative Blood Transfusion on Patient Outcome in Hepatic Transplantation. Arch Surg 1999;134:25.

178. Vitale A, Volk ML, Pastorelli D, Lonardi S, Farinati F, Burra P, et al. Use of sorafenib in patients with hepatocellular carcinoma before liver transplantation: a cost-benefit analysis while awaiting data on sorafenib safety. Hepatology 2010;51:165-73.

179. Lim KC, Wang VW, Siddiqui FJ, Shi L, Chan ESY, Oh HC, et al. Cost-effectiveness analysis of liver resection versus transplantation for early hepatocellular carcinoma within the Milan criteria. Hepatology 2015;61:227-37. 